This document was prepared in conjunction with work accomplished under Contract No. DE-AC09-96SR18500 with the U. S. Department of Energy.

\title{
DISCLAIMER
}

This report was prepared as an account of work sponsored by an agency of the United States Government. Neither the United States Government nor any agency thereof, nor any of their employees, nor any of their contractors, subcontractors or their employees, makes any warranty, express or implied, or assumes any legal liability or responsibility for the accuracy, completeness, or any third party's use or the results of such use of any information, apparatus, product, or process disclosed, or represents that its use would not infringe privately owned rights. Reference herein to any specific commercial product, process, or service by trade name, trademark, manufacturer, or otherwise, does not necessarily constitute or imply its endorsement, recommendation, or favoring by the United States Government or any agency thereof or its contractors or subcontractors. The views and opinions of authors expressed herein do not necessarily state or reflect those of the United States Government or any agency thereof. 


\section{REVIEW OF CATALYTIC HYDROGEN GENERATION IN THE DWPF CHEMICAL PROCESSING CELL, PART II}

David C. Koopman

Daniel P. Lambert

Mark A. Baich

August 2005

Immobilization Technology Section Savannah River National Laboratory Aiken, SC 29808

Prepared for the U.S. Department of Energy Under Contract Number DEAC09-96SR18500

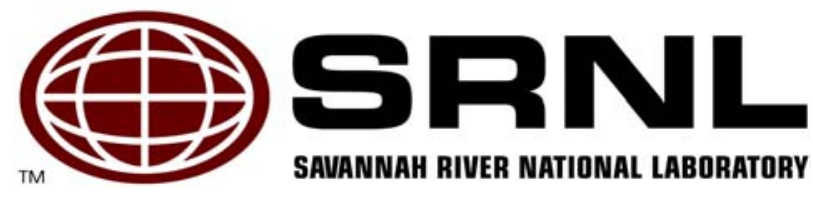




\section{DISCLAIMER}

This report was prepared by Westinghouse Savannah River Company (WSRC) for the United States Department of Energy under Contract No. DE-AC09-96SR18500 and is an account of work performed under that contract. Neither the United States Department of Energy, nor WSRC, nor any of their employees makes any warranty, expressed or implied, or assumes any legal liability or responsibility for the accuracy, completeness, or usefulness, of any information, apparatus, or product or process disclosed herein or represents that its use will not infringe privately owned rights. Reference herein to any specific commercial product, process, or service by trademark, name, manufacturer or otherwise does not necessarily constitute or imply endorsement, recommendation, or favoring of same by WSRC or by the United States Government or any agency thereof. The views and opinions of the authors expressed herein do not necessarily state or reflect those of the United States Government or any agency thereof.

\section{Printed in the United States of America}

Prepared For U.S. Department of Energy 
WSRC-TR-2005-00206

Revision 0

Key Words: SRAT, Hydrogen, Noble Metals, DWPF

Retention: permanent

\section{REVIEW OF CATALYTIC HYDROGEN GENERATION IN THE DWPF CHEMICAL PROCESSING CELL, PART II}

David C. Koopman

Daniel P. Lambert

Mark A. Baich

August 2005

Immobilization Technology Section Savannah River National Laboratory Aiken, SC 29808

Prepared for the U.S. Department of Energy Under Contract Number DEAC09-96SR18500

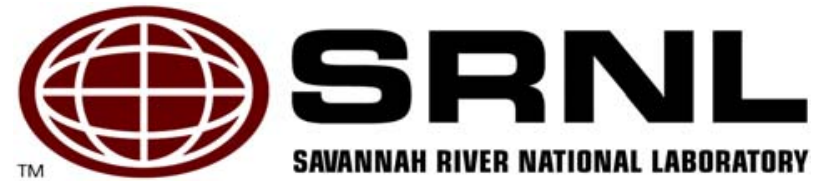




\section{REVIEWS AND APPROVALS}

\section{AUTHOR:}

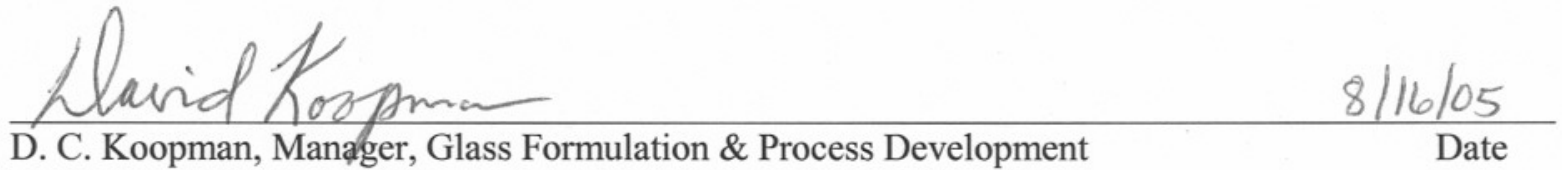

\section{TECHNICAL REVIEWER:}

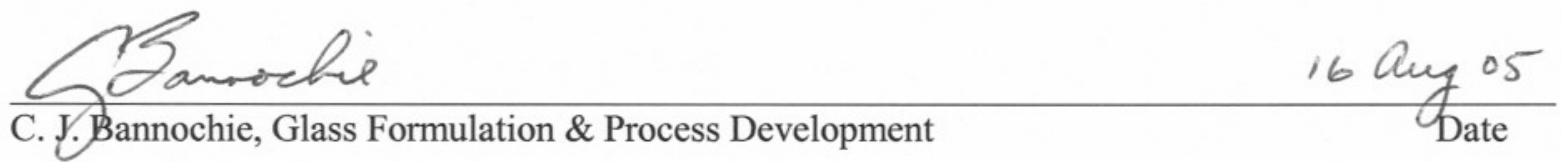

\section{APPROVERS:}

\section{Enttoltzokuls}

E. W. Holtzscheiter, Manager, Immobilization Technology Section

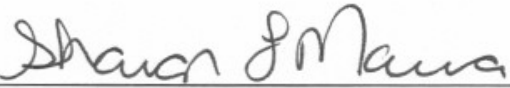

S. L. Marra, Manager, Glass Formulation \& Process Development
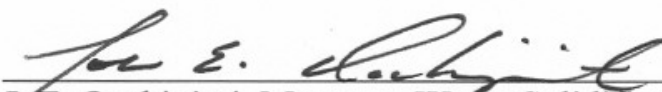

Y.E. Occhipinti, Manager, Waste Solidification Process Engineering
$8 / 22 / 05$

Date

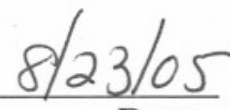

Date

Date 


\section{EXECUTIVE SUMMARY}

The Savannah River National Laboratory is in the process of investigating factors suspected of impacting catalytic hydrogen generation in the Defense Waste Processing Facility, DWPF, Chemical Process Cell, CPC. Noble metal catalyzed hydrogen generation in simulation work constrains the allowable acid addition operating window in DWPF. This constraint potentially impacts washing strategies during sludge batch preparation. It can also influence decisions related to the addition of secondary waste streams to a sludge batch.

Catalytic hydrogen generation data from 2002-2005 were reviewed. The data came from process simulations of the DWPF Sludge Receipt and Adjustment Tank, SRAT, and Slurry Mix Evaporator, SME. Most of the data was from the development work for the Sludge Batch 3 process flowsheet. This included simulant and radioactive waste testing. Preliminary Sludge Batch 4 data were also reviewed. A statistical analysis of SB3 simulant hydrogen generation data was performed. One factor considered in the statistical analysis was excess acid. Excess acid was determined experimentally as the acid added beyond that required to achieve satisfactory nitrite destruction.

Significant findings included:

- Peak hydrogen generation rate tended to fall with decreasing redox (decreasing formic acid additions) at a constant stoichiometric acid factor as expected.

- Some evidence exists that SRAT products may contain one or more species that partially inhibits hydrogen generation.

- Source of alkali tests indicated that the peak hydrogen generation rate tended to fall at constant acid stoichiometric correction factor as the stoichiometric acid requirement fell, i.e. as the sludge was washed more.

- Increasing the concentrations of soluble acid consumers, e.g. sodium hydroxide, in the SRAT feed by adding new streams can lead to excessive hydrogen generation unless the stoichiometric acid factor is reduced. This is consistent with the source of alkali testing results.

- Situations where the peak hydrogen generation rate occurs in the SME cycle rather than the SRAT cycle will probably occur more often as the window of allowed acid addition stoichiometries in the SRAT gets smaller.

- The impact of mercury on preliminary Sludge Batch 4 SRAT testing confirmed the findings from the previous phase of the hydrogen generation study. Mercury acted as an inhibitor to hydrogen generation.

- Statistical analysis of SB3 data showed that both the peak hydrogen generation rate and total hydrogen mass produced in the SRAT were strongly correlated to the product of noble metal concentration and the square of the concentration of excess acid. This is the first substantial validation for the role of excess acid in hydrogen generation on a large data set.

- The impact of mercury on hydrogen generation was inferred to be nonlinear based on the statistics from the Sludge Batch 3 data set.

- There have been some issues with data reproducibility on supposedly identically prepared runs. This may be indicating that hydrogen generation data is very sensitive to small changes.

Raw data taken under the direction of D. P. Lambert in 1998 were also evaluated. It was found that: 
- The peak hydrogen concentration increased with increasing initial nitrite ion concentration at constant moles of acid addition over the low nitrite ion concentration range $(0-8000 \mathrm{mg} / \mathrm{kg}$ nitrite).

- The peak hydrogen concentration occurred earlier with increasing nitrite ion concentration over the low nitrite ion concentration range.

- The two trends above were reversed as nitrite ion concentrations went above $8000 \mathrm{mg} / \mathrm{kg}$.

- An unidentified chemical compound or complex of rhodium derived from the nitrate salt is potentially more active than the elemental metal supported on alumina in the presence of nitrite.

- Ruthenium was relatively inactive for hydrogen generation on its own, i.e. without rhodium present to complex small amounts of nitrite ion. 


\section{TABLE OF CONTENTS}

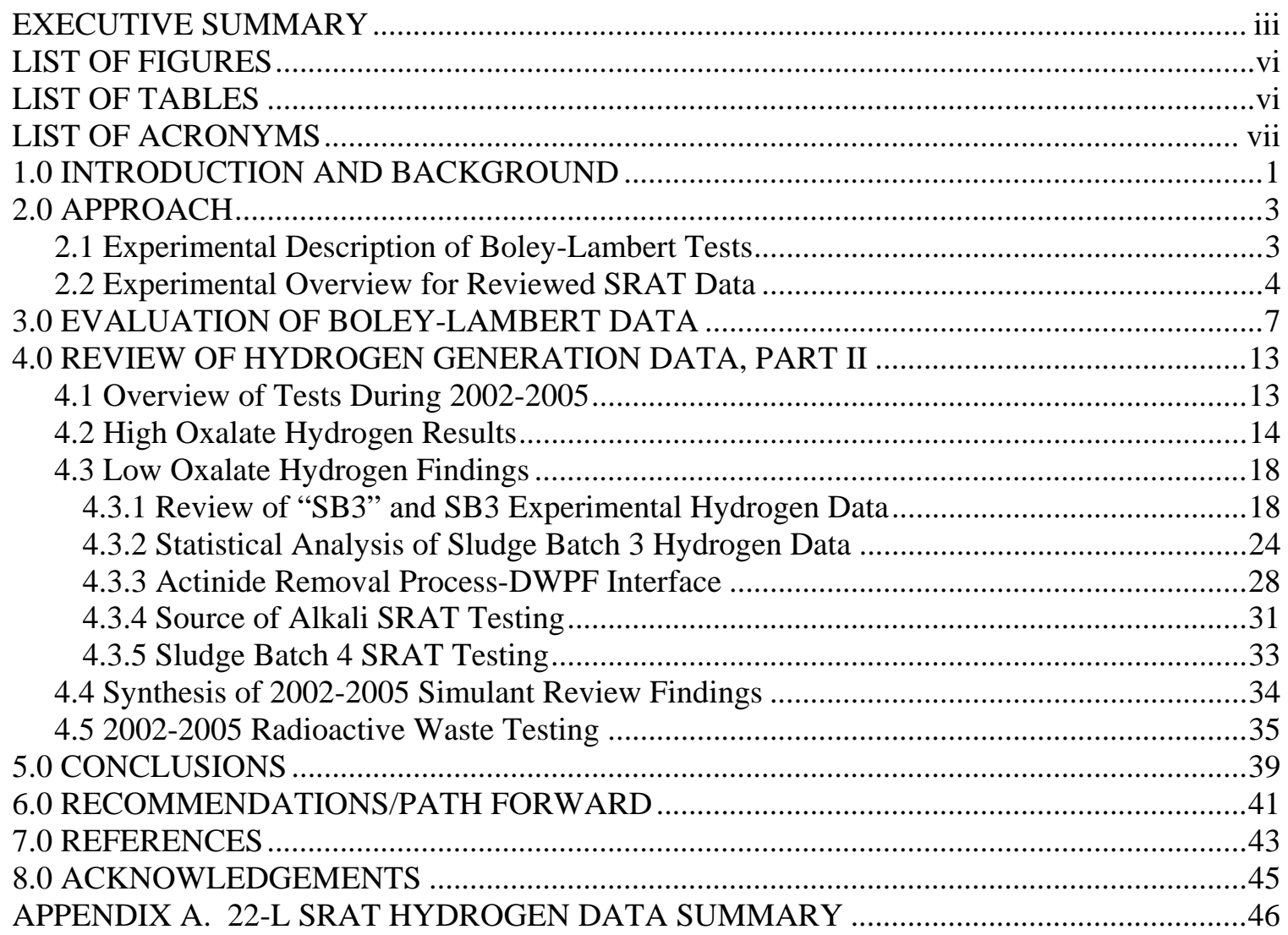




\section{LIST OF FIGURES}

Figure 1. Impact of Nitrite on Rh-catalyzed Hydrogen Generation ................................................. 7

Figure 2. Test of Experimental Reproducibility at 16,340 mg/kg Nitrite ....................................... 8

Figure 3. Rh Salt Compared to Elemental Rh at $8170 \mathrm{mg} / \mathrm{kg}$ Nitrite............................................... 9

Figure 4. Elemental Rh Compared to Rh Salt at Zero Nitrite ...................................................... 9

Figure 5. Comparison Between Rh and Ru at $2727 \mathrm{mg} / \mathrm{kg}$ Nitrite................................................ 10

Figure 6. C. W. Hsu Individual Noble Metal Hydrogen Data-I ....................................................... 11

Figure 7. C. W. Hsu Individual Noble Metal Hydrogen Data-II ..................................................... 12

Figure 8. Hydrogen Generation During High Oxalate SRAT Testing ….......................................... 16

Figure 9. Hydrogen in 22-L SME Cycle Test with Decant 5 Simulant.......................................... 17

Figure 10. SB3 Acid Window Study Hydrogen Data .............................................................. 18

Figure 11. SB3 Hydrogen Generation Results at 185\% Acid, 0.2 Redox ....................................... 19

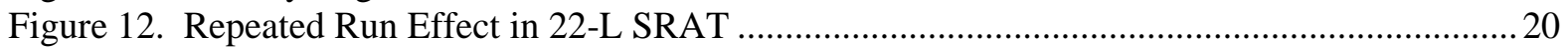

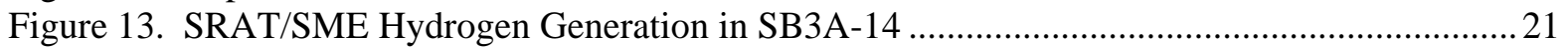

Figure 14. Delayed Hydrogen Peak in Acid Window Study .......................................................2

Figure 15. SB3 Heel Impact for SB3 Simulant at 0.2 Redox ....................................................... 22

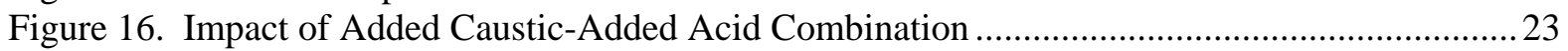

Figure 17. Hydrogen Generation in the ARP SRAT Cycle ................................................................ 30

Figure 18. Hydrogen Generation in the ARP SME Cycle................................................................. 31

Figure 19. Source of Alkali Hydrogen Data at 155\% Acid............................................................. 32

Figure 20. Impact of Hg in SB4 Testing at 160\% Stoichiometry ...................................................... 34

Figure 21. "SB3” Radioactive and Simulant Hydrogen Generation .................................................. 36

Figure 22. “SB3” Radioactive and Simulant SME Hydrogen Generation .......................................... 37

Figure 23. Comparison of "SB3” to SB3 Hydrogen Generation.................................................. 38

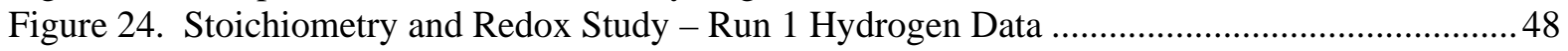

Figure 25. Stoichiometry and Redox Study - Run 2 Hydrogen Data .................................................. 48

Figure 26. Stoichiometry and Redox Study - 185\% Stoichiometry Hydrogen Data ......................... 49

Figure 27. Stoichiometry and Redox Study - Run 1 Carbon Dioxide Data........................................49

Figure 28. Stoichiometry and Redox Study - Run 2 Carbon Dioxide Data ........................................5 50

Figure 29. Stoichiometry and Redox Study - 185\% Stoichiometry Hydrogen Data ..........................50

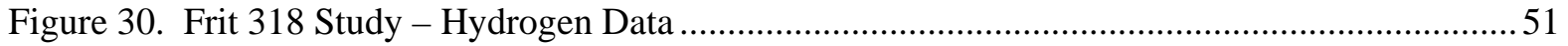

Figure 31. Frit 202+Caustic Study - Hydrogen Data ..................................................................... 51

Figure 32. Frit 202+Caustic Study - Carbon Dioxide Data ............................................................. 52

\section{LIST OF TABLES}

Table 1. Boley-Lambert Test Matrix.

Table 2. Summary of SB3 4-L SRAT Runs with High Oxalate..................................................... 15

Table 3. Summary of "SB3” and SB3 4-L SRAT Runs with Low Oxalate ........................................ 26

Table 4. Statistical Test of Factors Impacting Hydrogen Generation .............................................2

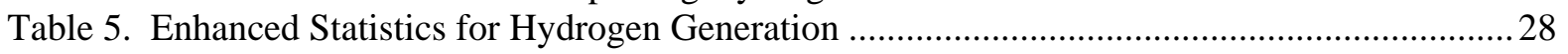

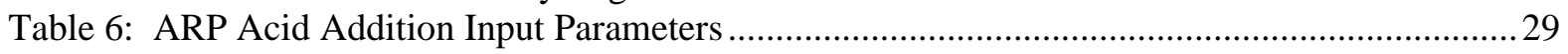

Table 7: Impact of ARP on DWPF SRAT Acid Stoichiometry .................................................... 30

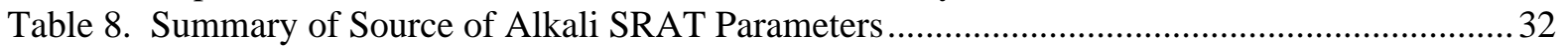

Table 9. Selected Acid Calculation Values for Early SB4 Tests........................................................ 33

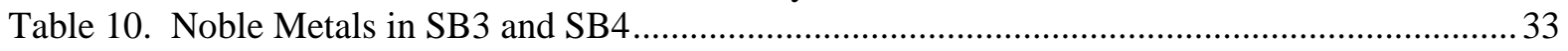

Table 11. Summary of 22-L SRAT Runs With Some GC Data......................................................47 


\section{LIST OF ACRONYMS}

$\begin{array}{ll}\text { ACTL } & \text { Aiken County Technical Laboratory } \\ \text { ADS } & \text { Analytical Development Section } \\ \text { ASP } & \text { Analytical Study Plan } \\ \text { CPC } & \text { Chemical Process Cell } \\ \text { CUF } & \text { Cross-flow Filtration Unit } \\ \text { DWPF } & \text { Defense Waste Processing Facility } \\ \text { FAVC } & \text { Formic Acid Vent Condenser } \\ \text { GC } & \text { Gas Chromatograph } \\ \text { GPD } & \text { Glass Formulation and Process Development group } \\ \text { HT } & \text { Heat-treated } \\ \text { IC } & \text { Ion Chromatography } \\ \text { ICP-AES } & \text { Inductively Coupled Plasma-Atomic Emission Spectroscopy } \\ \text { ICP-MS } & \text { Inductively Coupled Plasma-Mass Spectroscopy } \\ \text { ITS } & \text { Immobilization Technology Section } \\ \text { LEL } & \text { Lower Explosive Limit } \\ \text { MKS } & \text { Product line of gas mass flow measurement and flow controller devices } \\ \text { MWWT } & \text { Mercury Water Wash Tank } \\ \text { pph } & \text { pounds per hour } \\ \text { SB2 } & \text { Sludge Batch 2 } \\ \text { "SB3” } & \text { The new portion of Sludge Batch 3 prepared in Tank 51. } \\ \text { SB3 } & \text { Sludge Batch 3 (the combination of “SB3” with the heel of SB2) } \\ \text { SB4 } & \text { Sludge Batch 4 } \\ \text { SLM } & \text { Std. liters per minute } \\ \text { SME } & \text { Slurry Mix Evaporator vessel } \\ \text { SMECT } & \text { Slurry Mix Evaporator Condensate Tank } \\ \text { SRAT } & \text { Sludge Receipt and Adjustment Tank } \\ \text { SRS } & \text { Savannah River Site } \\ \text { SRNL } & \text { Savannah River National Laboratory } \\ \text { TIC } & \text { Total Inorganic Carbon } \\ \text { TR } & \text { Technical Report } \\ \text { TT\&QAP } & \text { Task Technical and Quality Assurance Plan } \\ \text { TTR } & \text { Task technical request } \\ \text { WSRC } & \text { Westinghouse Savannah River Company } \\ & \end{array}$


WSRC-TR-2005-00206

Revision 0

This page intentionally left blank.

viii 


\subsection{INTRODUCTION AND BACKGROUND}

The Defense Waste Processing Facility, DWPF, has requested that the Savannah River National Laboratory, SRNL, investigate the factors that contribute to hydrogen generation to determine if current conservatism in setting the DWPF processing window can be reduced. A phased program has been undertaken to increase understanding of the factors that influence hydrogen generation in the DWPF Chemical Process Cell, CPC. The main emphasis has been on Sludge Receipt and Adjustment Tank, SRAT, reactions. Slurry Mix Evaporator, SME, hydrogen generation potential will also be evaluated in each phase. The hydrogen generation in the CPC is primarily due to noble metal catalyzed decomposition of formic acid with a minor contribution from radiolytic processes.

Work commenced upon receipt of the HLW/DWPF/TTR-04-0028. A task technical and quality assurance plan, TT\&QAP, was prepared, Fellinger (2004). A phased program was developed to increase understanding of the factors that influence hydrogen generation in the DWPF CPC.

Phase I included the following activities and was divided into three parts:

Part 1 Issue the $\mathrm{H}_{2}$ generation literature review covering work through 2002, i.e. through Sludge Batch 2. Now issued, see Koopman (2004). Analyze some 1998 data found during the review. Update the review to cover Sludge Batch 2/3 and Sludge Batch 3, SB3, hydrogen generation data collected to date. These last two items are reported in this document.

Part 2 Document recent FY04 scoping tests performed with different forms of $\mathrm{Hg}$. WSRC-TR2004-00548 has been issued.

Part 3 Obtain a SB3 simulant from the Simulant Development Program without noble metals. Modify a SB3 recipe from the Simulant Development Program to include noble metals. This simulant, with co-precipitated noble metals, will be used to test the impact of the form of noble metals on hydrogen generation. This is reported in WSRC-TR-200500285, Koopman (2005b).

Phase II includes the following activities and was divided into two parts:

Part 1 Perform SRAT cycles to assess the impact of the form of noble metals on $\mathrm{H}_{2}$ generation in the SRAT. This will be reported on in WSRC-TR-2005-00286, Koopman (2005c).

Part 2 Follow-up form of noble metal work, including an assessment to determine if similar hydrogen production is achieved using simulants in the Shielded Cells equipment setup used in the Sludge Batch 3 qualification effort. This work is on-going.

Phase I, Part 1 includes an update to the original review. This phase was also used to evaluate and report on data taken in 1998 under the direction of D. P. Lambert, referred to as the "Boley-Lambert data" in Koopman (2004). This was a preliminary study into the impact of nitrite on rhodium catalyzed hydrogen generation. It also investigated two forms of rhodium, trimmed as a soluble salt or trimmed as metallic rhodium on alumina. There was also one test with ruthenium instead of rhodium. The updated review and the Boley-Lambert data evaluation are included here. 
WSRC-TR-2005-00206

Revision 0

This page intentionally left blank. 


\subsection{APPROACH}

This report is primarily a review of hydrogen generation data taken during 2002-2005. The sludge batch 3 simulant hydrogen data was subjected to a statistical analysis. Some older hydrogen data from 1998 that had not been previously analyzed is presented here for the first time.

\subsection{Experimental Description of Boley-Lambert Tests}

The tests referred to as the "Boley-Lambert data" were a series of twelve experiments. These occurred between 4/30/98 and 7/23/98. D. P. Lambert was the lead researcher. The data were located during the collection of raw hydrogen generation data prior to preparation of the initial hydrogen generation review report, Koopman (2004). It was noted in the review report that the analysis and conclusions from that set of tests had not been documented. This report undertakes an analysis of the 1998 data as it relates to hydrogen generation. Results for other off-gas species, $\mathrm{pH}$, nitrate and formate ion concentrations, etc. were not developed. These tests had a gas chromatograph for the primary measurement of off-gas composition. Some of the tests also had an Enerac analyzer, which provided additional off-gas analysis of the various oxides of nitrogen.

The twelve tests each started with $555 \mathrm{~g}$ of a nitrite-free Purex simulant. The simulant was $0.248 \mathrm{M}$ in base equivalents at $\mathrm{pH} 5.5,0.13 \mathrm{M}$ in base equivalents at $\mathrm{pH}$, and contained $548 \mathrm{mg} / \mathrm{kg}$ of nitrate. It was 16.7 wt. \% total solids. One noble metal was added to the Purex sludge in each test. This was either 4.933 wt. \% rhodium nitrate solution, 5\% elemental rhodium on alumina support, or dry ruthenium chloride $(41.74 \% \mathrm{Ru})$. Silver and palladium were not added in any of the tests. No mercury was added to any of the tests.

A varying quantity of sodium nitrite was added, ranging from 0 to 13.63 grams. De-ionized water was used to flush the reagents into the reaction vessel. The quantity ranged from at least $5 \mathrm{~g}$ up to $25 \mathrm{~g}$, or up to $4.5 \%$ of the Purex mass. $17.19 \mathrm{~g}$ of nitric acid solution and $20.93 \mathrm{~g}$ of formic acid solution were added to each trimmed sludge batch. The trimmed slurries, including acids, were then taken to boiling and refluxed under either a 10 or a $40 \mathrm{sccm}$ air purge for $9-20$ hours. GC data was obtained.

Table 1 summarizes the parameters that were varied in the twelve tests. 
Table 1. Boley-Lambert Test Matrix

\begin{tabular}{|l|c|c|c|c|c|c||}
\hline Name & $\begin{array}{c}\mathrm{g} 4.933 \% \\
\mathrm{Rh}\left(\mathrm{NO}_{3}\right)_{3} \\
\text { solution }\end{array}$ & $\begin{array}{c}\text { g 5\% Rh on } \\
\text { alumina } \\
\text { support }\end{array}$ & $\mathrm{g} \mathrm{RuCl}_{3}$ & $\mathrm{~g} \mathrm{NaNO}_{2}$ & $\begin{array}{c}\text { Nitrite, } \\
\mathrm{mg} / \mathrm{kg}\end{array}$ & $\begin{array}{c}\text { Estimated } \\
\text { Stoichiometric } \\
\text { Factor, \% }\end{array}$ \\
\hline Run 1 & 0.714 & 0 & 0 & 0 & 0 & 254 \\
\hline Run 2 & 0.714 & 0 & 0 & 0.15 & 180 & 252 \\
\hline Run 3 & 0.714 & 0 & 0 & 0.56 & 673 & 247 \\
\hline Run 4 & 0.714 & 0 & 0 & 2.27 & 2,727 & 227 \\
\hline Run 5 & 0.714 & 0 & 0 & 6.8 & 8,170 & 189 \\
\hline Run 6 & 0.714 & 0 & 0 & 13.63 & 16,340 & 150 \\
\hline Run 4-2 & 0.714 & 0 & 0 & 2.26 & 2,727 & 227 \\
\hline Run 5-2 & 0.714 & 0 & 0 & 6.8 & 8,170 & 189 \\
\hline Run 6-2 & 0.714 & 0 & 0 & 13.6 & 16,340 & 150 \\
\hline Run 5-NR & 0 & 0.7043 & 0 & 6.8 & 8,170 & 189 \\
\hline Run 5-NRONO2 & 0 & 0.7043 & 0 & 0 & 0 & 254 \\
\hline Run 5-Ru & 0 & 0 & 0.083 & 2.27 & 2,727 & 227 \\
\hline \hline
\end{tabular}

Nitrite concentration was computed from the addition masses. Because nitrite concentration was the major variable, it was often convenient to use it to identify runs on the figures in section 3.0. The stoichiometric factor was estimated assuming $14 \%$ insoluble solids containing $3.55 \% \mathrm{Mn}$. The $\mathrm{pH} 5.5$ base equivalents value was used along with a value of zero for TIC, instead of using the $\mathrm{pH} 7$ base equivalents along with a TIC value (the normal DWPF calculation).

These tests were not prototypical SRAT simulations. The nitric and formic acids were added cold and all at one time, instead of at the DWPF design bases of $93^{\circ} \mathrm{C}$ and the scaled equivalent rate of two gallons per minute. The slurry was brought to boiling after all of the acid was added. There was no dewatering step during the initial boiling period. The tests were performed on day shifts, so the longer tests occurred with one or two interruptions during which the test was shut down and then restarted the next day.

\subsection{Experimental Overview for Reviewed SRAT Data}

CPC data were obtained at various scales during 2002-2005. Off-gas data were primarily obtained from testing with the 4-L SRAT at Aiken County Technical Laboratory, ACTL. A smaller set of data was obtained from testing with the 22-L SRAT at ACTL. There were two runs with actual waste in the Shielded Cells that used a 1-L SRAT. The intention of all testing in this period was to duplicate DWPF SRAT and SME design and/or operational conditions as closely as possible.

Results for hydrogen generation were converted to DWPF-scale by using an internal standard flow of helium. The computation of the DWPF-scale hydrogen flow from the MKS and GC data was performed as follows:

$$
\begin{gathered}
\text { DWPF }- \text { scale } \mathrm{H}_{2} \text { flow, } \mathrm{lb} / \mathrm{hr}=(\text { He flow, sccm }) *\left(\frac{\text { vol\% } \mathrm{H}_{2}}{\text { vol\% He }}\right) *\left(\frac{1 \mathrm{gram}-\text { mole }}{22,415 \mathrm{std}_{\mathrm{cm}} \mathrm{cm}^{3}}\right) * \\
\left(\frac{2.016 \mathrm{~g} \mathrm{H}_{2}}{\text { gram }- \text { mole }}\right) *\left(\frac{60 \text { minutes }}{\text { hour }}\right) *\left(\frac{1 \mathrm{lb}}{453.6 \mathrm{~g}}\right) *\left(\frac{6000 \text { gallons }}{\text { sludgevolume } \mathrm{L}}\right) *\left(\frac{3.7854 \mathrm{~L}}{\text { gallon }}\right)
\end{gathered}
$$


The reader is directed to the referenced reports in the review for more detailed descriptions of the individual experiments.

Experimental data from SB3 simulant tests were used to determine the excess acid, or acid added beyond that required for acceptable nitrite destruction for a variety of composition and wash endpoints. Noble metal concentrations in the dried solids were converted to a slurry basis, e.g. mg noble metal/kg slurry, using wt. \% solids data. Total hydrogen produced in each test was determined by numerically integrating the hydrogen generation rate with respect to time. These factors and other available factors, such as the total acid added per test, were then analyzed using the JMP statistical analysis software package. The three noble metals in SRS waste were in constant relative proportions in the SB3 testing, i.e. if the amount of Rh doubled, then the amounts of Ru and Pd also doubled. Consequently, the statistical analysis could not identify effects related to individual noble metals. 
WSRC-TR-2005-00206

Revision 0

This page intentionally left blank. 


\subsection{EVALUATION OF BOLEY-LAMBERT DATA}

Hydrogen concentrations in the off-gas adjusted to a constant purge rate basis are presented in this section for the twelve experiments that form the Boley-Lambert data set. Hydrogen volume \% data from the initial series at six different nitrite ion concentrations, Runs 1-6, are presented in Figure 1. All six runs used a 10 sccm purge. Lab notebook data were used to present the GC data as a function of boiling time, rather than clock time, for a more appropriate comparison. Calculated time at boiling, however, may be off by over an hour on the second day. The break between the first and second days generally shows up as either a spike down or a spike up in the volume \% hydrogen data on the figure.

Figure 1. Impact of Nitrite on Rh-catalyzed Hydrogen Generation

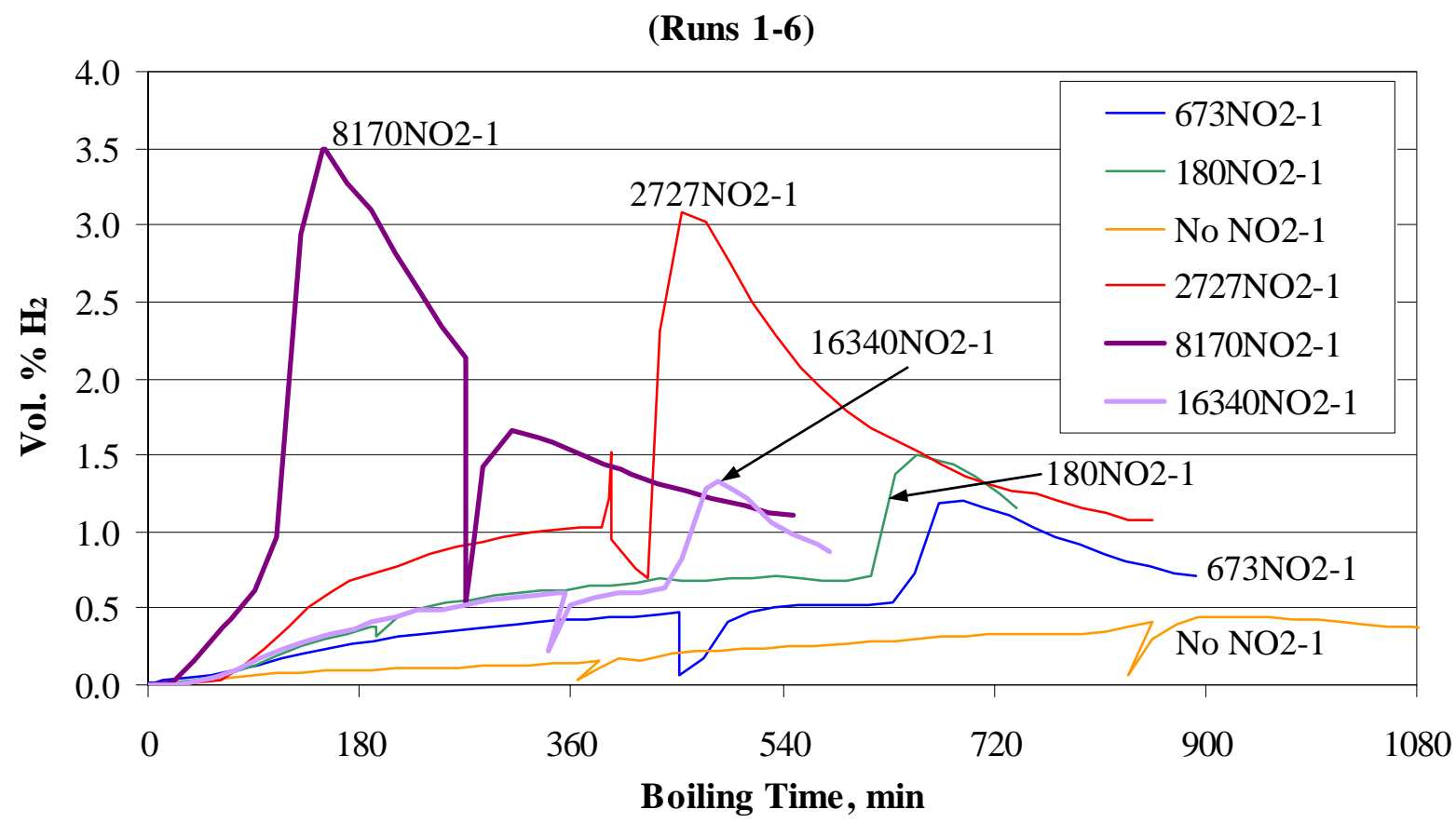

The peak hydrogen volume \% generally increased with increasing nitrite concentration from Runs 1 to 5, before falling off in Run 6. The increase during Runs 1-5 occurred in spite of the fact that the stoichiometric factor for acid was falling from Run 1 through Run 6 due to the increasing nitrite ion concentration. This may, however, explain the drop in peak hydrogen observed from Run 5 to Run 6 . As discussed later in this section, the data for Runs 4-6 was fairly reproducible (based on results of Runs 4-2, 5-2, and 6-2).

A second general trend was that the peak hydrogen volume \% occurred earlier with increasing nitrite concentration from Runs 1-5, before lagging behind in Run 6. The peak in the 180 and 673 nitrite runs occurred on the second day, and may not be following the trend, or, more probably, there may be bias in the calculated boiling time. The lag in Run 6 may be due to the acid requirement for nitrite destruction reaching a level that slowed down noble metal activation and also impacted the excess acid available for hydrogen generation. 
What is less clear in these tests relative to more recent work is the status of nitrite ion at the time of the hydrogen generation. Nitrite ion destruction may have taken 3-5 hours or longer to occur in the runs with more added nitrite. Nitrite destruction takes this long or longer in prototypical acid addition SRAT simulations. This nitrite destruction lag may have led to an optimum nitrite concentration for peak hydrogen volume percent that was driven by a competition between nitrite destruction kinetics and hydrogen generation kinetics. More prototypical SRAT tests have a fairly high fraction of the nitrite destroyed during acid addition and before significant hydrogen generation. These runs would perhaps be somewhat comparable to the $673 \mathrm{mg} / \mathrm{kg}$ initial nitrite case. This claim is made because most samples have shown $>100 \mathrm{mg} / \mathrm{kg}$ nitrite still present after acid addition, but frequently $<1000 \mathrm{mg} / \mathrm{kg}$ nitrite, when $>0.1 \% \mathrm{H}_{2}$ is made in a prototypical purge. The six $10 \mathrm{sccm}$ runs above were at about $6.7 \%$ of a prototypical DWPF SRAT air purge, so $1.5 \% \mathrm{H}_{2}$ above corresponds to about $0.1 \%$ in a prototypical purge by dilution calculation.

Three pairs of runs were made to assess reproducibility. Runs 6 and 6-2 should have been identical. The hydrogen data are shown in Figure 2.

Figure 2. Test of Experimental Reproducibility at $16,340 \mathrm{mg} / \mathrm{kg}$ Nitrite

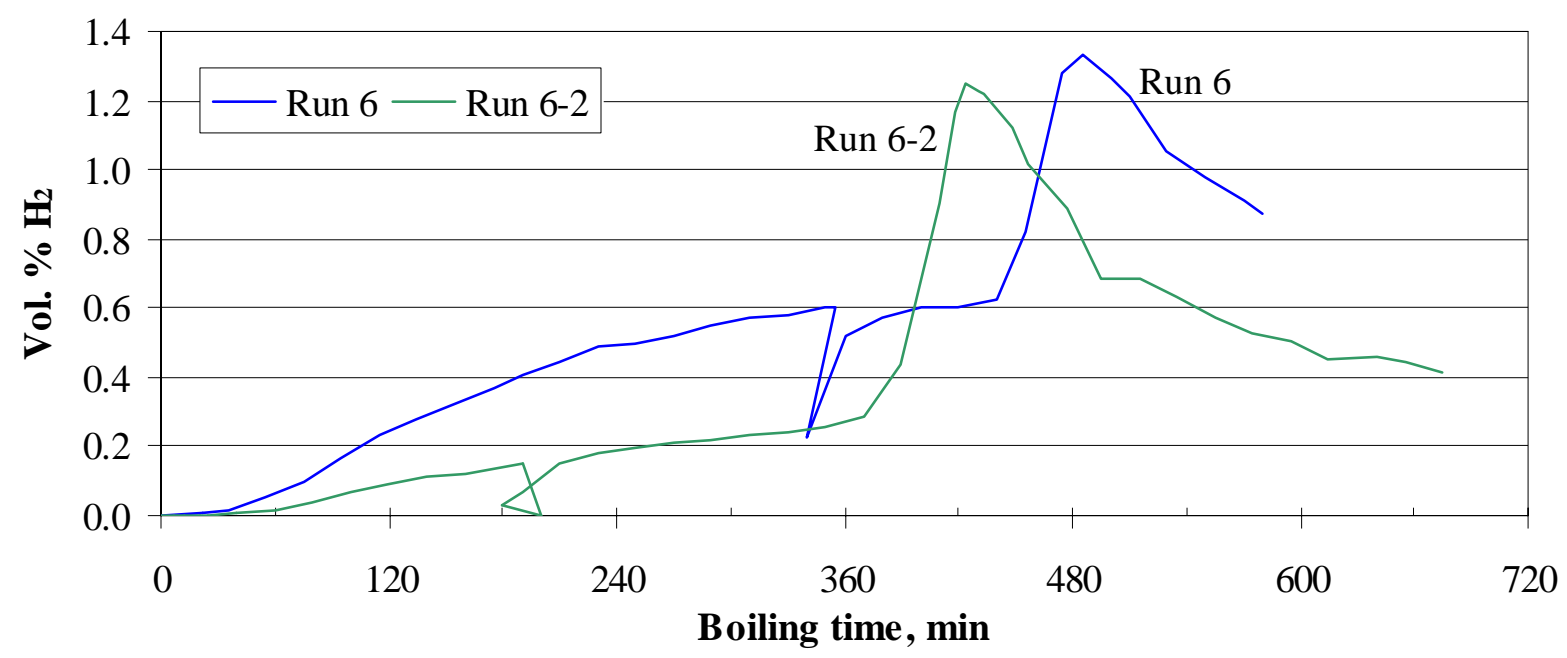

The peak volume \% hydrogen was very similar between these two runs. The timing was also similar. The peaks in both runs came on the second day of testing where the equivalent boiling time is less precise.

Runs 5 and 5-2 should also have been identical. In addition, Run 5-NR should have been identical to these two if elemental $\mathrm{Rh}$ on alumina behaved the same as rhodium precipitated into the slurry from rhodium nitrate solution. These three runs are compared in Figure 3. 
Figure 3. Rh Salt Compared to Elemental Rh at $8170 \mathrm{mg} / \mathrm{kg}$ Nitrite

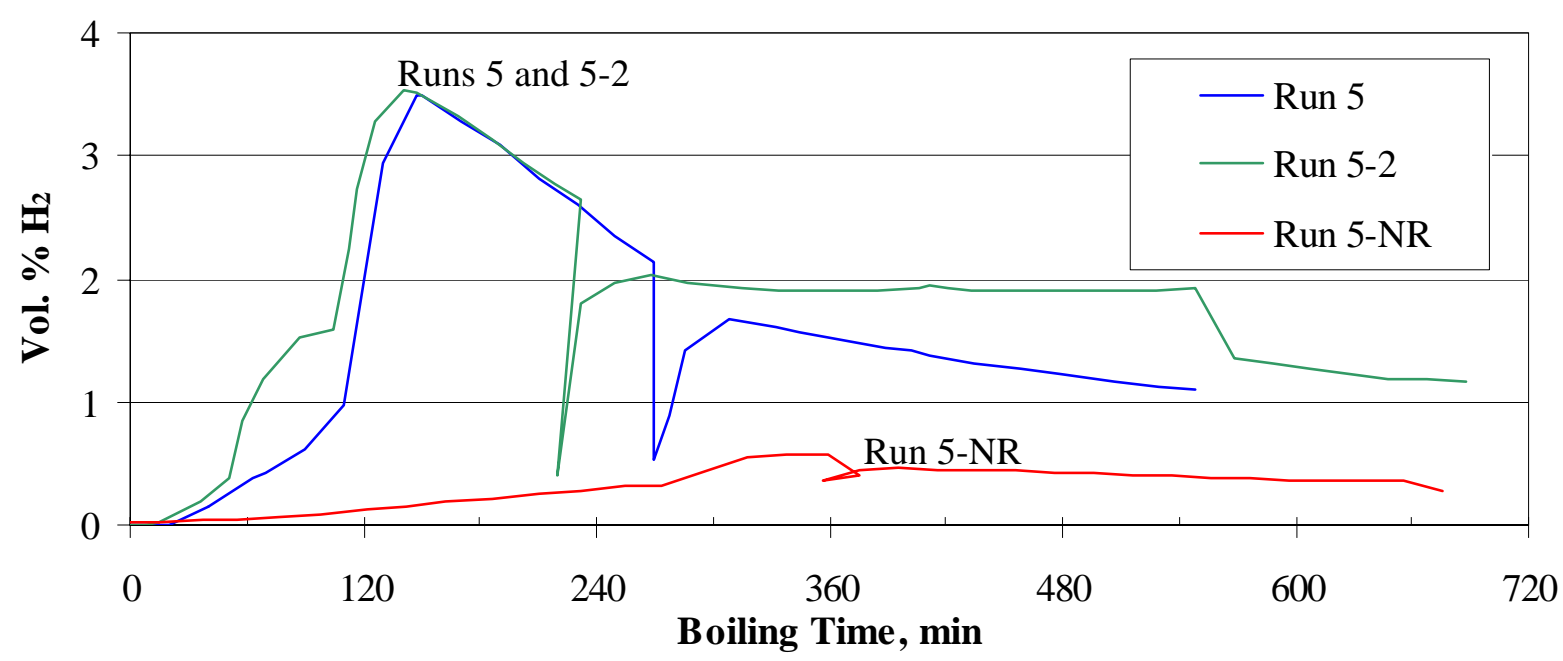

Reproducibility between Runs 5 and 5-2 was extremely good. Clearly, the supported elemental rhodium on alumina in Run 5-NR was less active than the precipitated rhodium in the other two runs. Run 5-NR used a $40 \mathrm{sccm}$ purge, while the other two used a $10 \mathrm{sccm}$ purge. Volume \%'s for Run 5-NR were multiplied by four to scale them to a $10 \mathrm{sccm}$ purge basis.

Figure 4 compares the elemental Rh supported on alumina from Run 1 and Run 5-NRONO2. These two runs had no added nitrite.

Figure 4. Elemental Rh Compared to Rh Salt at Zero Nitrite

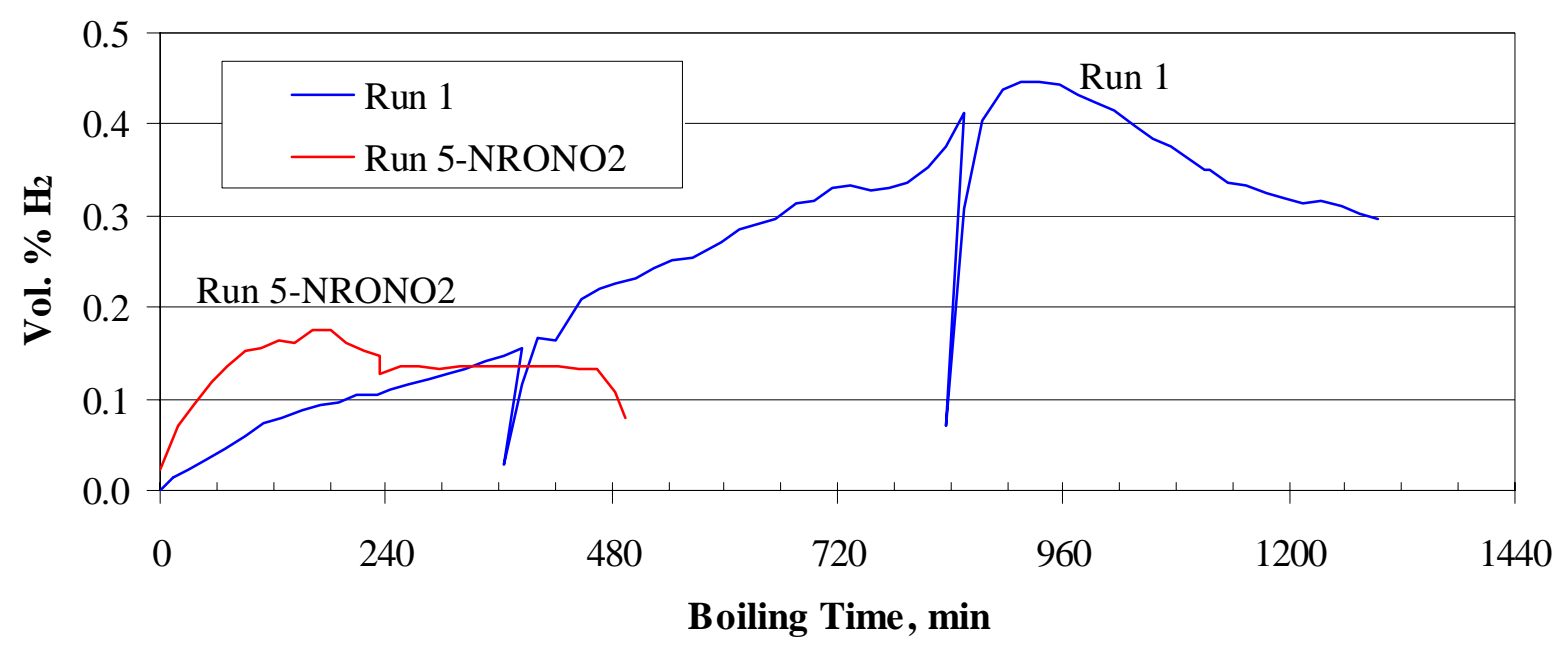

The rhodium on alumina test, Run 5-NRONO2, used a $40 \mathrm{sccm}$ purge. Its volume \% data were re-scaled to a $10 \mathrm{sccm}$ purge basis by multiplying by four for this plot. Run 5-NRONO2 produced hydrogen more quickly than the run with rhodium from the nitrate solution, Run 1. Ultimately the test based on rhodium nitrate gave a greater peak volume \% than the rhodium on alumina based test. The hydrogen concentrations reached in these two runs were lower than any of the five slurry preparations that had added nitrite. 
The data can be explained as follows. Run 1 was unable to form a nitro rhodium complex since no nitrite was available. It was initially less active than the rhodium supported on alumina because the rhodium ions had not yet been reduced to the metal. Once all of the rhodium was reduced to the metal in Run 1, it was more active because the metallic rhodium was more effectively dispersed in the slurry when precipitated from solution relative to the elemental rhodium supported on alumina. There could also be a contribution due to diffusional resistances within the alumina support matrix that reduced the activity of the elemental rhodium on alumina system relative to Run 1.

The overall data set indicates that elemental rhodium on alumina is not as active as rhodium introduced as the cation in the presence of nitrite. The hydrogen data for elemental rhodium versus rhodium cations may also support the Phase II observation that more hydrogen was seen in the runs which had the most soluble rhodium in the SRAT product, Koopman (2005c). It is not known whether any nitrite could have been produced during the tests with no sodium nitrite added initially, so it is not known for certain that the nitro rhodium complex could not have formed. Very little nitrite is required to complex the rhodium.

The data in Figure 3 and Figure 4 may be evidence to support the hydrogen work done for SRS at the University of Georgia that suggested that a nitro rhodium complex, $\mathrm{Rh}\left(\mathrm{NO}_{2}\right)_{6}{ }^{3-}$, was the most active form of rhodium for hydrogen generation, Koopman (2004). The rate of hydrogen generation could increase as more of this complex is formed. The existence of a peak would then require a second process that is reducing the concentration of the catalytically active complex. The elimination of nitrite ion may drive the elimination of species such as $\mathrm{Rh}\left(\mathrm{NO}_{2}\right)_{6}{ }^{3-}$.

A final set of comparisons comes from the three runs with $2727 \mathrm{mg} / \mathrm{kg}$ nitrite. Two of these runs had rhodium from rhodium nitrate, while the third had ruthenium from ruthenium chloride. Results from these three runs are given in Figure 5.

Figure 5. Comparison Between Rh and Ru at 2727 mg/kg Nitrite

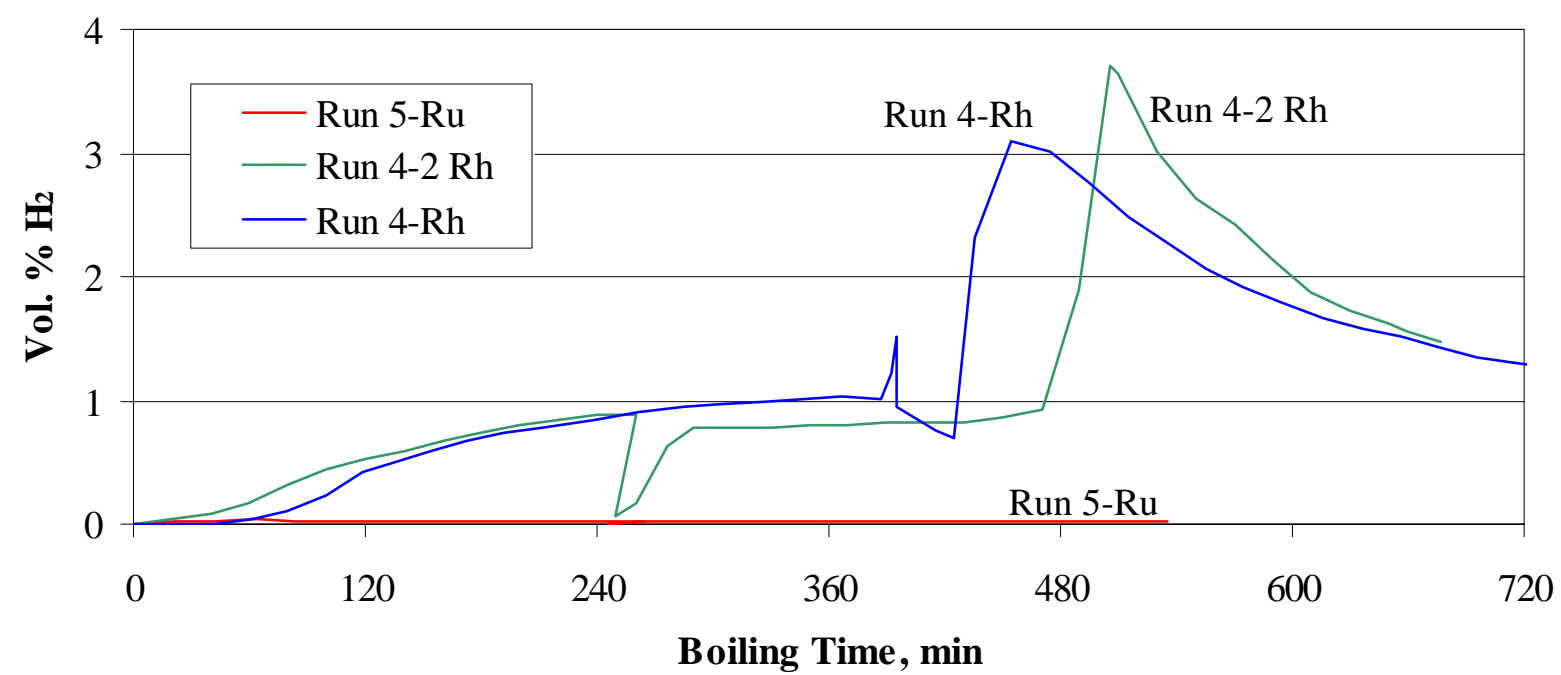

Reproducibility between Run 4 and Run 4-2 was good. Run 4-2 had a 40 sccm air purge, and its GC data were re-scaled to a $10 \mathrm{sccm}$ basis by multiplying by four. This was also done with the Run 5-Ru GC data. It is clear that ruthenium was not particularly active under the conditions of this test. Specifically, these tests all had about $0.035 \mathrm{~g}$ of noble metal, either $\mathrm{Rh}$ or $\mathrm{Ru}$. Real waste sludge tends to have 3-4 times 
more Ru than Rh because of the U-235 fission yields as discussed in the earlier review report, Koopman (2004). It is possible that $\mathrm{Rh}$ is important in complexing the residual nitrite in the slurry before Ru can become active. Ru might never become active in the absence of $\mathrm{Rh}$ if that is the case. The University of Georgia work cited earlier indicated the ruthenium was nearly inactive in the presence of nitrite. The previous review report, Koopman (2004), however, also included data obtained by C. W. Hsu that showed that both $\mathrm{Rh}$ and $\mathrm{Ru}$ were active catalysts for hydrogen generation in waste simulants. These data came from two series of tests. The two relevant graphs of volume \% hydrogen versus processing time follow, Figure 6 and Figure 7:

Figure 6. C. W. Hsu Individual Noble Metal Hydrogen Data-I

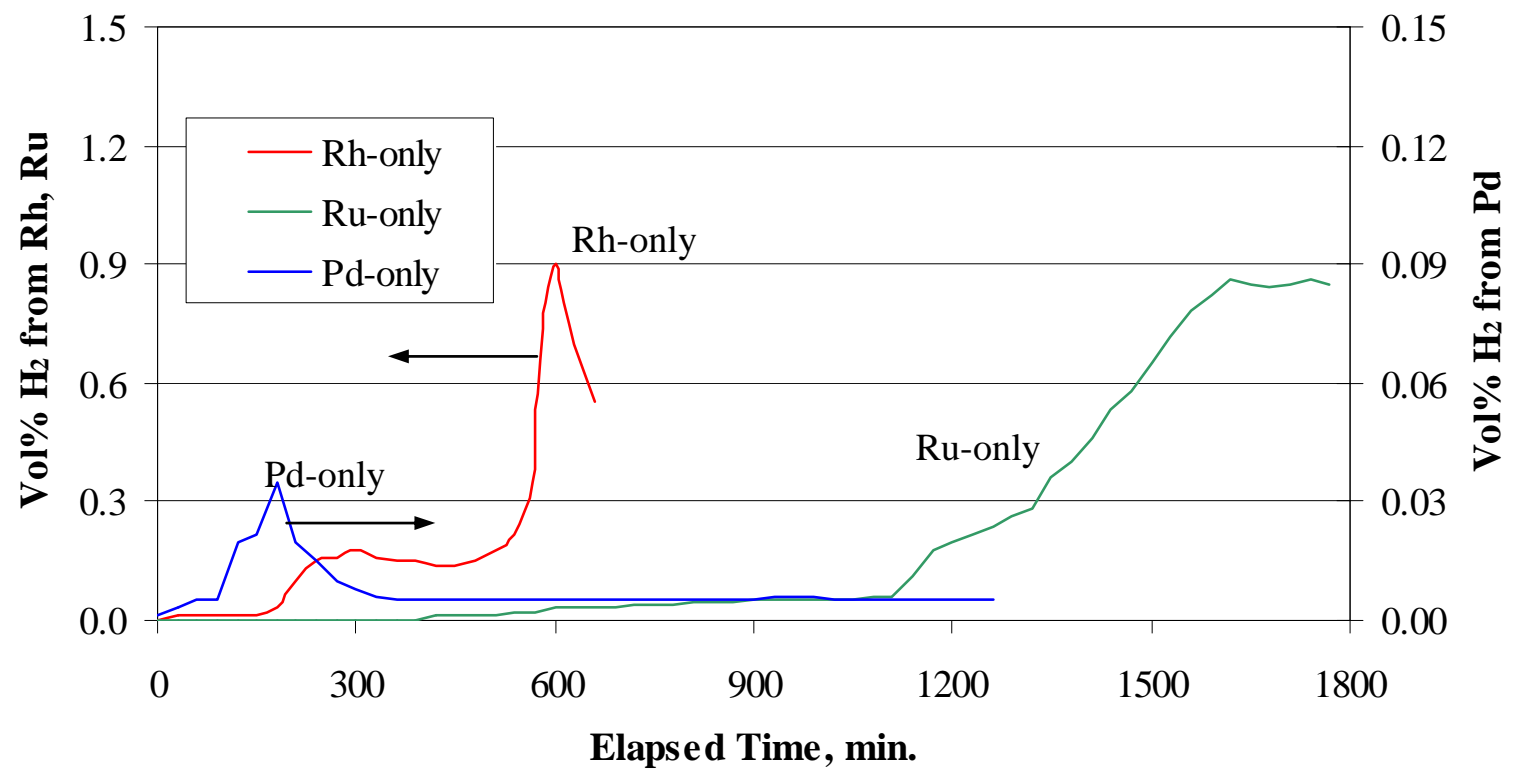

These runs each received $80 \mathrm{~mL}$ of formic acid. Note that palladium catalyzed results are on a different scale that is only one-tenth the range for the $\mathrm{Rh}$ and $\mathrm{Ru}$ data. The next three tests each received $120 \mathrm{~mL}$ of formic acid, i.e. $50 \%$ more total acid than the tests in Figure 6 
WSRC-TR-2005-00206

Revision 0

Figure 7. C. W. Hsu Individual Noble Metal Hydrogen Data-II

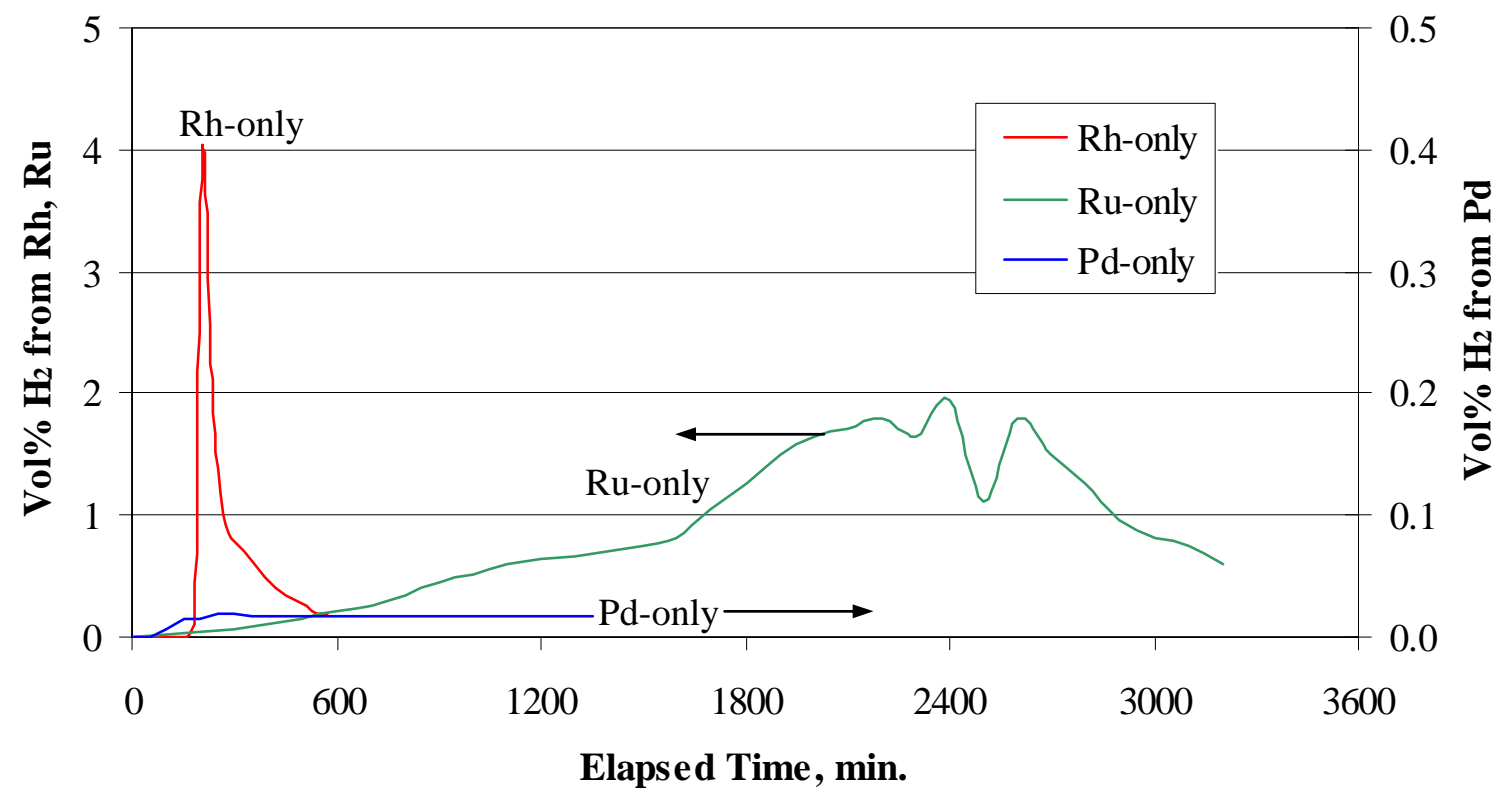

All of this SRAT simulation data is from formic acid only testing. The process flowsheet did not include nitric acid at this time. These tests did not have a precipitate hydrolysis aqueous waste component. Note that peak activity for ruthenium came after forty hours of processing. This duration of processing time would probably be in the SME cycle for the nitric acid, sludge-only flowsheet in use today. Slower activation of $\mathrm{Ru}$ than $\mathrm{Pd}$ or $\mathrm{Rh}$ is consistent with the technical literature. Comparatively early activation of palladium is also consistent with the technical literature. These points were reviewed in Koopman (2004). These studies by Hsu are the basis for the hypothesis that the small hydrogen peaks seen early in the form of noble metal testing SRAT data may have been caused by palladium, Koopman (2005c).

The data from this work suggest a complicated role for nitrite ion concentration in the rhodium-catalyzed production of hydrogen. The constant rhodium concentration results show that the stoichiometric acid factor alone is not sufficient to judge the extent of peak hydrogen generation as sludge nitrite composition changes. The data confirm that rhodium is an active catalyst for hydrogen generation in one or more forms in Purex sludge. The study suggests that ruthenium may be a less significant hydrogen catalyst than was indicated in earlier work by Hsu, or that the limitations on its activity may be more restrictive than have been identified. 


\subsection{REVIEW OF HYDROGEN GENERATION DATA, PART II}

A general review of hydrogen generation related work, Koopman (2004), was prepared several years ago. This document covered catalytic hydrogen generation studies at SRS and off-site through the qualification of Sludge Batch 2, SB2, in the SRTC (now SRNL) Shielded Cells. This can be taken as Part I. Requests to periodically update the review are expected in the future. This section updates the Part I review to include significant hydrogen generation findings from 2002-2005. It can be considered Part II.

\subsection{Overview of Tests During 2002-2005}

The new review period begins with the work on "Sludge Batch 3", or "SB3". The use of quotes is to differentiate the work done to prepare for qualification of a sample from Tank 51 prior to transferring this material into the balance of SB2 in Tank 40. "SB3" was primarily the waste that had been stored in Tank 7. Tank 7 was believed to contain up to 300 metric tons of sodium oxalate in addition to the waste slurry. Early testing had significant added oxalate in the starting sludge. Once samples indicated that the projected oxalate mass was no longer in Tank 7, the testing shifted to lower oxalate concentrations. Additional work was undertaken to understand the processing characteristics of the blend of "SB3" and SB2 that was formed after the transfer of Tank 51 to Tank 40. This blend is referred to as Sludge Batch 3, or SB3 (no quotes denotes the official Sludge Batch 3). Preliminary simulant flowsheet studies for Sludge Batch 4, SB4, are underway. Early findings from this work are covered here as well.

Initial "SB3" studies were performed using a simulant of Tank 8 waste produced at the University of South Carolina in Columbia. This was trimmed with gadolinium to simulate a Pu-Gd precipitate addition. The simulant was also trimmed with sand and coal to simulate material in Tank 7 from a sand filter column that was dumped into Tank 7. The major impact on processing, particularly acid consumption, came from the introduction of sodium oxalate to simulate up to 300 metric tons of sodium oxalate in Tank 7. When a new "SB3" simulant became available, the studies shifted from Tank 8 simulant to that basis. When sampling indicated that a significant quantity of sodium oxalate was no longer in the tank, the flowsheet studies shifted from high to low oxalate content. Simulant studies covered a variety of hypothetical wash endpoints both with and without sodium oxalate. There were various concentrations of the noble metals as well, in order to bound their impact on processing.

The main simulant reports along with the lead author's name that summarize "SB3" and SB3 related CPC simulations with off-gas data were:

$\begin{array}{lll}\text { WSRC-TR-2002-00322 } & \text { Herman (2002) } & \text { First } 8 \text { “SB3” tests using USC Tank } 8 \text { simulant } \\ \text { SRT-GPD-2002-00121 } & \text { Herman (2003a) } & \text { Next } 8 \text { “SB3” tests using USC Tank } 8 \text { simulant } \\ \text { SRT-GPD-2002-00200 } & \text { Herman (2003b) } & \text { Last 6 “SB3” tests using USC Tank } 8 \text { simulant } \\ \text { WSRC-TR-2003-00088 } & \text { Herman (2003c) } & \text { First } 4 \text { “SB3” tests using CETL SB3 simulant (Phase I) } \\ \text { WSRC-TR-2003-00158 } & \text { Herman (2003d) } & \text { Next } 2 \text { “SB3” tests using CETL SB3 simulant (Phase II) } \\ \text { WSRC-TR-2003-00283 } & \text { Koopman (2003c) } & \text { Next } 4 \text { “SB3” tests using CETL SB3 simulant (Phase III) } \\ \text { WSRC-TR-2003-00422 } & \text { Herman (2003e) } & \text { Final } 7 \text { “SB3” tests using CETL SB3 simulant (Final phase) } \\ \text { WSRC-TR-2003-00326 } & \text { Baich (2003) } & \text { Five tests of SB3 blend to support ARP } \\ \text { WSRC-TR-2003-00403 } & \text { Koopman (2003d) } & \text { Hydrogen bounding work to support ARP in SB3 } \\ \text { WSRC-TR-2004-00042 } & \text { Baich (2004a) } & \text { SB3 acid window determination (4 tests) } \\ \text { WSRC-TR-2004-00225 } & \text { Baich (2004b) } & \text { Five SB3 tests (redox and heel study) }\end{array}$


The list of reports is given in essentially chronological order, so that the evolution of the simulant work can be followed by reading the reports in the order given. In addition, Phase I of the hydrogen generation study consisted of six tests using SB3 simulant from CETL similar to that used in the last four studies above, Koopman (2005a). This work followed the redox and heel study.

Additional studies were done in 2002-2005 that were not in direct support of qualifying a new sludge batch. A preliminary investigation into the impact of the actinide removal process, ARP, on DWPF processing was undertaken in 2003. A study into the impact of mercury - noble metal interactions on SB3 hydrogen generation was undertaken in 2004 as part of Phase I of the hydrogen program. A study into the impact of the source of alkali, SOA, from either sludge or frit on melt rate also occurred in this period. Some GC data from 22-L scale SRAT simulations were obtained in parallel with the traditional 4-L studies. Equipment modifications to both scales were made in late 2004. Smaller scale tests, e.g. 1-L simulations, generally did not obtain off-gas data. There were other studies during this period that also did not acquire off-gas data, such as the SB2 depleted uranium studies and investigations into SB2 processing issues, e.g. air entrainment.

The studies from the past three years logically subdivide into two broad categories. There is a body of work on simulants containing large quantities of oxalate ion, i.e. $>10,000 \mathrm{mg}$ oxalate/kg sludge slurry. This work was fundamentally different from past work. These oxalate levels had not been previously studied. Oxalate promoted additional acid consumption beyond what was anticipated from the current stoichiometric acid requirement calculation. This led to the development of a new stoichiometric acid calculation equation to handle high oxalate wastes.

The rest of the work from 2002-2005 concerned slurries with less than 3,000 mg oxalate/kg slurry. Presently, the data for the systems with $<3,000 \mathrm{mg} / \mathrm{kg}$ oxalate are more relevant, since the current and next sludge batches are in this category. There were 24 4-L SRAT vessel simulations for "SB3" based on USC Tank 8 simulant. Five of these were low oxalate and 19 were high oxalate. These were followed by 17 4-L SRAT simulations for "SB3" based on CETL SB3 simulant. Five of these were high oxalate, and 12 were low oxalate. The SB3 and SB4 data are all low oxalate. There were twelve 22-L simulations with GC data. Two of these were high oxalate, and ten were low oxalate. Two Shielded Cells tests were performed, one for "SB3" and one for SB3. These were both low oxalate. ARP, SOA, and Hg-noble metal interaction testing were all low oxalate.

\subsection{High Oxalate Hydrogen Results}

Preliminary "SB3" testing with significant oxalate concentrations was not characterized by hydrogen generation problems, but by high SRAT product nitrite ion concentrations. The introduction of oxalate was assumed initially to have no impact on the acid requirement. This turned out to be incorrect. The presence of oxalate showed up in the measured base equivalents as an increase in acid requirement over what would have been expected if oxalate had simply been a diluent. There was additional consumption of acid that occurred when oxalate was present beyond that indicated by the base equivalents. The primary focus of the early "SB3" flowsheet program was to properly compensate for oxalate in the stoichiometric acid calculation and in the redox balance equation.

Most "SB3" and SB3 testing also involved the presence of sand and coal. They were minor components. Coal was still of concern because it is a reductant in the melter and is also a potentially high surface area per unit volume substrate upon which catalytic metals could precipitate.

A listing of high oxalate 4-L SRAT simulations with GC data is given in Table 2. The total grams of hydrogen production are given for each test. Volume percent data was converted to flow rates per section 2.2, and the flow rates were integrated numerically using Simpson's rule to get the total masses. Runs 
with an SB3- prefix used USC Tank 8 simulant as a starting point. Runs with an SB3A- prefix used CETL SB3 simulant as a starting point. CETL SB3 simulant was a closer match to the measured composition of "SB3". Mercury and noble metals were linked to the insoluble sludge solids. Consequently, their concentrations varied as the fraction of sodium oxalate in the sludge-sodium oxalate insoluble solids varied. Higher mercury correlated with less oxalate and more sludge solids. In addition the noble metals were studied at both $100 \%$ and $10 \%$ of a conservative estimate of their concentration. The sludge slurry masses given in Table 2 do not include about $350 \mathrm{~g}$ of rinse water that simulated the DWPF line flush accompanying each batch. The masses do include sodium oxalate.

Table 2. Summary of SB3 4-L SRAT Runs with High Oxalate

\begin{tabular}{|l|c|c|c|c|c|c|c|c||}
\hline & Sludge \\
mass, & gh, & mg/kg & $\begin{array}{c}\text { Hg/kg } \\
\text { Test ID: }\end{array}$ & $\begin{array}{c}\text { Initial } \\
\text { Oxalate, } \\
\text { mg/kg }\end{array}$ & $\begin{array}{c}\text { Minimum } \\
\text { acid for } \\
<1000 \\
\text { mg/kg } \\
\text { nitrite, } \\
\text { moles/L }\end{array}$ & $\begin{array}{c}\text { Total } \\
\text { acid } \\
\text { added, } \\
\text { moles/L }\end{array}$ & $\begin{array}{c}\text { SRAT } \\
\text { product } \\
\text { nitrite, } \\
\text { mg/kg }\end{array}$ & $\begin{array}{c}\text { SRAT } \\
\mathrm{H}_{2} \text { made, } \\
\text { g }\end{array}$ \\
\hline SB3-5 & 2342 & 88.3 & 130 & 37570 & unknown & 0.930 & 2900 & 0 \\
\hline SB3-6 & 2274 & 90.9 & 134 & 19340 & unknown & 0.957 & 100 & 0.006 \\
\hline SB3-7 & 2408 & 69.1 & 102 & 30995 & 0.985 & 0.920 & 440 & 0.006 \\
\hline SB3-8 & 2414 & 69.1 & 130 & 30995 & 0.985 & 0.920 & 100 & 0.0001 \\
\hline SB3-9 & 2400 & 69.1 & 130 & 30995 & 0.985 & 0.985 & $<100$ & 0.006 \\
\hline SB3-10 & 2400 & 69.1 & 130 & 30995 & 0.985 & 0.985 & $<100$ & 0.006 \\
\hline SB3-11 & 2400 & 6.91 & 130 & 30995 & 0.985 & 0.985 & 1080 & 0 \\
\hline SB3-12 & 2400 & 6.91 & 130 & 30995 & 0.985 & 0.985 & 1010 & 0 \\
\hline SB3-13 & 2400 & 6.91 & 130 & 30995 & 0.985 & 0.985 & 870 & 0 \\
\hline SB3-14 & 2400 & 69.1 & 130 & 30995 & 0.985 & 0.985 & $<100$ & 0.003 \\
\hline SB3-15 & 2400 & 6.91 & 130 & 30995 & 0.985 & 0.985 & 843 & 0 \\
\hline SB3-16 & 2400 & 69.1 & 130 & 30995 & 0.985 & 0.985 & $<100$ & Unknown \\
\hline SB3-17 & 2400 & 69.1 & 130 & 30995 & 0.985 & 0.985 & $<100$ & 0.006 \\
\hline SB3-19 & 2174 & 7.61 & 113 & 34130 & unknown & 1.415 & $<100$ & 0.014 \\
\hline SB3-20 & 2400 & 6.19 & 117 & 42298 & 1.03 & 1.28 & $<100$ & 0.004 \\
\hline SB3-21 & 2400 & 61.8 & 117 & 42298 & 1.03 & 1.28 & $<100$ & 0.090 \\
\hline SB3-22 & 2400 & 6.91 & 102 & 30995 & 0.985 & 1.20 & $<100$ & 0.002 \\
\hline SB3-23 & 2800 & 80.1 & 119 & 17957 & 0.8 & 1.08 & $<100$ & 0.034 \\
\hline SB3-24 & 2402 & 50.2 & 74 & 56686 & unknown & 0.76 & $<100$ & 0 \\
\hline SB3A-1 & 2760 & 6.24 & 93 & 41590 & 1.19 & 1.19 & $<100$ & 0.0003 \\
\hline SB3A-2 & 2760 & 8.32 & 124 & 29740 & 0.85 & 1.07 & $<100$ & 0 \\
\hline SB3A-3 & 2760 & 7.6 & 110 & 32610 & 0.95 & 1.02 & $<100$ & 0.0008 \\
\hline SB3A-8 & 2800 & 62.4 & 92 & 39700 & 1.19 & 1.54 & $<100$ & 0.175 \\
\hline SB3A-9 & 2800 & 83.2 & 128 & 22500 & 0.85 & 1.31 & $<100$ & 0.121 \\
\hline & & & & & & & & \\
\hline
\end{tabular}

The minimum acid in Table 2 was based on the $10 \%$ noble metal case, e.g. values of $\mathrm{Rh}<10 \mathrm{mg} / \mathrm{kg}$. For runs with $100 \%$ noble metals, the minimum acid was for a sludge with one-tenth the concentration actually tested. This was done to remove noble metals as a potential variable in the determination of the 
minimum acid required for processing with oxalate present in order to simplify the problem of acid addition. Much of the testing was done at conditions close to the minimum acid requirement in order to refine a new stoichiometric acid equation.

There were two runs with USC Tank 8 simulant, SB3-21 and SB3-23, and two with CETL SB3 simulant, SB3A-8 and SB3A-9, that did establish that oxalate does not completely inhibit hydrogen generation. The apparent inhibition had been due to the unrecognized acid demand associated with the presence of oxalate. This led to acid additions that were typically barely adequate to destroy nitrite ion. Once the acid requirement for a given wash endpoint composition had been determined experimentally, it was possible to perform additional SRAT batches with typical amounts of excess acid. These batches behaved much as previous batches without oxalate discussed later in this review as well as in the previous review, Koopman (2004). Peak hydrogen generation rate generally tracked with excess acid and noble metal concentrations. Data are given from the last two oxalate runs in Figure 8. The axis scaling was chosen to highlight the DWPF SRAT limit of $0.65 \mathrm{lbs} / \mathrm{hr}$, or $0.65 \mathrm{pph}$, of hydrogen generation.

Figure 8. Hydrogen Generation During High Oxalate SRAT Testing

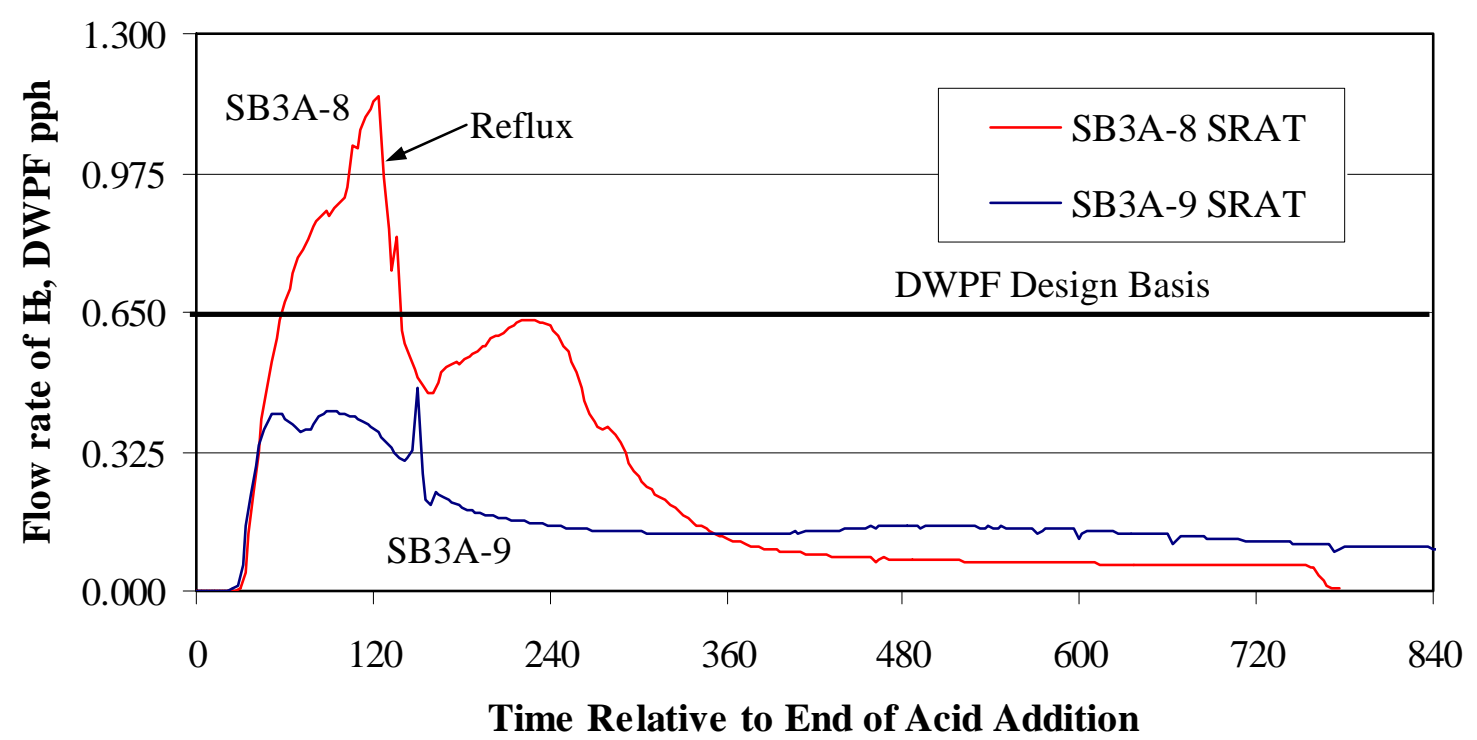

SB3A-8 was thought to have a little less excess acid than SB3A-9, and it also had somewhat lower concentrations of noble metals. The fact that SB3A-8 had more hydrogen generation than SB3A-9 was puzzling. Based on what is known now, it can be seen in Table 2 that SB3A-9 also had more mercury with the additional noble metals. The inhibition by mercury may have dominated over excess acid and noble metal concentration. Disruptions in the data at about 130 minutes coincide with the end of dewatering and the onset of reflux.

There were two 22-L SRAT/SME simulations with GC data. These were the first and third runs of a set of four making feed for the Slurry-Fed Melt Rate Furnace (SMRF). They were at the Decant 5 wash endpoint, i.e. similar to SB3A-8 and SB3A-1 starting sludge in composition. There was no mercury in the simulant, however, unlike the 4-L tests. The acid addition was similar to that in SB3A-1. No significant hydrogen generation was seen in the SRAT cycle. This was also true in SB3A-1. SME cycle hydrogen generation data in Figure 9 are shown for the third run of four. 
Figure 9. Hydrogen in 22-L SME Cycle Test with Decant 5 Simulant

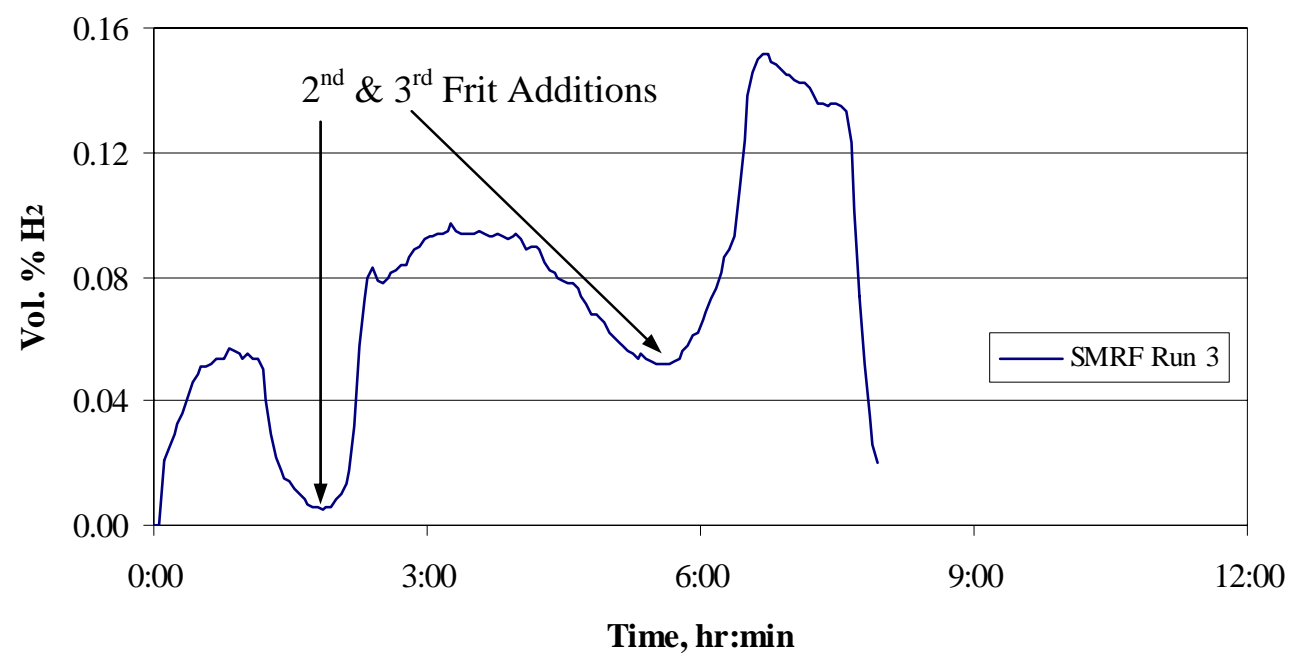

Significant hydrogen generation was seen in the SME cycle after none was seen in the SRAT cycle. The hydrogen generation rate, however, stayed below 25\% of the DWPF SME limit. Hydrogen in the other SME cycle did not appear until after the second dewatering period following the second of three frit additions. It peaked at just over $0.20 \%$ hydrogen, or slightly higher than that in Figure 9.

During "SB3" testing it was observed that under certain processing conditions, oxalate was catalytically converted to formate faster than formate was consumed. This is typical of catalytic wet air oxidation, CWAO, of organic molecules. This class of reactions breaks both carbon-carbon and carbon-hydrogen bonds. The high oxalate "SB3" test series showed the presence of CWAO in ways that had not been observed in traditional low oxalate tests. Splitting the oxalate carbon-carbon bond led to formate generation, while net formate destruction was characteristic of traditional low oxalate tests. CWAO is accompanied by simultaneous generation of carbon dioxide. Consequently, CWAO was responsible for some carbon dioxide generation during SRAT refluxing. Generation of $\mathrm{CO}_{2}$ during reflux is typically several times greater than that for hydrogen on a molar basis, but they are clearly interrelated after reviewing sufficient off-gas data sets. CWAO is one reaction pathway that can produce $\mathrm{CO}_{2}$ from formate or formic acid without producing hydrogen.

CWAO was investigated further in Phase I of the hydrogen generation study, Koopman (2005a). There it was found that eliminating oxygen, the other reactant in $\mathrm{CWAO}$, did in fact lead to lower $\mathrm{CO}_{2}$ concentrations during reflux. That is, eliminating oxygen eliminated CWAO steps that actually add oxygen to organic molecules. The added oxygen shows up as $\mathrm{CO}_{2}$ and water production, since CWAO reaction end products are the same as combustion products. The SRAT data indicated, however, that additional reactions are present besides hydrogen generation and CWAO during SRAT reflux, since $\mathrm{CO}_{2}$ was still produced in excess of $\mathrm{H}_{2}$ when CWAO was eliminated. That is, CWAO explains some of the excess production of $\mathrm{CO}_{2}$ during reflux above what is made with hydrogen, but not all of the excess.

High oxalate testing ended before consideration of how the blend of "SB3" with SB2 would process. During this phase, however, an alternative stoichiometric acid calculation was developed. This equation fit the minimum acid requirement at $10 \%$ of the nominal "SB3" noble metals to the usual terms: base equivalents at $\mathrm{pH}$ 7, TIC, Mn on a slurry basis, nitrite, and mercury. The model also had a term for oxalate. Inclusion of a TIC term did little to reduce error in the model. This was probably due to the relatively constant TIC concentration across the entire data set. Manganese was also not found to 
contribute. This may have meant that manganese was not being reduced effectively. More likely, however, it meant that manganese was overly correlated with other variables in the model, e.g. as oxalate went up manganese went down in concentration. The details of this alternative acid addition equation can be found in Koopman (2003b). It was developed to fit the experimentally determined minimum acid requirement, so it only needed a factor of about $110 \%$ to cover uncertainties in the model. The data that it was based on, however, were dominated by tests with high oxalate. New data are being added to the database as time passes. An improved stoichiometric algorithm for low oxalate sludges may be developed in the future.

\subsection{Low Oxalate Hydrogen Findings}

This section groups the low oxalate hydrogen findings based on the general program(s) that generated them.

\subsubsection{Review of “SB3” and SB3 Experimental Hydrogen Data}

Data for the low oxalate simulations fall into two groups. These are either simulation sets on specific sludges which approximately found the minimum acid required for nitrite destruction experimentally or those that did not. Many of the sludge compositions prepared during the various phases of the "SB3" and SB3 test programs were tested at multiple acid stoichiometries. This was done to evaluate the acid window, or range of stoichiometric factors that achieved acceptable nitrite destruction without excessive hydrogen generation. Tracking the SRAT product nitrite concentration allowed an estimate to be made of the minimum acid required to destroy nitrite to less than $1000 \mathrm{mg} / \mathrm{kg}$ during the SRAT cycle.

Some visual observations were made on the graphical hydrogen data collected during "SB3" and SB3 simulations. As the acid added during the acid window study for SB3 fell, the time of peak hydrogen generation seemed to shift to later in the SRAT cycle, Baich (2004a). The volume percent hydrogen data from the four runs in the acid window study are plotted as a group in Figure 10.

Figure 10. SB3 Acid Window Study Hydrogen Data

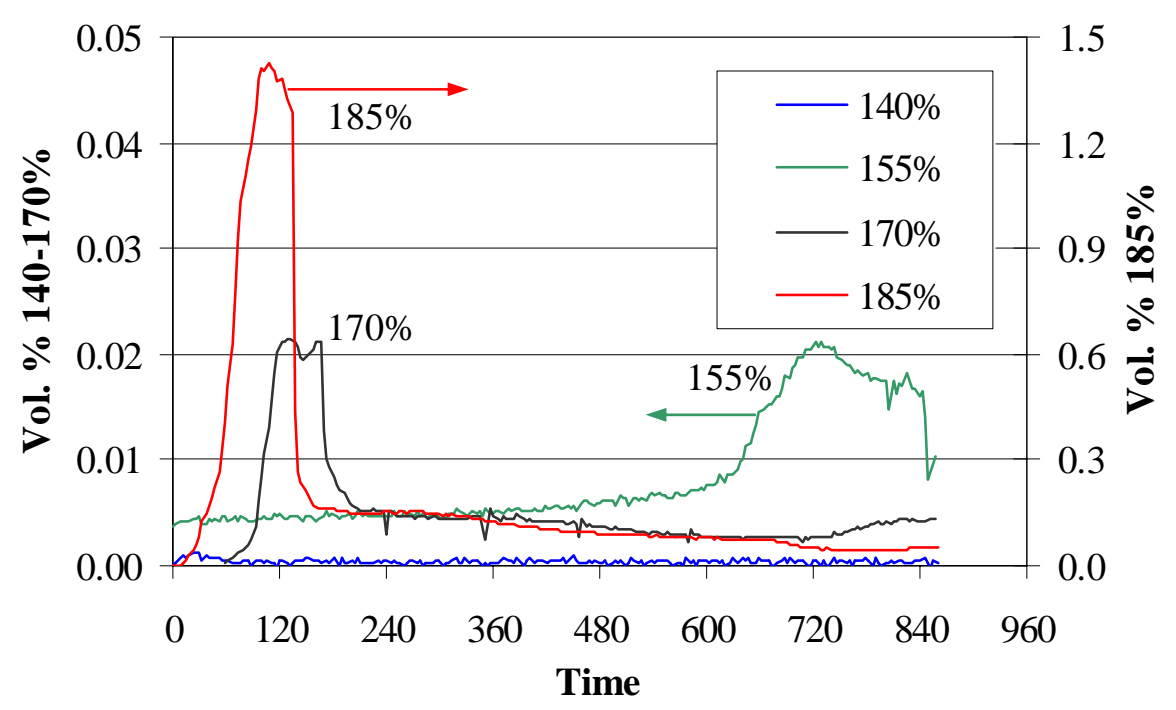

The peak at $155 \%$ was not that different in magnitude from the peak at $170 \%$, but it came about eight hours later. This is not that different from the behavior seen in the Phase II experimental hydrogen generation program work, Koopman (2005c), where the reduction in total noble metal concentration by $35 \%$ produced a delay in peak hydrogen generation, but no reduction in magnitude. 
Another observation was that the operation of the bench-scale equipment and the concentration of mercury both seemed to be important at $185 \%$ of stoichiometry. Compiled data at $185 \%$ from several programs is included in Figure 11 to illustrate. This figure includes data from testing in the 22-L SRAT equipment. More details on the individual 22-L SRAT runs can be found in Appendix A.

Figure 11. SB3 Hydrogen Generation Results at 185\% Acid, 0.2 Redox

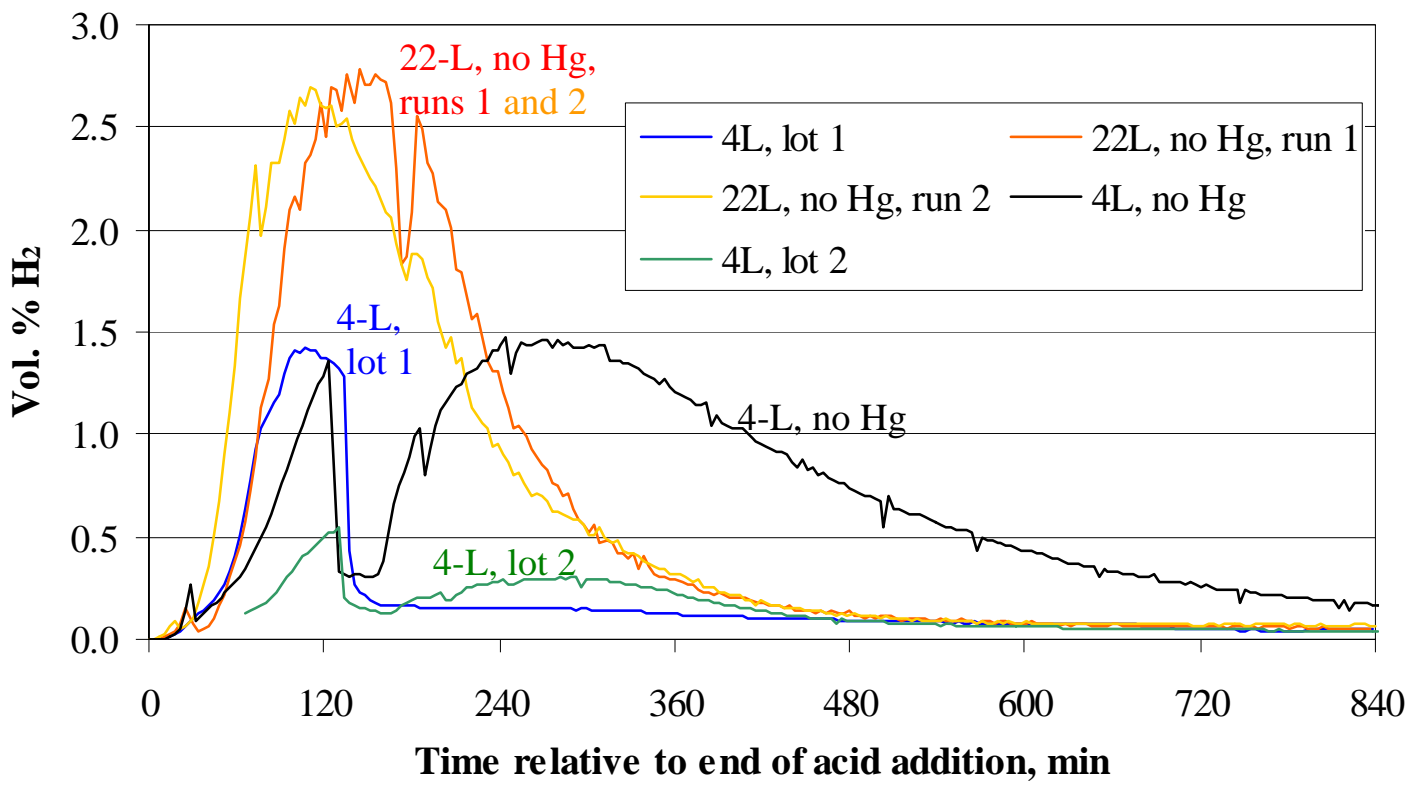

Variations in hydrogen production in runs made about eight months apart are seen in the data for lots 1 and 2. These were two essentially identical preparations of the SB3 simulant by the same blending strategy starting with two simulants produced at CETL and with $0.119 \% \mathrm{Hg}$. One gave nearly 2.5 times more hydrogen at the peak than the other. Accurately modeling hydrogen data will be impacted as long as such variability is found in the results. Peak hydrogen production in the 22-L SRAT exceeded that seen in the 4-L SRAT for runs with no Hg. The 4-L SRAT, however, produced hydrogen at higher levels than the 22-L SRAT for much of the reflux period. It was hypothesized that some of the variations in hydrogen concentration were due to equipment and operational differences between the two scales. The interaction between hydrogen generation and the onset of reflux in the 4- $\mathrm{L}$ compared to the 22-L rigs contributed to the decision to modify the lab equipment used in CPC tests. Modifications to the benchscale test protocols may also be found to reduce the variability in future testing.

Another interesting observation was made related to the 22-L SRAT tests. Often these vessels are used for two consecutive SRAT cycles (same sludge plus same acid addition) without cleaning them inbetween. Consequently, there is a coating of SRAT product present inside the vessel when the fresh sludge is charged for the second SRAT cycle. Two sets of GC data were obtained covering both an initial SRAT cycle and the second SRAT cycle. In both cases, there was less hydrogen production in the second SRAT cycle than in the first, Figure 12. 
Figure 12. Repeated Run Effect in 22-L SRAT

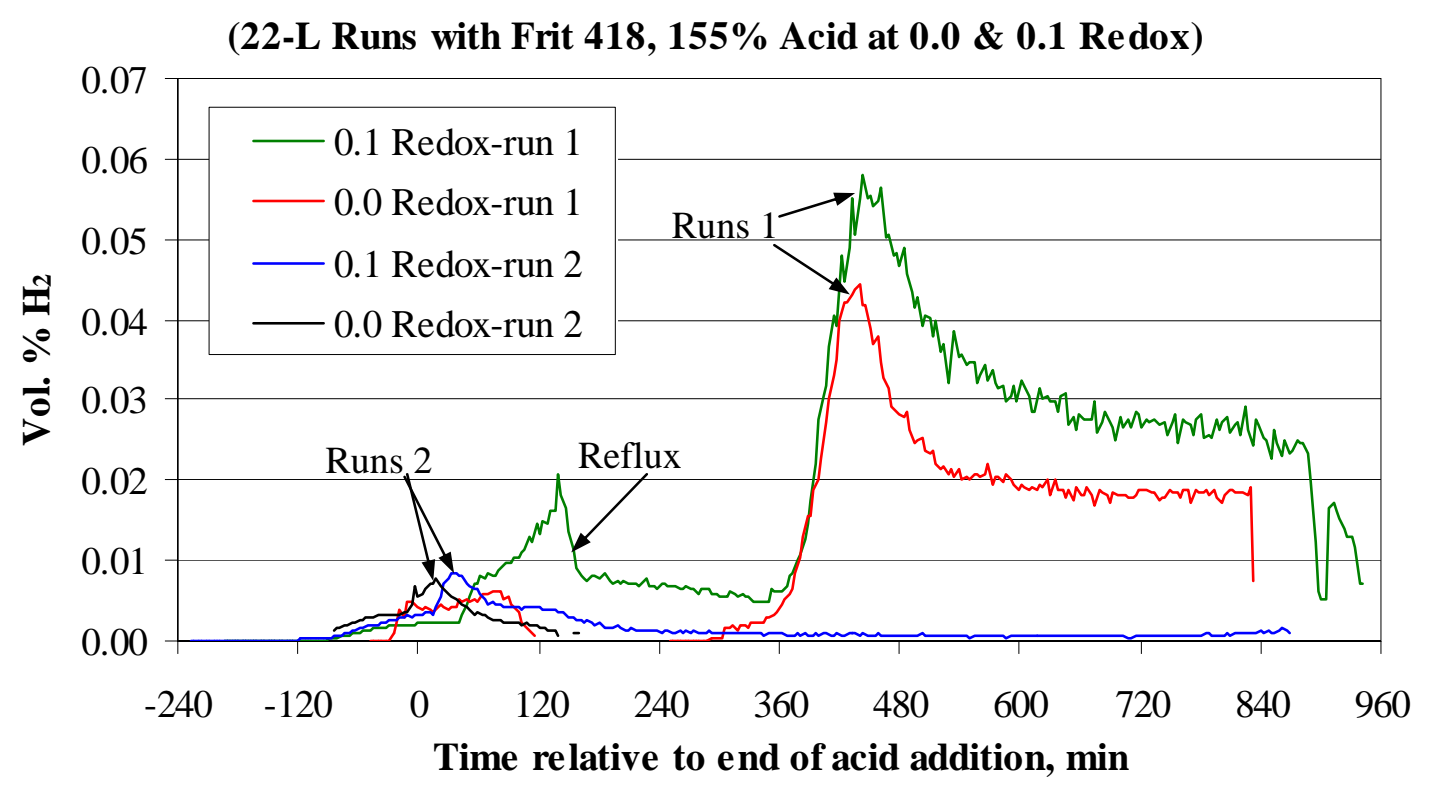

The late peak in hydrogen around 400 minutes in the initial runs came sooner than, but was similar to, the profile seen in the $4-\mathrm{L}$ test at $155 \%$, Figure 10. There was no GC data from the first 22-L run at a redox of 0.2 , but data from the second run was very close to that for the second runs at redox targets of 0.1 and 0.0 in Figure 12, so there are actually three second runs that show suppressed hydrogen generation at 155\%. Another interesting observation was that hydrogen was detected before the end of acid addition in these 22-L runs. This was not seen in similar 4 -L runs at $155 \%$ acid, e.g. Figure 10 . The drop in hydrogen in "0.1 Redox-run 1" at 143 minutes coincides with the onset of reflux. The 22-L SRAT equipment was modified in January 2005 to be more nearly prototypical through the SRAT condenser and MWWT. Evaluation of comparable SRAT data between scales is planned during the next year of SRNL CPC testing.

During "SB3" flowsheet development, it was observed that there were some acid stoichiometries and sludge composition combinations that seemed to produce significant hydrogen generation, but the peak did not come early during SRAT boiling. In a few of these cases, the scaled DWPF hydrogen limit for the SME cycle was exceeded following a successful SRAT cycle. In other cases, neither the SRAT nor the SME limits were exceeded. An example of peak hydrogen generation delayed to the SME cycle was SB3A-14, Figure 13, where SME cycle hydrogen exceeded the DWPF SME design basis after falling to near $0.33 \mathrm{lbs} / \mathrm{hr}$ at DWPF-scale by the end of the SRAT, Herman (2003e). 
Figure 13. SRAT/SME Hydrogen Generation in SB3A-14

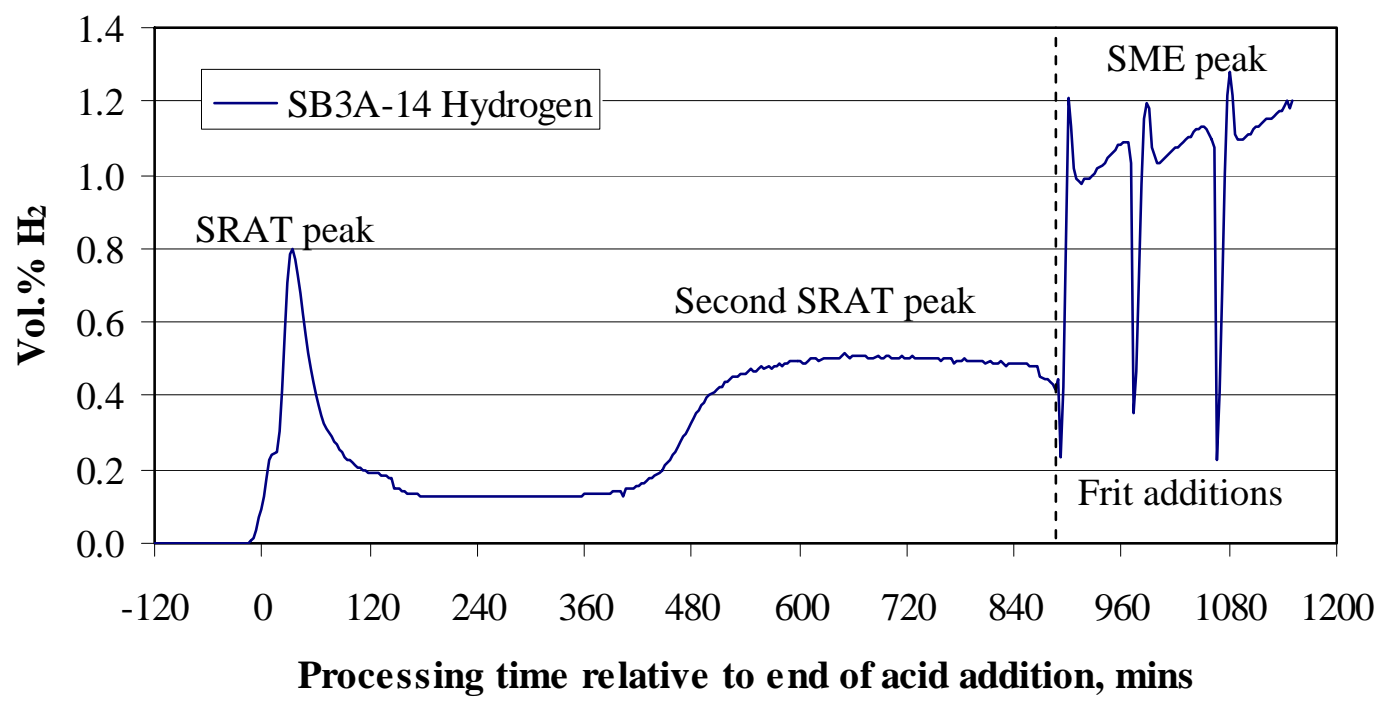

This run also had two distinct peaks during the SRAT cycle. The first came right after acid addition during dewatering. The second came nine hours after acid addition during reflux.

Figure 14 provides another example of SME hydrogen concentrations exceeding SRAT concentrations. The data are from the $155 \%$ stoichiometry run of SB3 processing window study, Baich (2004a):

Figure 14. Delayed Hydrogen Peak in Acid Window Study

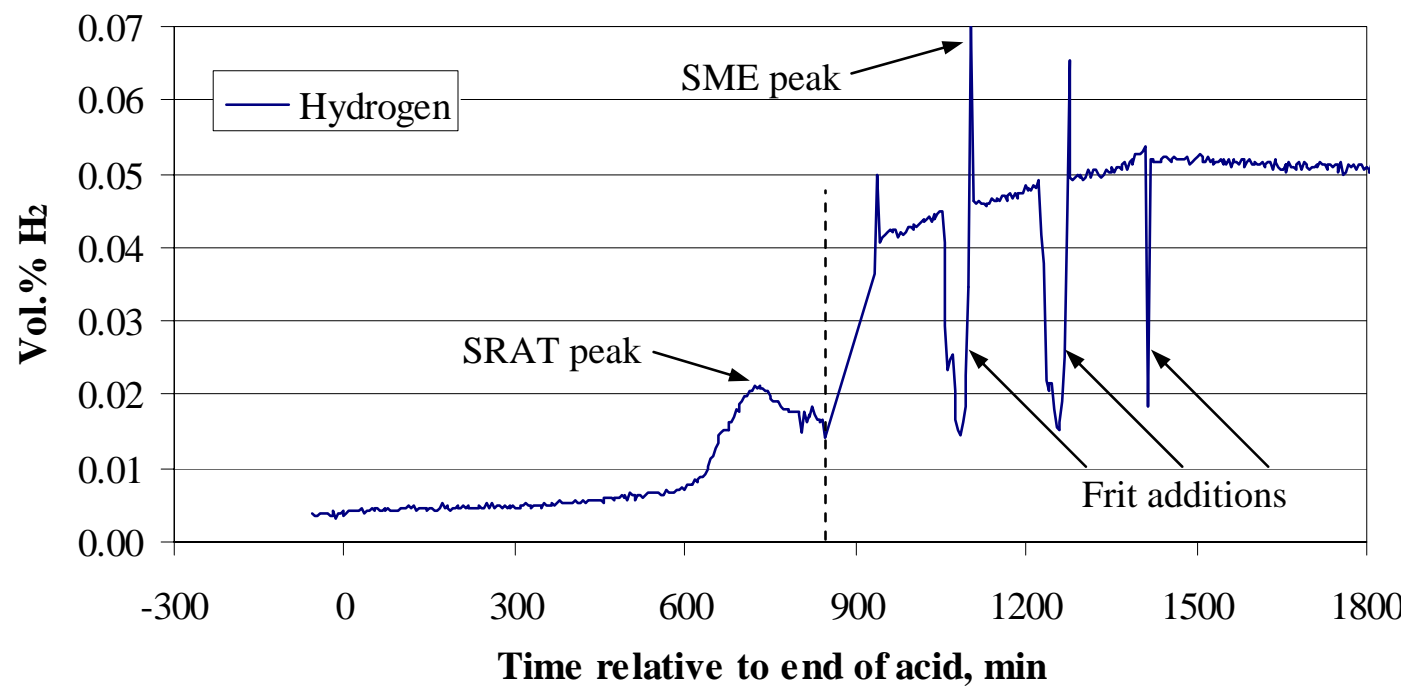

Hydrogen concentration peaks after the onset of boiling following each of the frit additions in the SME cycle were at a higher volume percent than was reached in the SRAT, $\sim 0.02 \%$. Note that this run did not have an early SRAT peak in hydrogen similar to SB3A-14, but instead rose to its maximum in the SRAT near the end of the reflux period like the $155 \%$ run in Figure 10. SB3A-14 had two SRAT peaks in hydrogen, one shortly into boiling and a smaller, broader peak later during reflux. 
This delayed peak (or delayed second peak) in hydrogen generation until the SME cycle was apparently caused by a combination of two factors. First, hydrogen generation either did not peak, or had only just peaked, by the end of the SRAT cycle. Second, this hydrogen generation level was then matched to the lower air purge flow of the SME, resulting in a higher volume \% of hydrogen than at the end of the SRAT. When the acid addition was decreased, neither the SRAT nor the SME exceeded their design bases for hydrogen generation. The likelihood of finding cases where peak hydrogen is delayed to the SME cycle appears to have increased as the window of allowable acid additions in the SRAT shrinks (window between minimum acid processing and too much hydrogen in the SRAT). At 170\%, the peaks in the SRAT and the SME were the same volume percent during the SB3 acid window study, i.e. a higher fraction of the hydrogen generation had been pulled back into the SRAT compared to the $155 \%$ case.

One test was made in the 4-L rig using a heel of SRAT product produced in a prior run to simulate a SRAT heel, Baich (2004b). Acid was added based on the mass and properties of the fresh sludge added to the heel. A sample of the fresh sludge-heel mixture was analyzed. Based on the properties of the sludge-heel mixture, the actual acid needed for $155 \%$ of stoichiometry was $6.2 \%$ lower than what was actually used. This reduction was presumably due to the acid contained in the heel. The recomputed factor for the heel run is $165 \%$ of stoichiometry. The corresponding hydrogen data are given in Figure 15.

Figure 15. SB3 Heel Impact for SB3 Simulant at 0.2 Redox

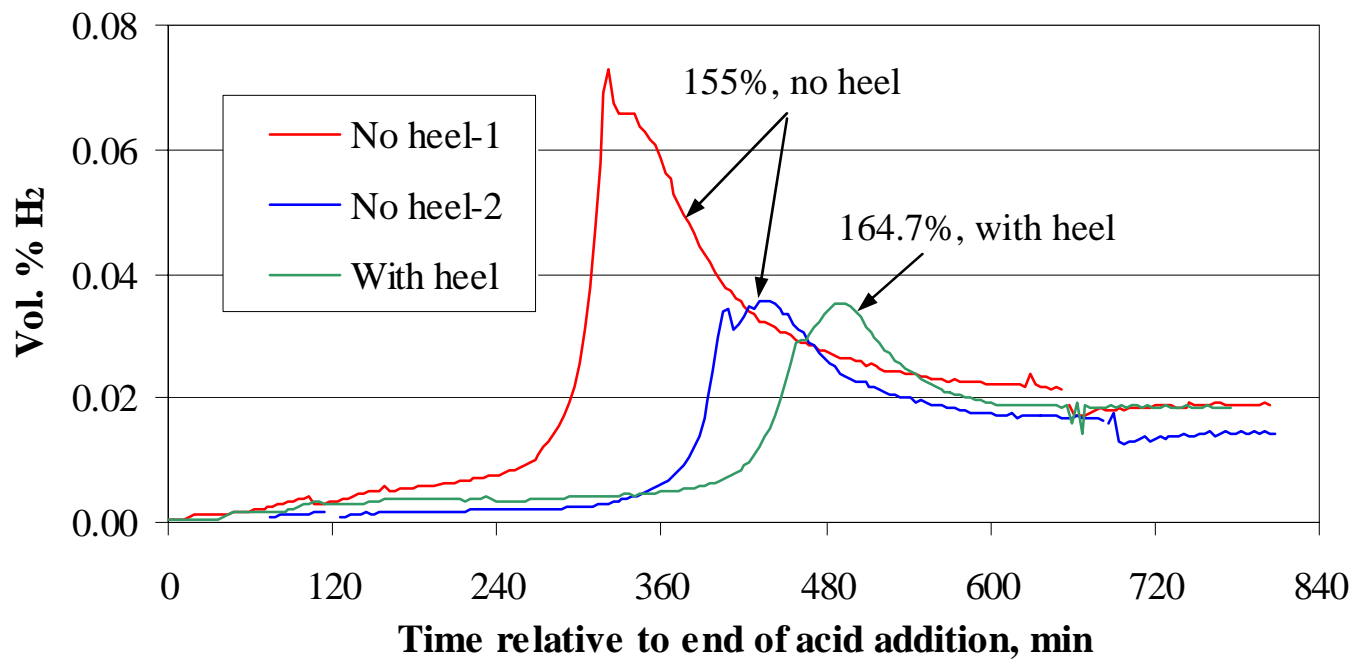

Hydrogen generation was significantly different in the two identical runs with no heel. The run with heel, however, produced comparable hydrogen to one of the two runs. This was probably aided by the additional excess acid indicated by the $165 \%$ factor versus $155 \%$. There is insufficient experimental data to conclude that the minimum acid required for the primary processing goals was not also effected by the presence of the heel. It seems reasonable that the minimum acid required should have decreased with the addition of the heel, e.g. Mn that has already been reduced from +4 to +2 , slightly more of the carbonate is present as bicarbonate as $\mathrm{pH}$ falls, some of the insoluble hydroxides have already been through one SRAT cycle, etc. Consequently, these data tend to confirm what was seen in the 22-L SRAT second runs: SRAT products, e.g. heels, tend to inhibit hydrogen generation.

There was one other 22-L SRAT study that should be reviewed at this point. In this study, sodium hydroxide was added to the starting sludge. This was done to offset using a lower sodium frit. The acid 
calculation was modified by changing the base equivalents to adjust for the increased sodium hydroxide. This was done by adding the equivalent molarity of the $\mathrm{NaOH}$ to that measured in the sludge prior to adding the $\mathrm{NaOH}$. The SRAT acid addition targeted 155\%.

Figure 16. Impact of Added Caustic-Added Acid Combination

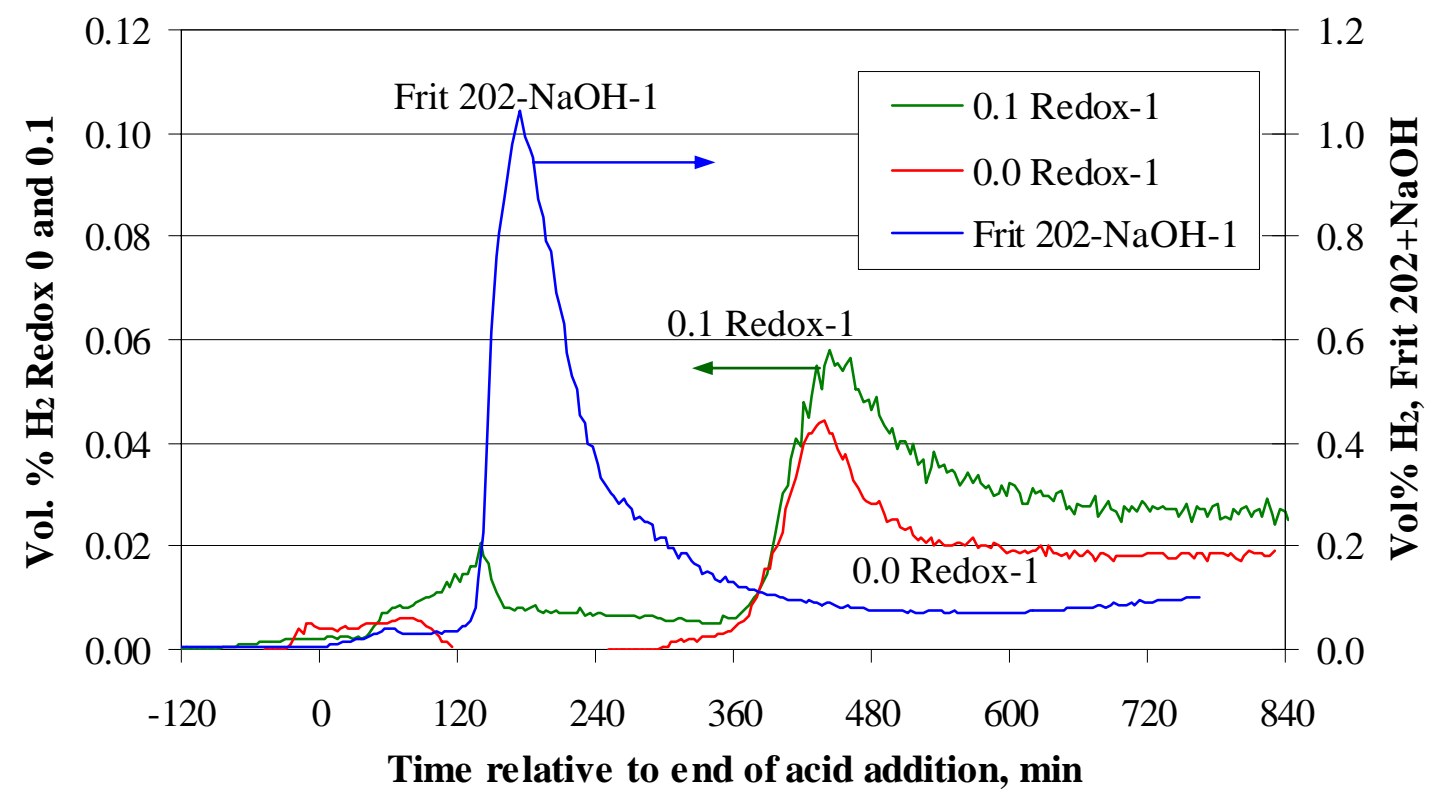

Note the two different scales that are a factor of ten different in Figure 16. These three 22-L runs were all the first runs of a set, so there was no SRAT product in the vessel initially. By adding caustic to the stoichiometric acid calculation without simultaneously reducing the factor, it appears that significantly more excess acid was present. A generally similar conclusion was reached in the study of the impact of the Actinide Removal Process, ARP, feed on DWPF processing. This stream contained some other acid consumers than $\mathrm{NaOH}$, but the impact on the stoichiometric acid calculation was dominated by the contribution from caustic. (ARP testing is reviewed in section 4.3.3.)

The common argument from the ARP and added caustic tests is that a stoichiometric acid correction factor of $100 \%$ is the appropriate factor for $\mathrm{NaOH}$, i.e. no excess acid is needed to neutralize caustic. Consequently, there were $55 \%$ more moles of excess acid for every mole of added $\mathrm{NaOH}$ in this SRAT. This led to an almost 20-fold increase in peak hydrogen generation. A first principles methodology was developed for adjusting the correction factor downwards when adding simple supernate species to the SRAT during the ARP flowsheet program, Koopman (2003d).

The hydrogen data in Figure 16 would have been more similar between runs, if the increase in excess acid had only been $5-10 \%$ more moles for every mole of $\mathrm{NaOH}$ added instead of 55\%. This would require separate correction factors for base and the other four terms in the current stoichiometric acid requirement equation or an improved stoichiometric equation that requires correction factors close to $100 \%$. An improved stoichiometric acid equation would also benefit future hydrogen studies by allowing immediate and more accurate calculation of the excess acid present for hydrogen generation from the stoichiometric acid requirement and the correction factor. 
Nearly all of the 4-L SRAT off-gas data has been documented in technical reports. That is not as true for the 22-L SRAT rig off-gas data. Some of this data was collected and reported on in Appendix A. The emphasis in reports related to the 22-L SRAT runs has tended to be on the downstream studies of melt rate rather than on the CPC processing, which has presumably already been studied at 4-L scale. For example, there have been several 4-L simulations of SB3 processing at both $155 \%$ and $185 \%$ of stoichiometry. The exclusion of mercury in the 22-L tests, however, generally leads to more hydrogen generation than in the 4-L tests at the same stoichiometry. This needs to be recognized and justifies taking GC data during 22-L SRAT simulations. The data are somewhat different between scales for other reasons, as well, although there are still many similarities. Modifications have been made to both the 22$\mathrm{L}$ and the 4-L SRAT equipment since the data above were obtained in order to make them perform in a more prototypical manner. Future GC data should be obtained to evaluate the relative performance of the different scales as a result of these modifications.

One final observation was made on this large body of off-gas data. Careful examination of the carbon dioxide data during boiling showed a behavior that often mirrored what was seen in the hydrogen data. This was used as an empirical check of whether or not there was something suspicious in the hydrogen generation GC data. For example, the long delay in the hydrogen peak at 155\% acid compared to 170\% and 185\% in Figure 10 at first looked suspicious, but the same behavior was seen in the $\mathrm{CO}_{2}$ data. The two big peaks in the 22-L runs at $155 \%$ acid and redox 0.0 and 0.1 around 400 minutes after acid addition in Figure 16 are also mirrored in the $\mathrm{CO}_{2}$ data.

\subsubsection{Statistical Analysis of Sludge Batch 3 Hydrogen Data}

Hydrogen generation has generally been found to increase with increasing acid stoichiometric factors and noble metal concentrations. Since hydrogen generation occurs in simulant tests following the majority of nitrite destruction, it had been postulated that only excess acid (acid not required for base and carbonate neutralization, nitrite destruction, etc.) was available for hydrogen generation. It had further been hypothesized that the best way to study hydrogen generation was to correlate it to the excess acid.

The estimation of excess acid by the stoichiometric acid equation is not very accurate, however, since it does not calculate the acid needed for the main reactions with sufficient accuracy. A correction factor has been needed to ensure sufficient acid is added to complete the main reactions. This correction factor varies as the sludge composition changes (other factors may impact the factor, such as the storage history of the waste).

During "SB3" flowsheet development, it was not always necessary to estimate the quantity of excess acid present using an equation for the stoichiometric acid requirement. Many of the starting sludge compositions were processed at two or more levels of total acid. This often provided a more direct measure of the quantity of excess acid, e.g. by producing a SRAT product with about $100-1000 \mathrm{mg} / \mathrm{kg}$ nitrite in one of the runs. Such a SRAT batch presumably had very little, if any, excess acid present. When one or more runs of the same starting sludge had larger acid additions, these tended to produce some measurable amount of hydrogen. Table 3 groups such sets of runs. The groups are given in generally chronological order with the oldest runs first and the most recent runs last. The list was restricted to tests in the 4-L SRAT equipment in order to limit any impacts due to scale.

The first 17 entries in Table 3 are from "SB3" studies based on Tank 8 simulant. Bold borders denote blocks of similar starting composition. SB3-1 to SB3-18, i.e. the first five runs listed, were made with USC Tank 8 simulant. They were essentially identical compositions except for variations in sand, coal, noble metals, and mercury. There was an additional test at smaller scale to help refine the experimental acid requirement. SB3A- prefixes indicate "SB3" runs based on the newer SB3 simulant from CETL. SB3A-4 was a special low oxalate test. There were two small scale tests to help refine the minimum acid 
requirement for SB3A-4. SB3A-10 through SB3A-20 consisted of five compositions related to different wash endpoints. Four cases were tested twice and one was tested three times, SB3A-14 to SB3A-16. The last ten entries in Table 3 are all tests at the baseline SB3 composition, except for variations in mercury concentration during the last five. These five were part of Phase I of the hydrogen generation study program.

The experimental stoichiometric acid requirement was determined for baseline SB3 simulant during the acid window study, Baich (2004a). The smaller scale runs used to help fix the true acid requirements had no GC data, and they were not included in the table. Ru and Pd were approximately proportional to Rh in these simulants. The numbers in red in the SRAT product nitrite column give some indication of how the minimum acid requirement was estimated. Data tabulated also included the fraction of the total acid that was added as formic acid instead of nitric acid. 
Table 3. Summary of "SB3” and SB3 4-L SRAT Runs with Low Oxalate

\begin{tabular}{|c|c|c|c|c|c|c|c|c|}
\hline Test ID: & $\begin{array}{l}\text { Sludge } \\
\text { mass, } \\
\mathrm{g} \\
\end{array}$ & $\begin{array}{c}\mathrm{Rh}, \\
\mathrm{mg} / \mathrm{kg}\end{array}$ & $\begin{array}{c}\mathrm{Hg}, \\
\mathrm{mg} / \mathrm{kg}\end{array}$ & $\begin{array}{c}\text { Minimum } \\
\text { acid for } \\
<1000 \\
\mathrm{mg} / \mathrm{kg} \\
\text { nitrite, } \\
\text { moles/L } \\
\end{array}$ & $\begin{array}{c}\text { Total } \\
\text { acid } \\
\text { added, } \\
\text { moles/L } \\
\end{array}$ & $\begin{array}{c}\text { SRAT } \\
\text { product } \\
\text { nitrite, } \\
\mathrm{mg} / \mathrm{kg} \\
\end{array}$ & $\begin{array}{c}\text { SRAT } \\
\mathrm{g} \mathrm{H}_{2} \\
\text { made } \\
\end{array}$ & $\begin{array}{c}\text { SRAT } \\
\text { peak } \mathrm{H}_{2} \text {, } \\
\text { lb/hr } \\
\text { DWPF } \\
\end{array}$ \\
\hline SB3-1 & 2200 & 93.73 & 137 & 0.71 & 0.99 & 0 & 0.02624 & 0.242 \\
\hline SB3-2 & 2200 & 93.73 & 137 & 0.71 & 0.99 & 0 & 0.04223 & 0.515 \\
\hline SB3-3 & 2200 & 0 & 137 & 0.90 & 0.99 & 12 & 0.00000 & 0.0 \\
\hline SB3-4 & 2200 & 93.75 & 137 & 0.71 & 0.99 & 0 & 0.04518 & 0.606 \\
\hline SB3-18 & 2400 & 92.77 & 138 & 0.72 & 1.19 & 0 & 0.11716 & 0.829 \\
\hline SB3A-4 & 2760 & 10.74 & 161.4 & 0.76 & 1.02 & 6 & 0.00000 & 0 \\
\hline SB3A-10 & 2737 & 86.01 & 784.3 & 1.8 & 1.861 & 240 & 0.00116 & 0 \\
\hline SB3A-11 & 2744 & 86.01 & 784.3 & 1.8 & 2.246 & 0 & 0.40297 & 1.25 \\
\hline SB3A-12 & 2816 & 84.54 & 882.6 & 1.49 & 1.467 & 1010 & 0.00000 & 0 \\
\hline SB3A-13 & 2813 & 84.54 & 882.6 & 1.49 & 1.755 & 0 & 0.05200 & 0.132 \\
\hline SB3A-14 & 2626 & 26.65 & 785.9 & 1.9 & 2.584 & 0 & 0.12800 & 0.533 \\
\hline SB3A-15 & 2752 & 26.65 & 785.9 & 1.9 & 1.922 & 747 & 0.00000 & 0 \\
\hline SB3A-16 & 2753 & 26.65 & 785.9 & 1.9 & 2.4595 & 0 & 0.06770 & 0.184 \\
\hline SB3A-17 & 2819 & 14.9 & 644.8 & 1.65 & 1.499 & 1970 & 0.00000 & 0 \\
\hline SB3A-18 & 2818 & 14.9 & 644.8 & 1.65 & 1.79 & 0 & 0.00575 & 0.014 \\
\hline SB3A-19 & 2800 & 13.88 & 673 & 1.82 & 1.723 & 1620 & 0.00000 & 0 \\
\hline SB3A-20 & 2800 & 13.88 & 673 & 1.82 & 2.136 & 0 & 0.00660 & 0.014 \\
\hline MB2/3-140 & 3030 & 18.32 & 284.4 & 1.93 & 1.893 & 1215 & 0.00059 & 0.00114 \\
\hline MB2/3-155 & 3030 & 18.32 & 284.4 & 1.93 & 2.096 & 0 & 0.00586 & 0.0173 \\
\hline MB2/3-170 & 3030 & 18.32 & 284.4 & 1.93 & 2.29 & 0 & 0.00275 & 0.01665 \\
\hline MB2/3-185 & 3030 & 18.32 & 284.4 & 1.93 & 2.501 & 0 & 0.09368 & 0.953 \\
\hline $60 \%$ FA-155 & 3030 & 17.17 & 0 & 1.92 & 2.06 & 0 & 0.00353 & 0.0543 \\
\hline HGRUN1 & 2700 & 17.02 & 0 & 1.92 & 2.483 & 0 & 0.32750 & 1.1158 \\
\hline HGRUN2 & 2700 & 17.02 & 4480 & 1.95 & 2.498 & 0 & 0.02116 & 0.1435 \\
\hline HGRUN3 & 2700 & 17.02 & 266.6 & 1.93 & 2.4579 & 0 & 0.04991 & 0.27394 \\
\hline HGRUN4 & 2700 & 17.02 & 4424 & 1.95 & 2.4909 & 0 & 0.01260 & 0.13745 \\
\hline HGRUN5 & 2700 & 17.02 & 266.6 & 1.93 & 2.482 & 0 & 0.07310 & 0.45775 \\
\hline
\end{tabular}

There were indications that some of the hydrogen data were not highly reproducible. These came from approximately identical runs that produced significantly different peak concentrations of hydrogen (not all such runs are shown in the table). The differences may have been partly due to changing conditions within the lab hoods that impacted internal refluxing in the SRAT. Internal refluxing was linked to acid consumption during the Phase I hydrogen generation program testing, Koopman (2005a), so it can be inferred with confidence that the extent of internal refluxing was altering the excess acid present for hydrogen generation. This led to uncertainty in the column of minimum acid requirements for taking nitrite to $<1000 \mathrm{mg} / \mathrm{kg}$ as well. 
There have also been some issues with the integration of the hydrogen peak to produce a volume percent in the GC software. Some of the raw hydrogen chromatograms have been re-analyzed to improve the quality, but this extra effort was not warranted in all cases to meet the objectives of the specific test program. There have also been some issues with the measurement of the helium that is added as an internal standard. Helium is critical to converting the hydrogen data to an equivalent DWPF-scale flow rate. When there were obvious helium issues, nitrogen was used as a substitute for flow estimation purposes or the data were omitted from the database.

The "SB3" and SB3 data in Table 3 were imported into the JMP ${ }^{\mathrm{TM}}$ statistical analysis program for further study. An F-test of significance was given to the following factors versus the DWPF-scale peak hydrogen generation rate.

Table 4. Statistical Test of Factors Impacting Hydrogen Generation

\begin{tabular}{|l|c|c|l||}
\hline Factor & F & Prob > F & \multicolumn{1}{|c|}{ Comment } \\
\hline Rh, mg/kg & 3.045 & 0.0932 & Borderline \\
\hline Hg, mg/kg & 0.681 & 0.4170 & Not very significant \\
\hline Minimum acid, M & 0.191 & 0.6660 & Not very significant \\
\hline Actual acid, M & 0.859 & 0.3630 & Not very significant \\
\hline $\begin{array}{l}\text { Fraction of acid that } \\
\text { was formic acid }\end{array}$ & 0.337 & 0.5666 & Not very significant \\
\hline Excess acid, M & 14.434 & 0.0008 & Very significant \\
\hline
\end{tabular}

These are the F factors shown in JMP ${ }^{\mathrm{TM}}$ before bringing any of the factors into the model. Even with the issues in some of the database entries, the quantity of excess acid was found to be very significant to hydrogen generation. Excess acid was much more significant than total (actual) acid. This would be a justification for developing better methods of determining the excess acid. A linear model with excess acid only had an $\mathrm{R}^{2}$ of 0.366 . That is, although excess acid is very significant, a linear model containing excess acid does not explain most of the variation in hydrogen generation seen in the data set. Generally similar statistics were found when applying the same test to the total grams of hydrogen produced per gram of starting sludge instead of to the peak hydrogen generation rate.

The lack of statistical significance of Hg was difficult to explain. Taking the last five rows (the mercury study) and performing the F-test again did not indicate mercury was particularly significant, even though the data themselves showed overwhelming significance. This presumably indicates that the role of mercury in hydrogen generation is nonlinear in the initial mercury concentration.

The factor $\mathrm{Rh}$ is indistinguishable from the factor $\mathrm{Ru}$, since these two variables were in constant proportions during the tests. The factor Rh in the analysis is actually the role of all three noble metals as a group, since Pd, Rh, and Ru rose and fell together (were perfectly correlated statistically). One physical interpretation of the $\mathrm{Rh} \mathrm{F}$-factor is that hydrogen generation is not a zeroth-order reaction, i.e. one that depends on a rate constant but no reactants. Presumably the role of the noble metals as catalysts is dependent on the rate constant(s) for the chemical kinetic relationship(s) describing hydrogen generation.

Three additional factors were constructed to look at non-linear effects. These were Rh*Excess Acid, $\mathrm{Rh}^{*}$ Excess $\mathrm{Acid}^{2}$, and $\mathrm{Rh}^{2} *$ Excess Acid. The same table was constructed as above except that it included three additional factors. 
Table 5. Enhanced Statistics for Hydrogen Generation

\begin{tabular}{|l|c|c|l||}
\hline Factor & F & Prob $>$ F & \multicolumn{1}{|c|}{ Comment } \\
\hline Rh, mg/kg & 3.045 & 0.0932 & Borderline \\
\hline Hg, mg/kg & 0.681 & 0.4170 & Not very significant \\
\hline Minimum acid, M & 0.191 & 0.6660 & Not very significant \\
\hline Actual acid, M & 0.859 & 0.3630 & Not very significant \\
\hline $\begin{array}{l}\text { Fraction of acid that } \\
\text { was formic acid }\end{array}$ & 0.337 & 0.5666 & Not very significant \\
\hline Excess acid, M & 14.434 & 0.0008 & Very significant \\
\hline $\mathrm{Rh}$ Ex Acid $^{\text {Rh*Ex Acid }}$ & 23.558 & 0.0001 & Very significant \\
\hline $\mathrm{Rh}^{2} *$ Ex Acid & 35.021 & 0.0000 & Very significant \\
\hline
\end{tabular}

The roles of the previous factors did not change. Combining the noble metals with the excess acid as products, however, produced improved fits. A simple linear fit of "Rh*Excess Acid" $^{2}$ " had an $\mathrm{R}^{2}$ of 0.5835 . This could be increased to 0.81 by excluding runs "MB2/3-185" and "HGRUN1" from the data set. The results from "MB2/3-185" were not reproduced well in the Phase $\mathrm{I}_{2}$ study. "HGRUN1" was the only run in Table 3 with no Hg.

These simple statistical studies confirm hypotheses concerning the importance of noble metals and excess acid on hydrogen generation. They also establish a joint role for these two factors such as might be found in a kinetic rate expression. An actual kinetic model was not established by these statistical tests. Such a model would need to incorporate chemical activation, e.g. reduction, dissolution, etc., and deactivation, e.g. poisoning, of the catalyst species in addition to establishing the correct rate expressions for hydrogen generation in the presence of excess acid and noble metals. The actual kinetic model would probably also need to incorporate the role of nitrite ion on the noble metals, and to cover parallel reaction paths to hydrogen, e.g. the conversion of formate ion to hydrogen versus the conversion of molecular formic acid to hydrogen.

\subsubsection{Actinide Removal Process-DWPF Interface}

Actinide removal process, ARP, testing involved the addition of various volumes of simulated ARP waste to the SRAT. This was added to a SB3 sludge simulant in the SRAT. The ARP waste was the composite of the back-flush insoluble solids and cleaning solutions from the cross-flow filter. It was to contain insoluble species removed during the ARP. The stream was still low in solids compared to the sludge feed to DWPF. The main acid requirement in the stream came from sodium hydroxide, but there were other species in the stream that would also consume acid during SRAT processing, e.g. carbonate, nitrite, oxalate, manganese, and monosodium titanate.

The combination of ARP waste and sludge waste in the SRAT produced an increase in the calculated stoichiometric acid requirement. The calculated stoichiometric acid requirement tends to undercount consumers of acid. A correction factor is used to increase the amount of acid added above that calculated to cover consumption by other reactions. Increasing the acid requirement in the SRAT by adding the ARP waste was seen as primarily increasing consumption that was being accounted for in the calculation. If the factor was held constant for batches that had anywhere from no ARP waste up to 9000 gallons of ARP waste present with the 6000 gallons of fresh sludge, then it was expected that considerable variation in the excess acid would occur.

Excess acid, or that acid not consumed to accomplish the primary SRAT reactions, is probably the primary reagent for hydrogen generation; see the statistical results in section 4.3.2. A methodology was 
developed to reduce the factor being applied to the stoichiometric acid calculation as the quantity of ARP waste varied. Koopman (2003d) was the later of two reports summarizing the work. It focused on hydrogen generation and the bounding ARP volume case.

There were six SRAT and two SME simulations in the program overall.

SB2/3-Base Nominal, 6000 gallon SB3 sludge, baseline SRAT case.

ARP-1

1000 gallon ARP charge added to a normal 6000 gallon SRAT batch.

ARP-2 6000 gal SRAT batch caustic boiled to reduce volume, combined with a 1000 gallon ARP charge.

ARP-3 Caustic boil a 6000 gallon SRAT batch to reduce the tank volume to accommodate a 3000 gallon ARP charge.

ARP-4 Caustic boil a 3000 gallon SRAT sludge batch combined with a 3000 gallon ARP charge, then add an additional 3000 gallons of sludge. This SRAT product was later put through a SME cycle.

ARP-H2 Caustic boil 6000 gallons SRAT batch and a 3000 gallon ARP charge, add a second 3000 gallon ARP charge and boil down, add a third 3000 gallon ARP charge and boil down. Perform a SME cycle as well.

Inputs for the acid calculations are summarized in Table 7. The results are from the SRAT receipt samples taken after the ARP, if any, was added and the volume adjusted.

Table 6: ARP Acid Addition Input Parameters

\begin{tabular}{||l|c|c|c|c|c|c||}
\hline Parameter & $\begin{array}{c}\text { SB2/3- } \\
\text { Base }\end{array}$ & ARP-1 & ARP-2 & ARP-3 & ARP-4 & ARP-H2 \\
\hline Total Solids, wt\% & 21.3 & 18.21 & 21.64 & 20.89 & 22.54 & 25.99 \\
\hline Insoluble Solids, wt\% & 13.13 & 10.94 & 12.90 & 12.10 & 13.11 & 14.6 \\
\hline Density, Kg/L & 1.147 & 1.138 & 1.169 & 1.163 & 1.155 & 1.16 \\
\hline Nitrite, mg/Kg & 18680 & 16230 & 19800 & 17900 & 18900 & 21,700 \\
\hline Nitrate, mg/Kg & 14160 & 12800 & 15900 & 15400 & 16400 & 20,000 \\
\hline Mn, wt\% of solids ${ }^{1}$ & 3.25 & 3.18 & 3.18 & 3.21 & 3.21 & 3.14 \\
\hline Base Equivalents at pH 7, M & 0.562 & 0.544 & 0.581 & 0.651 & 0.659 & 1.039 \\
\hline TIC, mg/Kg & 1100 & 990 & 1300 & 1324 & 1385 & 1175 \\
\hline Oxalate, mg/Kg & 1790 & 1910 & 1910 & 2053 & 3000 & 5980 \\
\hline Acid Stoichiometry, \% ${ }^{2}$ & $130 \%$ & $130 \%$ & $120 \%$ & $118 \%$ & $139 \%$ & $138 \%$ \\
\hline
\end{tabular}

${ }^{1}$ Calculated value based on the known amount in the sludge and assumption that Mn concentration was not affected by caustic boiling.

${ }^{2}$ The acid stoichiometry numbers reflect the as-measured stoichiometry used in the run based on the TIC and pH 7 titration. The first four flowsheet tests, SB2/3-Base and ARP-1 to ARP-3 targeted 130\%, while ARP-4 and ARP-H2 targeted $135 \%$.

The approximate change in the stoichiometric acid demand with increasing ARP content is given in Table 7. Also given is the increase in moles of acid required per $~ 2,800 \mathrm{~g}$ of starting SB2/3 sludge slurry as the ARP addition volume increased. The $2.8 \mathrm{~kg}$ mass of sludge slurry was taken as equivalent to 6000 gallons of fresh waste from the tank farm. 
WSRC-TR-2005-00206

Revision 0

Table 7: Impact of ARP on DWPF SRAT Acid Stoichiometry

\begin{tabular}{|l|c|c|c|c|}
\hline & No ARP & $\begin{array}{c}1000 \text { gallons } \\
\text { ARP }\end{array}$ & $\begin{array}{c}3000 \text { gallons } \\
\text { ARP }\end{array}$ & $\begin{array}{c}9000 \text { gallons } \\
\text { ARP }\end{array}$ \\
\hline Moles acid/2.8 kg SB2/SB3 sludge & 3.15 & 3.31 & 3.69 & 4.56 \\
\hline Increment in acid/1000 gallons ARP & - & 0.16 & 0.18 & 0.16 \\
\hline
\end{tabular}

The increment in acid due to ARP waste is the ratio of the difference in the stoichiometric acid between an ARP test and the no ARP baseline test divided by the number of 1000 gallon ARP additions, e.g. (3.65-3.15)/3 for the 3000 gallon case. The values in the 1000 and 3000 gallons ARP columns are averages for the two flowsheet runs at each level.

The impact of ARP additions on the stoichiometric acid requirement was essentially cumulative and not trivial. Each 1000 gallon ARP addition added about 5\% additional acid requirement relative to the ARPfree SB2/3 baseline case. By 9000 gallons of ARP waste, there was a 45\% increase in the stoichiometric acid demand. It could be argued that little if any adjustment factor should be applied to the $45 \%$ extra stoichiometric acid calculated with 9000 gallons of ARP waste present. A methodology for empirically reducing the factor applied to the stoichiometric acid requirement was developed and presented in Koopman (2003d). This assumes that the ARP will be added before acid addition.

Hydrogen generation increased at 135\% of the stoichiometric acid calculation as the quantity of ARP added to the fresh sludge increased. This is seen in Figure 17 for the SRAT and in Figure 18 for the SME cycle. The two runs, ARP-4 and ARP-H2, are shown. These had 3000 gallons and 9000 gallons, respectively, of ARP waste simulant added to them.

Figure 17. Hydrogen Generation in the ARP SRAT Cycle

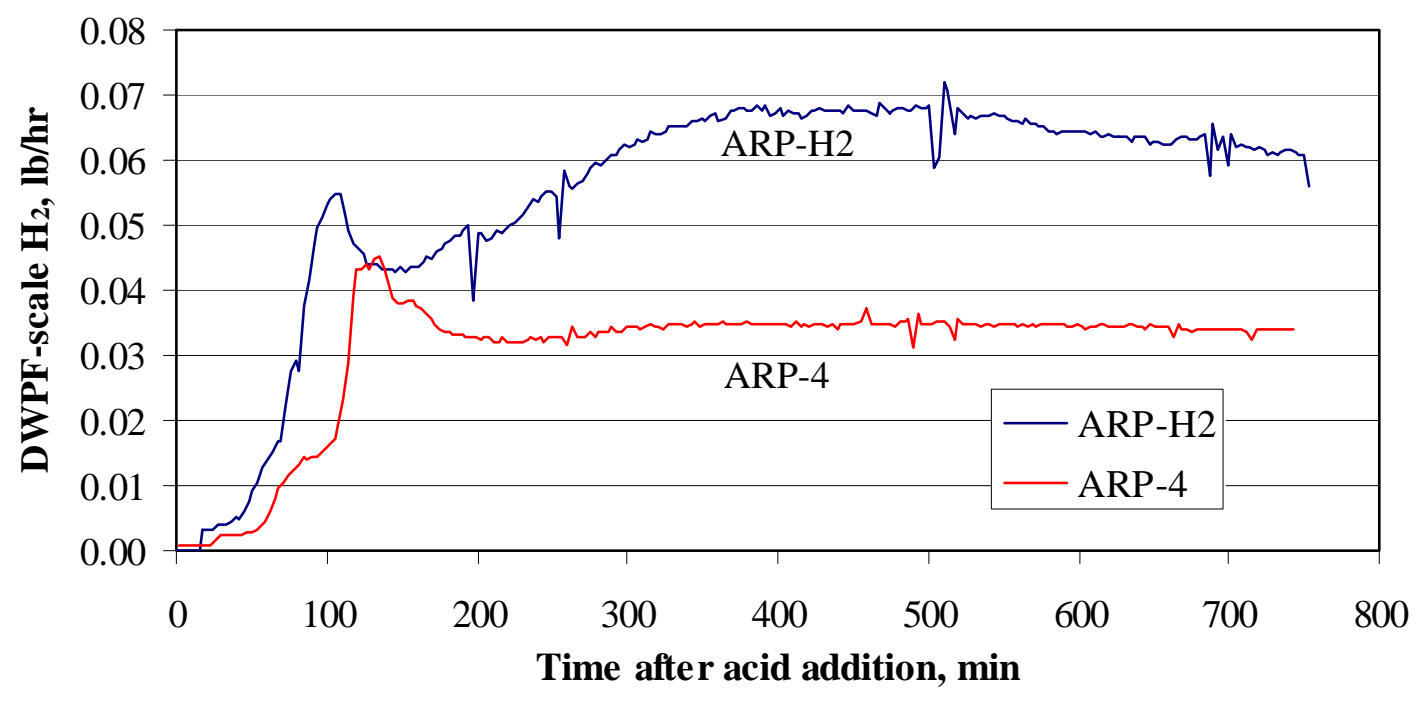

Hydrogen generation in the SRAT was relatively small compared to the design basis limit of $0.65 \mathrm{lbs} / \mathrm{hr}$. Both cases activated quickly. Later work with a slightly modified SB3 simulant showed that 135\% stoichiometry was near the lower end of the acid window defined by nitrite destruction and excessive hydrogen generation. About $150 \%$ of stoichiometry was needed to produce significant hydrogen. The late peak in ARP-H2 was higher than the initial peak at 100 minutes. This has only been seen 
infrequently, and it may have been caused by the start of reflux. No late peak was not seen in the ARP-4 SRAT cycle, however see the SME cycle data in Figure 18.

Figure 18. Hydrogen Generation in the ARP SME Cycle

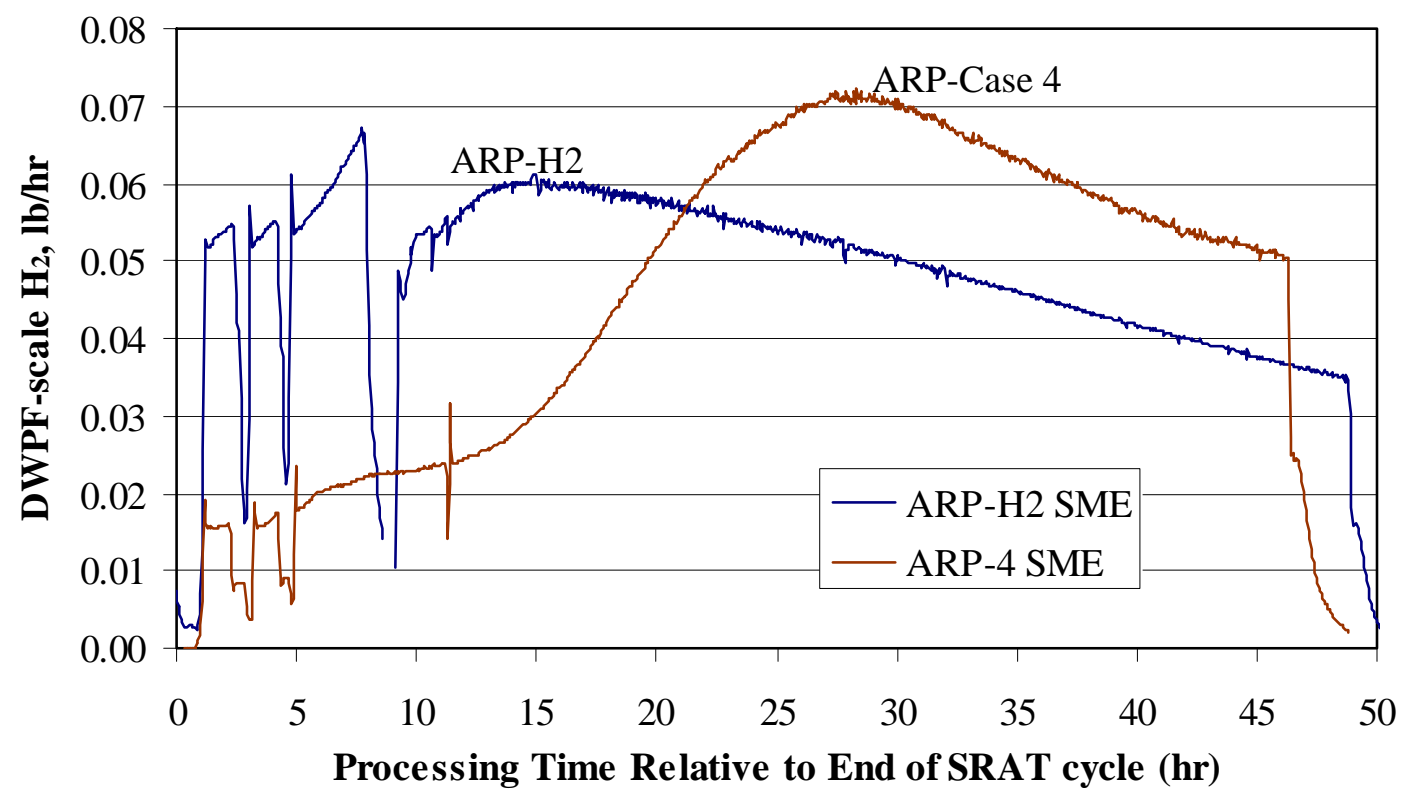

SME cycle hydrogen generation did not exceed the $0.23 \mathrm{lbs} / \mathrm{hr}$ limit. Interesting behavior was seen. The ARP-H2 hydrogen generation rate increased after each of three frit additions, but did not exceed the maximum rate seen in the SRAT cycle. The ARP-Case 4 hydrogen generation rate continued to increase after the frit additions. The SME was refluxed in both cases to extend the processing time to more closely match the duration of the DWPF SME cycle. The maximum in hydrogen generation for ARP-4 occurred nearly 30 hours into the SME cycle. It was much higher than might have been guessed from the SRAT cycle that peaked at $0.045 \mathrm{lbs} / \mathrm{hr}$. This SME peak may be produced by the same reactions that produced the second, larger peak in the ARP-H2 SRAT cycle. In ARP-Case 4, this just took much longer to occur. It would not be unusual for a system with slower reaction rates, such as ARP-Case 4, to take longer to reach a certain point than a system with higher reaction rates, such as ARP-H2.

\subsubsection{Source of Alkali SRAT Testing}

The source of alkali testing took SB3 simulant with frit 418 as a baseline, and then shifted sodium between simulant and frit in increments of $4 \% \mathrm{Na}_{2} \mathrm{O}$ in the frit composition. The proportions of simulant to frit were varied to keep the final glass composition constant. Four increments were made, two up in frit sodium and two down in frit sodium. These are the $0 \%, 4 \%, 8 \%, 12 \%$, and $16 \%$ cases. The $16 \%$ case has approximately twice the sodium content in the frit as the baseline SB3 case at $8 \%$. The simulant sludge supernate was reduced in sodium species, i.e. washed more, to compensate. Consequently, the five sludges constitute a set of wash endpoints covering a fairly wide range of sodium molarity. The overall CPC data can be found in Lambert (2005). Selected run parameters are given in Table 8: 
Table 8. Summary of Source of Alkali SRAT Parameters

\begin{tabular}{|l|c|c|c|c|c|c||}
\hline Run: & $\begin{array}{c}\text { Feed } \\
\text { Nitrite, } \\
\mathrm{mg} / \mathrm{kg}\end{array}$ & $\begin{array}{c}\text { Feed } \\
\text { Base } \\
\text { Equiv, } \mathrm{M}\end{array}$ & $\begin{array}{c}\text { Feed } \\
\text { TIC, } \\
\mathrm{mg} / \mathrm{kg}\end{array}$ & $\begin{array}{c}\text { Feed Mn, } \\
\mathrm{mg} / \mathrm{kg}\end{array}$ & $\begin{array}{c}\text { Rh, } \\
\mathrm{mg} / \mathrm{kg}\end{array}$ & $\begin{array}{c}\text { Total Acid, } \\
\text { moles/L } \\
\text { sludge }\end{array}$ \\
\hline $0 \% \mathrm{Na}_{2} \mathrm{O}$ Frit & 31,800 & 0.822 & 1650 & 6273 & 18.36 & 2.975 \\
\hline $4 \% \mathrm{Na}_{2} \mathrm{O}$ Frit & 25,150 & 0.708 & 1500 & 6686 & 18.06 & 2.551 \\
\hline $8 \% \mathrm{Na}_{2} \mathrm{O}$ Frit & 18,550 & 0.630 & 1250 & 6862 & 17.25 & 2.119 \\
\hline $12 \% \mathrm{Na}_{2} \mathrm{O}$ Frit & 10,700 & 0.371 & 1126 & 7020 & 16.13 & 1.475 \\
\hline $16 \% \mathrm{Na}_{2} \mathrm{O}$ Frit & 766 & 0.161 & 901 & 6439 & 13.17 & 0.755 \\
\hline \hline
\end{tabular}

Ruthenium and palladium were 4.737 and 0.1842 times the rhodium concentration, respectively, in all five tests. Sludge slurry density ran $1.11-1.21 \mathrm{~g} / \mathrm{mL}$. As sodium shifted from the slurry to the frit, the feed nitrite concentration and base equivalents both fell sharply. TIC fell as well to represent decreasing dissolved carbonate. These changes led to a factor of four range in the moles of total acid added per liter of starting sludge slurry.

Only one 4-L SRAT run was performed per sludge composition. SOA testing occurred following modifications to the lab-scale CPC equipment in late 2004. Since prior processing data did not exist for the $0 \%, 4 \%, 12 \%$, and $16 \% \mathrm{Na}_{2} \mathrm{O}$ frit case sludges, the stoichiometric factor was held constant for all five SRAT cycles at $155 \%$. The expectation was that excess acid would increase as the extent of washing decreased. Therefore, the $0 \%$ case (low sodium frit-high sodium sludge) was expected to produce the most hydrogen. The 16\% case (low sodium sludge) met the DWPF SRAT product target for nitrite concentration without being processed. Nevertheless, it was put through a SRAT cycle with an acid addition to allow any manganese reduction to occur. This run was expected to have the least excess acid and the least hydrogen generation.

Hydrogen concentration data from the five tests are given in Figure 19.

Figure 19. Source of Alkali Hydrogen Data at 155\% Acid

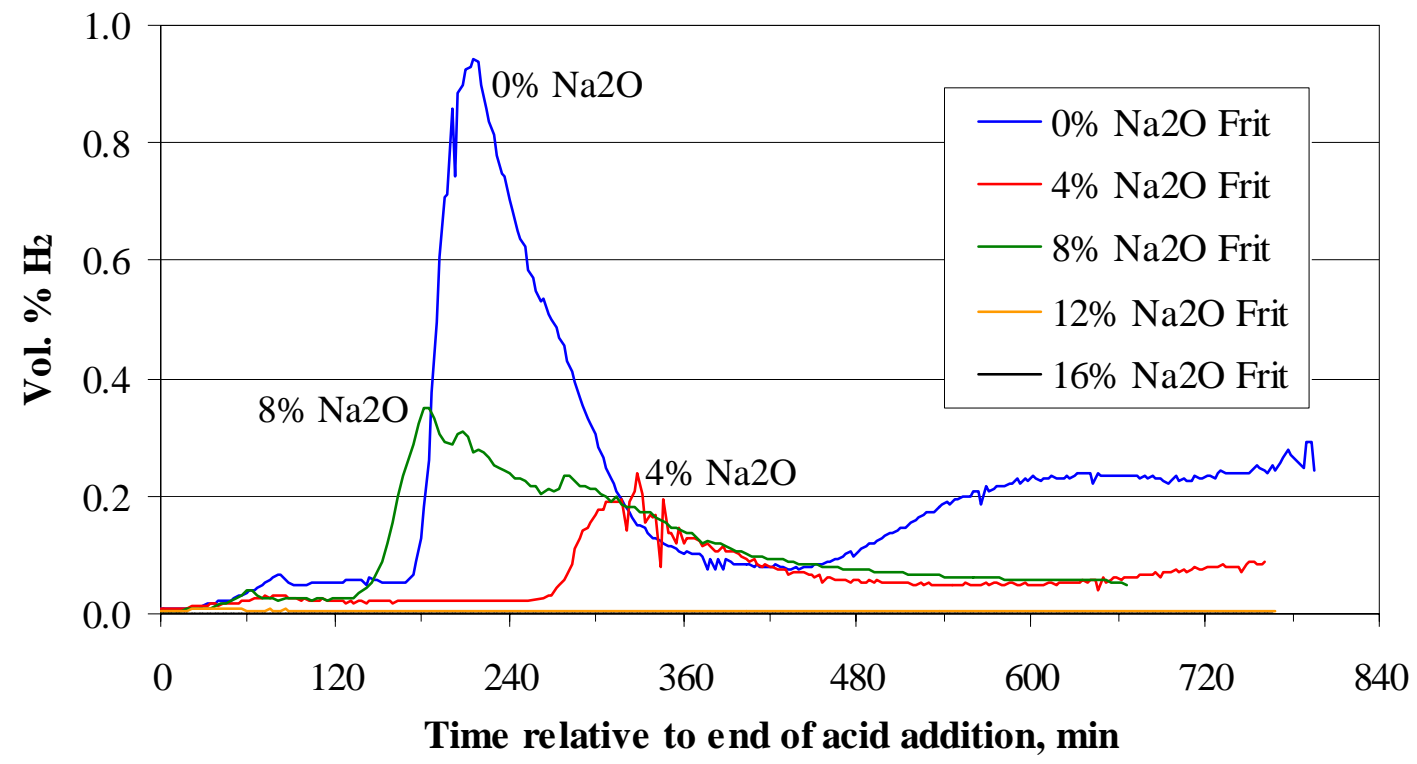


The maximum acid run, " $0 \% \mathrm{Na} 2 \mathrm{O}$ Frit" had the maximum hydrogen generation as expected. This occurred even though acid weight data indicated that the actual formic acid addition was somewhat below target, i.e. the run did not reach $155 \%$. The $4 \%$ and $8 \%$ runs were next, but the $8 \%$ had more hydrogen than the $4 \%$, and was slower to activate. The $12 \%$ run made more hydrogen than the $16 \%$ run as expected. The generally expected trend was seen, that as the stoichiometric acid requirement fell, the peak hydrogen concentration also fell at constant stoichiometric factor. Timing effects were seen on the peak hydrogen concentrations along with magnitude effects. Peak rate timing effects were also seen in the SB3 acid window study.

\subsubsection{Sludge Batch 4 SRAT Testing}

Preliminary Sludge Batch 4, SB4, simulant testing is underway in SRNL, Baich (2005). Hydrogen generation has been seen in some of the early tests. Results from four tests using the initial baseline composition targets were reviewed. Selected details from the acid calculation are given in Table 9 . Mercury is given as wt. \% $\mathrm{Hg}$ in the total solids. The factor is the factor for the stoichiometric acid calculation.

Table 9. Selected Acid Calculation Values for Early SB4 Tests

\begin{tabular}{|l|c|c|c|c||}
\hline \hline & $\begin{array}{c}\text { Acid } \\
\text { Factor }\end{array}$ & $\begin{array}{c}\text { Hg in } \\
\text { solids }\end{array}$ & $\begin{array}{c}\text { Total Acid, } \\
\text { moles/L sludge }\end{array}$ & $\begin{array}{c}\text { Fraction total acid } \\
\text { that was HCOOH }\end{array}$ \\
\hline SB4-1 & $130 \%$ & $1 \%$ & 1.554 & 0.9071 \\
\hline SB4-3 & $130 \%$ & $0 \%$ & 1.554 & 0.9071 \\
\hline SB4-10 & $160 \%$ & $0 \%$ & 1.936 & 0.8854 \\
\hline SB4-11 & $160 \%$ & $1 \%$ & 1.953 & 0.8836 \\
\hline
\end{tabular}

This was particularly useful data in the broader sense of CPC studies since the two $130 \%$ stoichiometry runs had nitrite destruction to nearly $1000 \mathrm{mg} / \mathrm{kg}$. This is interpreted to be close to the true stoichiometric acid requirement. Therefore, the amount of excess acid in the $160 \%$ runs was about 0.39 moles/L sludge as determined experimentally (difference between pairs at 130\% and 160\%).

Noble metal concentrations in preliminary SB4 simulations were higher than other recent simulant testing. Table 10 compares noble metal concentrations in the total solids to those in SB3 and "SB3". The SB3 values are from the acid window study, Baich (2004a). The "SB3" values are from the final flowsheet simulations (SB3A-19 and SB3A-20), Herman (2003e).

Table 10. Noble Metals in SB3 and SB4

\begin{tabular}{|l|c|c|c|c|}
\hline & Pd, \% & Rh, \% & Ru, \% & Total Solids, \% \\
\hline SB4 & 0.012 & 0.022 & 0.0810 & 22.95 \\
\hline SB3 & 0.0014 & 0.0076 & 0.0360 & 23.90 \\
\hline “SB3” & 0.0018 & 0.0063 & 0.0319 & 21.50 \\
\hline
\end{tabular}

The set of four SB4 runs was another test of the mercury-noble metal interaction effect studied in Phase I of the hydrogen generation program, Koopman (2005a) with SB3 simulant. This was also a test of the impact of acid on hydrogen generation, since there were two different stoichiometries. Hydrogen concentration data for the two runs at 160\% of the stoichiometric acid calculation are given in Figure 20. 
Figure 20. Impact of $\mathrm{Hg}$ in SB4 Testing at $160 \%$ Stoichiometry

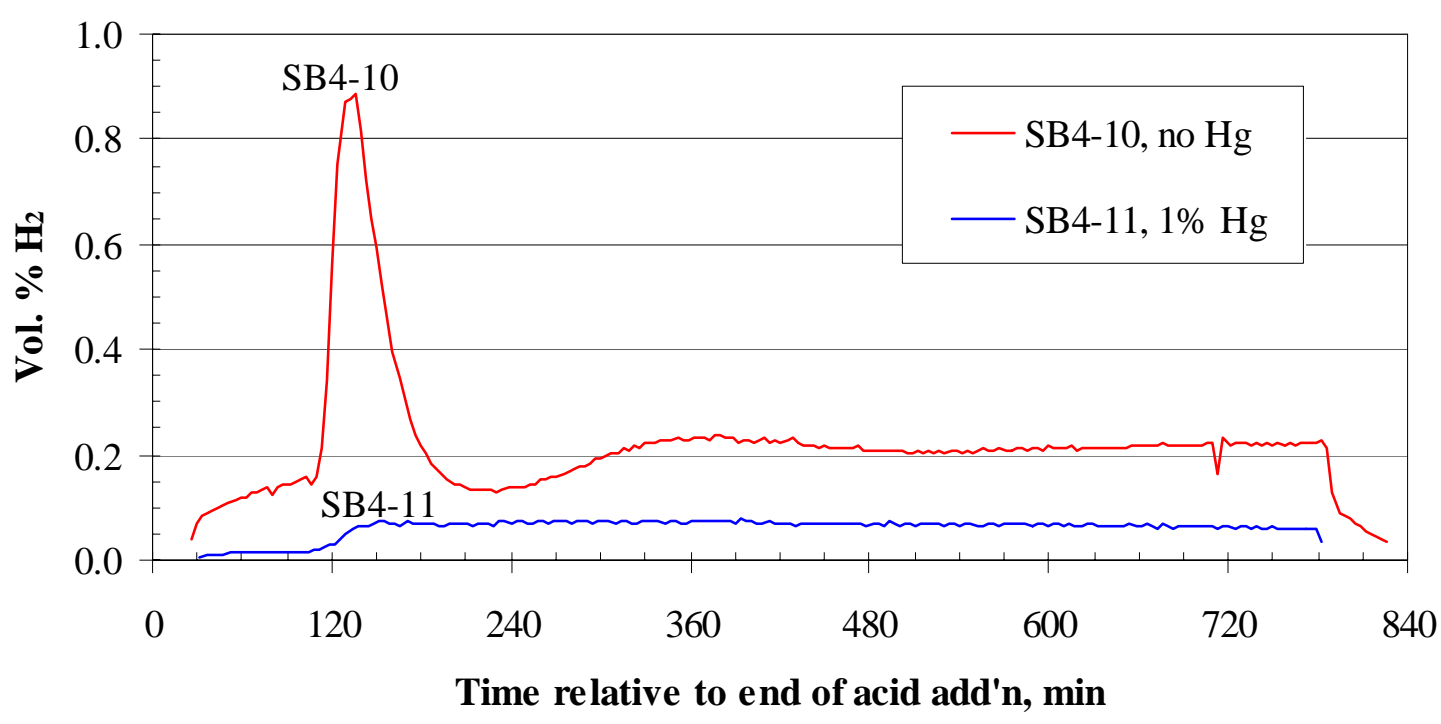

Peak and total hydrogen generation in SB4-10 significantly exceeded that in SB4-11. This appears to be another example of the inhibiting effect due to mercury. The SB4 testing used the modified lab-scale CPC equipment. This shows the inhibiting effect due to mercury seen in the earlier testing was not driven by the test equipment. A similar, though more subtle, effect was seen in SB4-1 and SB4-3 at 130\% stoichiometry. These tests were at the same bulk composition and wash endpoint as SB4-10 and SB4-11. SB4-3, with no $\mathrm{Hg}$, peaked at $0.006 \% \mathrm{H}_{2}$, while SB4-1, with $1 \% \mathrm{Hg}$, had no detectable $\mathrm{H}_{2}$. These two tests had about $1000 \mathrm{mg} / \mathrm{kg}$ nitrite in the SRAT product. Hydrogen was produced in SB4-3, even though nitrite was not completely destroyed.

\subsection{Synthesis of 2002-2005 Simulant Review Findings}

All simulant studies reviewed above used trimmed noble metals. The data sets collectively suggest the presence of a middle ground region where hydrogen generation behavior is more complicated, i.e. less predictable, than under extreme conditions. Extreme conditions could be defined as very large or small concentrations of noble metals coupled with very large or small amounts of excess acid. In these cases hydrogen generation generally has seemed to increase with increasing noble metal concentration and/or increasing quantity of excess acid.

In the SB3 acid window study, middle ground was identified when the $155 \%$ case matched the $170 \%$ case for peak concentration, but at a later time. In the SOA testing, middle ground was seen when the lower acid $8 \%$ case peaked faster and higher than the higher acid $4 \%$ case. In SB3 flowsheet studies, there were instances where delayed hydrogen peaks were seen that led to issues with SME hydrogen generation. The common theme was that peak hydrogen generation typically corresponded to concentrations in the 0.1-1.0 volume \% range. Increasing acid beyond this middle ground generally gave a sharp, early hydrogen generation peak that was higher than any subsequent peak. Decreasing acid below the middle ground generally gave a low, sustained concentration of hydrogen with subdued to nonexistent peaks in generation rate. It is not yet clear how variations in the noble metal concentrations tie in, but tests at $65 \%$ and $100 \%$ of the co-precipitated noble metal concentration in the experimental work for Phase II showed what might be defined as behavior not typically seen when using extreme conditions, Koopman (2005c). 
Previous hydrogen generation findings, reviewed in Koopman (2004), were generally not contradicted by the new data. The new data did expand the understanding of what different types of hydrogen generation rate data might be possible. Previous findings from Phase I related to mercury-noble metal interactions were not contradicted by the SB3-SB4 data. Collectively, the data are starting to characterize a region of reduced washing coupled with higher noble metals compared to sludge batches $1 \mathrm{~A}$ and $1 \mathrm{~B}$. The quantity of high nitrite SRAT feed simulation data prior to the "SB3" testing was quite small.

Data from the ARP program were used in developing a methodology for off-setting changes in supernate acid consumers by adjusting the stoichiometric factor. This methodology could be extended to other waste streams brought into existing sludge batches during CPC operations. This methodology could have been applied to the added caustic test of SB3, and it would have led to a lower acid addition and less hydrogen generation. It could have potentially been adapted to the source of alkali study to give a range of stoichiometric factors that would have left about the same quantity of excess acid in each SRAT test. That effort may not have been necessary to successfully meet the goals of the program.

Data on the impact of a heel, or of SRAT product, on hydrogen generation were obtained directly and indirectly during 2002-2005. These data indicated some degree of inhibition on hydrogen generation, but the details are not clear. The 22-L data suggest that it is not merely a question of dilution of key species leading to lower reaction rates because of lower concentrations, since the dilutions were minor. This suggests a poisoning effect on the noble metals. The 4-L data with a prototypically sized heel, however, still showed a significant hydrogen generation rate. This suggests that there is a limit to what the heel can do to inhibit hydrogen generation. The one common result was that omitting a heel led to conservatively high hydrogen generation rates. Comparing runs with a prototypical heel to runs without a prototypical heel is complicated for the same reasons that the comparisons in the Phase II experimental work were difficult. It is difficult to adjust the acid addition to give comparable quantities of excess acid when the inputs to the stoichiometric acid calculation change. Heel studies are further complicated by issues such as whether or not to consider manganese from the heel as already processed, or in need of further processing, and whether or not to consider noble metals in the heel as partially deactivated or potentially still fully active.

\subsection{2-2005 Radioactive Waste Testing}

Shielded Cells testing of the CPC occurred during 2002-2005. Two SRAT simulations and one SME simulation were successfully completed with GC data. The SRAT-SME simulation was based on a sample from Tank 51 combined with samples of an H-Canyon plutonium stream and an F-Canyon americium/curium stream. Tank 51 contained the new portion of Sludge Batch 3, "SB3". Testing of this composite sample is reported in Pareizs (2004). This was the qualification work for SB3, since the SB2 material in Tank 40 had already been qualified. The second SRAT simulation was based on a blend of the above composite sample with a sample of SB2 material from Tank 40 to simulate the final blend that became SB3. This run is reported in Bannochie (2004).

Hydrogen generation rate data for the "SB3" SRAT cycle are given in Figure 21. The test was done using about $350 \mathrm{~mL}$ (427 g) of slurry as feed. The closest simulant data are shown for comparison. 
WSRC-TR-2005-00206

Revision 0

Figure 21. “SB3” Radioactive and Simulant Hydrogen Generation

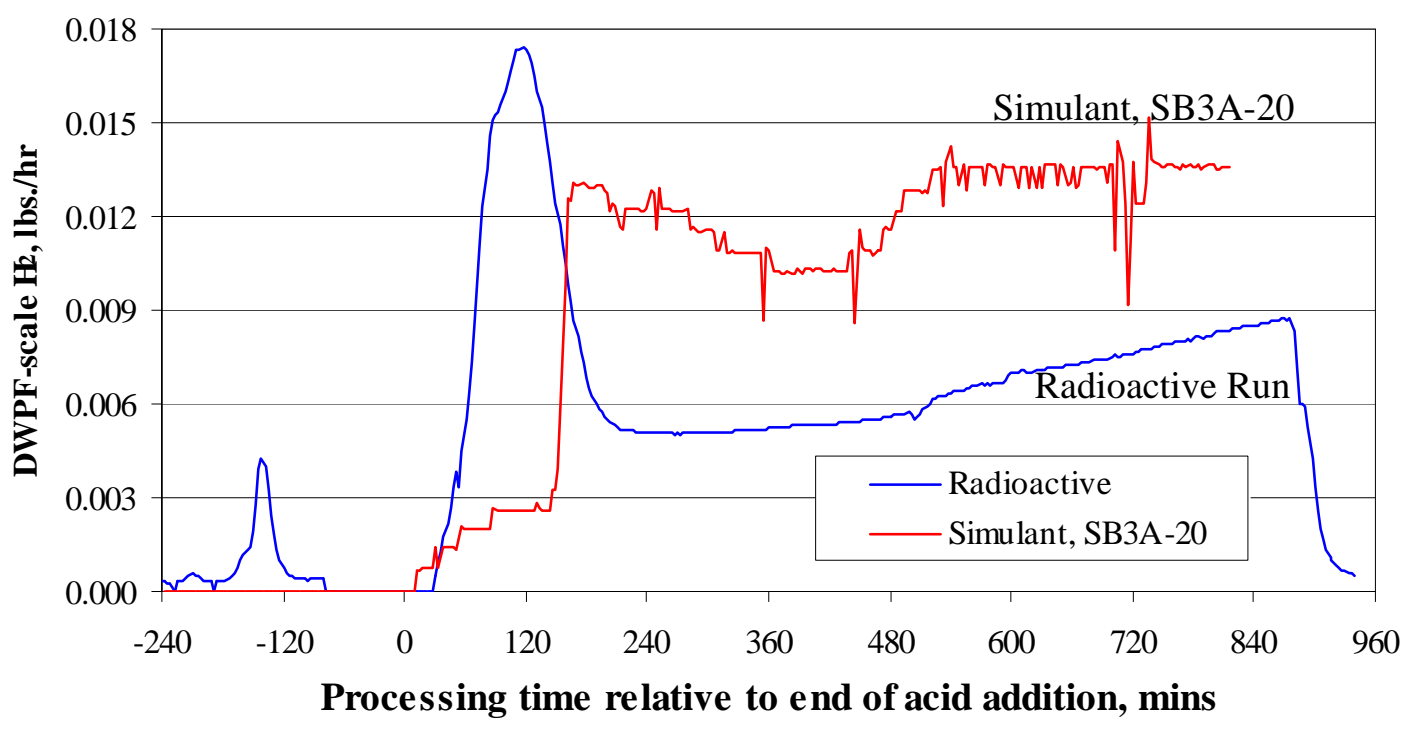

The stoichiometry for the radioactive SRAT cycle was nominally $141 \%$, while the stoichiometry for SB3A-20 was $155.5 \%$. An issue was identified during the radioactive test of the SB2-"SB3" blend with the formic acid molarity. The actual acid factor may have been as high as $\sim 148 \%$ instead of $141 \%$ depending on the method used to determine formic acid molarity. Experience with different test equipment indicates that comparisons between these two runs should be limited. SB3A-20 was done in the 4-L SRAT starting with 2800 grams. The simulant rig is also better insulated during boiling than the Shielded Cells equipment. These sorts of differences have been shown to impact the amount of acid available for hydrogen generation. Noble metals appeared to activate quickly in the radioactive waste SRAT. This does not match what was seen with the co-precipitated noble metal simulant in the Phase II hydrogen generation program experimental work, Koopman (2005c). The comparability of these results is not known since the sludge compositions and acid stoichiometries were very different.

There is a small peak in hydrogen generation at -120 minutes in the Shielded Cells test. Small peaks toward the end of acid addition were also seen in most of the Phase II hydrogen program experimental work discussed in Koopman (2005c).

Figure 22 shows the corresponding SME cycle data to the data in Figure 21. 
WSRC-TR-2005-00206

Revision 0

Figure 22. “SB3” Radioactive and Simulant SME Hydrogen Generation

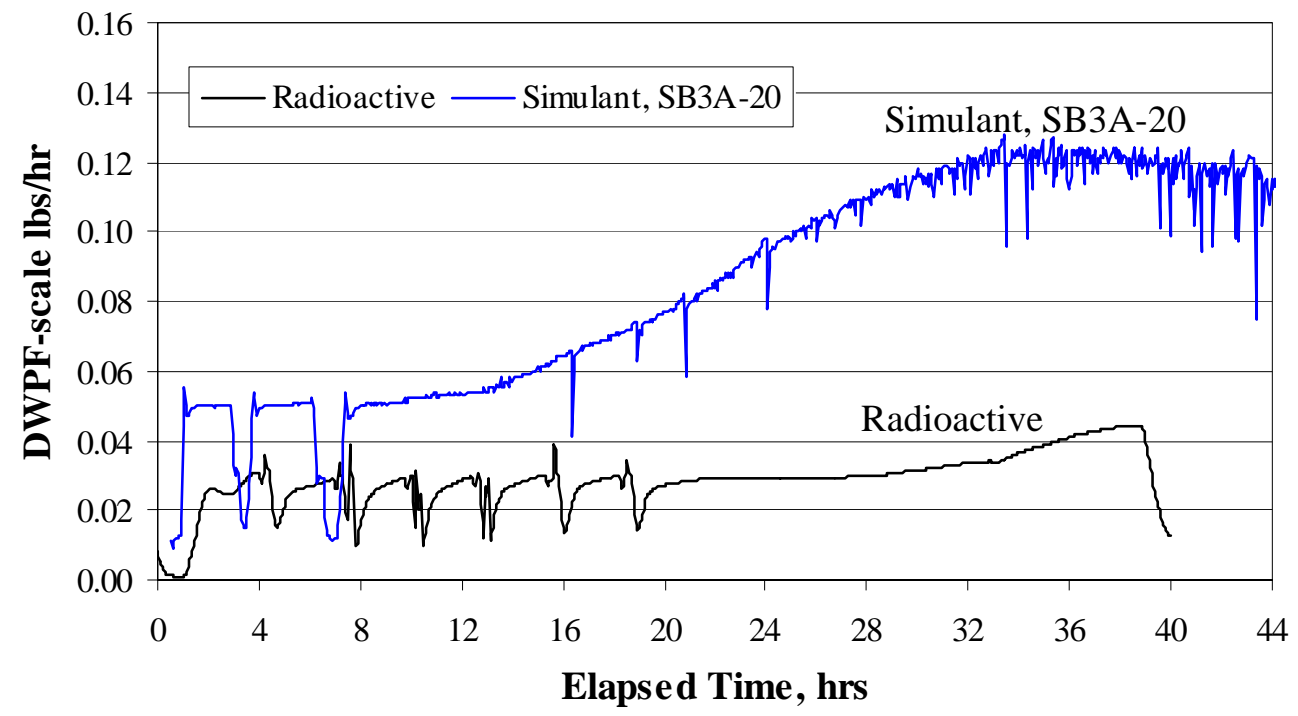

The Shielded Cells test included several simulated additions of canister decontamination water with the frit additions. Hydrogen generation in the simulant test continued to increase more than was seen in the radioactive test, although some increase in hydrogen generation rate was seen in the last 7-8 hours in the radioactive test.

The combined SB2 and "SB3" material was tested in the Shielded Cells at $140 \%$ of the stoichiometric acid requirement several months after the test for "SB3". The formic acid molarity issue makes it possible that the actual factor was as high as 147\%. The SRAT equipment was identical. The starting mass was about 297 grams. Figure 3-3 from Bannochie (2004) is reproduced below, Figure 23. "SB3" is the older radioactive work also shown in Figure 21. "SB2/3" is the newer SB3 work. 
WSRC-TR-2005-00206

Revision 0

Figure 23. Comparison of “SB3” to SB3 Hydrogen Generation

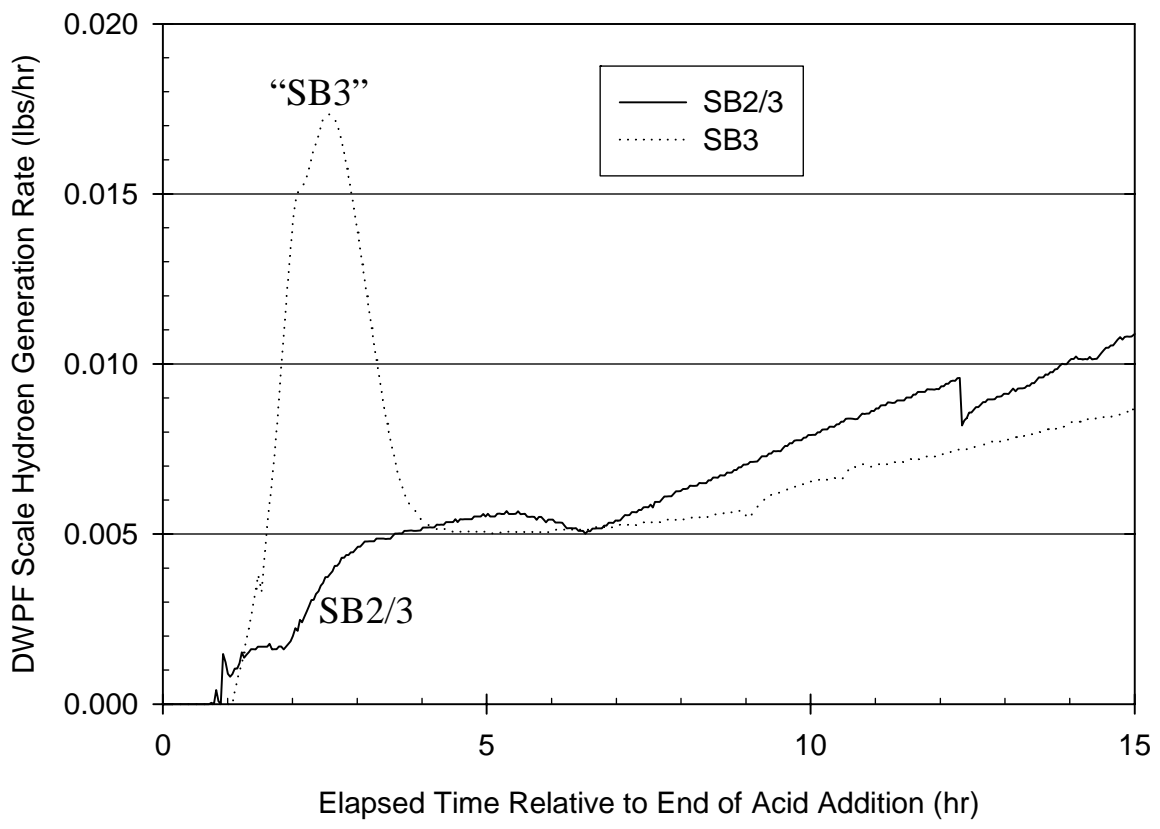

The big peak seen early in the boiling period in "SB3" did not occur for the SB2/3 run. The SB3 noble metals seemed to be activating more slowly, e.g. more like the co-precipitated noble metal simulant tested in Phase II of the hydrogen generation program. The peak hydrogen generation rate occurred at the end of the SRAT cycle. This slow rise to peak generation was also similar to the $155 \%$ simulant run in the SB3 acid window study, Figure 10.

It is not clear why the behavior in the two radioactive waste SRAT runs was as different as it was. It is not clear what role the equipment played in altering the results relative to 4-L SRAT runs with simulants. One way to better understand these issues would be to run simulants in the same equipment configuration as that used in the Shielded Cells runs for comparison. The co-precipitated noble metal simulant recipe would need to be adjusted to have lower TIC and base equivalents, and higher total solids, before it could reasonably match the acid calculation inputs of the previous Shielded Cells test. 


\subsection{CONCLUSIONS}

The goals set forth for the hydrogen generation program to complete Phase I per the TT\&QAP were accomplished. This included a work-up of some 1998 data and a review of catalytic hydrogen generation data from 2002-2005.

Catalytic hydrogen generation data from 2002-2005 were reviewed in section 4.0. Highlights include:

- Increasing the concentrations of soluble acid consumers, e.g. sodium hydroxide, in the SRAT feed can lead to excessive hydrogen generation unless the stoichiometric acid correction factor is reduced.

- Peak hydrogen generation rate tends to fall with decreasing redox at constant stoichiometric factor.

- Some evidence exists that SRAT products may contain one or more species that partially inhibits hydrogen generation in addition to residual Hg.

- The likelihood of finding cases where the peak hydrogen generation in the CPC is delayed to the SME cycle seems to have increased as the window of allowable acid addition stoichiometries in the SRAT shrinks.

- The impact of mercury on preliminary sludge batch 4 SRAT testing confirmed the findings from the previous phase of the hydrogen generation study. Mercury acts as an inhibitor to hydrogen generation.

- Peak and total hydrogen generation correlated with a non-linear term depending on the product of noble metal concentration and the square of the concentration of excess acid.

- The impact of mercury on hydrogen generation is inferred to be nonlinear based on the statistics from the SB3 data set.

- There have been some issues with data reproducibility on supposedly identically prepared runs. This may simply be indicating that hydrogen generation data is very sensitive to small changes.

- Source of alkali tests indicated that the peak hydrogen generation rate tended to fall as the stoichiometric acid requirement fell at constant stoichiometric factor.

- An intermediate region of acid stoichiometry was indicated within which the hydrogen generation rate is more complicated in its interactions with other processing parameters.

The analysis of the Boley-Lambert data from 1998, section 3.0, indicated that:

- Rh interacts with nitrite in hydrogen generation. More nitrite could lead to more hydrogen at constant moles acid added, i.e. no extra acid added to offset the extra nitrite. This was true for low initial nitrite ion concentrations.

- The peak hydrogen concentration increased with increasing initial nitrite at constant moles of acid addition over the low nitrite concentration range.

- The peak hydrogen concentration occurred earlier with increasing nitrite over the low nitrite concentration range.

- The two trends above were reversed as nitrite concentrations went above $8000 \mathrm{mg} / \mathrm{kg}$.

- A chemical compound or complex form of rhodium derived from the nitrate salt is potentially more active than the reduced metal supported on alumina.

- Ruthenium was relatively inactive for hydrogen generation on its own, i.e. without rhodium present to complex small amounts of nitrite ion. 
The Boley-Lambert study presents evidence for a complicated role for nitrite ion concentration in the rhodium-catalyzed production of hydrogen. The constant rhodium concentration results show that the stoichiometric acid factor alone is not sufficient to judge the extent of peak hydrogen generation as sludge nitrite composition changes. The study confirms that rhodium is an active catalyst species for hydrogen generation in Purex sludge. The study suggests that ruthenium may be a less significant hydrogen catalyst than was indicated in earlier work, or that the limitations on its activity may be more restrictive than have been identified. 


\subsection{RECOMMENDATIONS/PATH FORWARD}

The following recommendations for future studies are made:

- It is not clear why the behavior in the two radioactive waste SRAT runs was as different as it was. It is not clear what role the equipment played in altering the results relative to 4-L SRAT runs with simulants. One way to better understand these issues would be to run simulants in the same equipment configuration as that used in the Shielded Cells runs for comparison.

- The evaluation of the heel impact on hydrogen generation was already on the list for further study. Data found during this review seem to indicate that one or more compounds in the SRAT product have an inhibiting effect on hydrogen generation. This provides additional justification for studying this factor in the future.

- There are unresolved questions concerning the role of ruthenium that need to be investigated. Ruthenium has the highest concentration of the three noble metals. It has made significant hydrogen in some tests but not others. It may be more active in the presence of rhodium and/or palladium than when it is alone.

- An investigation into the role of nitrite ion should be undertaken in prototypical SRAT simulations once some of the other factors influencing hydrogen generation are better understood.

- $\quad$ Samples should be taken of the SRAT and/or SME slurry supernates in order to measure dissolved noble metal ion concentrations, particularly rhodium. These may explain some of the changing catalytic activity observed during processing.

- Additional work is required to better understand the relationship between radioactive wastes and simulants during SRAT and SME processing with respect to hydrogen generation. Modification of the Shielded Cells test equipment may be needed to obtain performance comparable to the simulant test equipment.

- Exclusion of mercury in many 22-L tests leads to higher hydrogen generation than in 4-L tests with mercury. This needs to be recognized. Provisions for GC monitoring of the off-gas should be made for 22-L runs when the acid stoichiometry has not been processed without mercury in the 4-L equipment successfully, i.e. below the scaled DWPF design basis hydrogen flow. 
WSRC-TR-2005-00206

Revision 0

This page intentionally left blank. 


\subsection{REFERENCES}

Baich, M. A., C. C. Herman, D. R. Best, M. F. Williams, and E. K. Hansen, Sludge Batch 4 Initial Simulant Flowsheet Studies: Phase I SRAT Results. WSRC-TR-2005-00194, Savannah River Site, Aiken, SC 29808 (2005).

Baich, M. A., D. R. Best, T. K. Snyder, and M. F. Williams, Sludge Batch 2-3 Blend Flowsheet Simulations: Determination of the Acid Addition Window (U). WSRC-TR-2004-00042, Savannah River Site, Aiken, SC 29808 (2004a).

Baich, M. A., D. R. Best, M. E. Stone, and M. F. Williams, Sludge Batch 2-3 Blend Flowsheet Simulations: Process Variability Study (U). WSRC-TR-2004-00225, Savannah River Site, Aiken, SC 29808 (2004b).

Baich, M. A., C. C. Herman, D. C. Koopman, D. R. Best, T. K. Snyder, and M. F. Williams, Processing Options and Impact of Incorporation of ARP in the DWPF Process Flow Sheet (U). WSRC-TR-200300326, Savannah River Site, Aiken, SC 29808 (2003).

Bannochie, C. J., J. M. Pareizs, and D. C. Koopman, Sludge Batch 2/3 Blend SRAT Cycle in the SRNL Shielded Cells. WSRC-TR-2004-00097, Savannah River Site, Aiken, SC 29808 (2004).

Fellinger, T. L., and D. C. Koopman, Hydrogen Generation for Sludge Receipt and Adjustment Tank (SRAT) and Slurry Mix Evaporator (SME), WSRC-RP-2004-0028 (TT\&QAP), Savannah River Site, Aiken, SC 29808 (2004).

Herman, C. C., D. C. Koopman, N. E. Bibler, D. R. Best, and M. F. Williams, SRAT Processing of Sludge Batch 3 Simulant to Evaluate Impacts of H-Canyon Slurry Containing Precipitated Pu and Gd. WSRCTR-2002-00322, Savannah River Site, Aiken, SC 29808 (2002).

Herman C. C. et al., Data Summary from Sludge Batch 3 Simulant SRAT Runs to Evaluate Impacts of Noble Metals Mass and Coal Size, Mass, and Treatment. SRT-GPD-2002-00121, Savannah River Site, Aiken, SC 29808 (2003a).

Herman, C. C., D. C. Koopman, D. R. Best, and M. F. Williams, Data Summary from SRAT Runs SB3-19 to SB3-24 to Evaluate Sodium Oxalate Addition Levels and SME Processing. SRT-GPD-2002-00200, Savannah River Site, Aiken, SC 29808 (2003b).

Herman, C. C., D. C. Koopman, D. R. Best, and M. F. Williams, Sludge Batch 3 Simulant Flowsheet Studies: Phase I SRAT Results (U). WSRC-TR-2003-00088, Savannah River Site, Aiken, SC 29808 (2003c).

Herman, C. C., D. C. Koopman, D. R. Best, and M. F. Williams, Sludge Batch 3 Simulant Flowsheet Studies: Phase II SRAT/SME Results. WSRC-TR-2003-00158, Savannah River Site, Aiken, SC 29808 (2003d).

Herman, C. C., D. C. Koopman, D. R. Best, T. K. Snyder, and M. F. Williams, Sludge Batch 3 Simulant Flowsheet Studies: Final Phase SRAT/SME Results. WSRC-TR-2003-00422, Savannah River Site, Aiken, SC 29808 (2003e). 
Hsu, C. W. and J. A. Ritter, Study on Hydrogen Evolution During Treatment of SRS High Level Radioactive Waste Simulant with Formic Acid. WSRC-MS-92-270, Savannah River Site, Aiken, SC 29808 (1992).

Jantzen, C.M., J.R. Zamecnik, D.C. Koopman, C.C. Herman, and J.B. Pickett, Electron Equivalents Model for Controlling Reduction-Oxidation (Redox) Equilibrium during High Level Waste (HLW) Vitrification. WSRC-TR-2003-00126, Savannah River Site, Aiken, SC 29808 (2003).

Koopman, D. C., C. C. Herman, and N. E. Bibler, Sludge Batch 3 Preliminary Acid Requirement Studies with Tank 8 Simulant (U). WSRC-TR-2003-00041, Savannah River Site, Aiken, SC 29808 (2003a).

Koopman, D. C., C. M. Jantzen, and T. B. Edwards, Acid Addition Stoichiometry for Sludge Batch 3 Processing in the Defense Waste Processing Facility (U). WSRC-TR-2003-00118, Savannah River Site, Aiken, SC 29808 (2003b).

Koopman, D. C., C. C. Herman, D. R. Best, and M. F. Williams, Sludge Batch 3 Simulant Flowsheet Studies: Preliminary Phase III SRAT/SME Results (U). WSRC-TR-2003-00283, Savannah River Site, Aiken, SC 29808 (2003c).

Koopman, D. C., C. C. Herman, M. A. Baich, D. R. Best, T. K. Snyder, and M. F. Williams, Impact of a Bounding Quantity of ARP Waste on the DWPF Process Flow Sheet (U). WSRC-TR-2003-00403, Savannah River Site, Aiken, SC 29808 (2003d).

Koopman, D. C., Review of Catalytic Hydrogen Generation in the Defense Waste Processing Facility (DWPF) Chemical Processing Cell (U). WSRC-TR-2002-00334, Savannah River Site, Aiken, SC 29808 (2004).

Koopman, D. C., and M. A. Baich, Effect of Mercury-Noble Metal Interactions on SRAT Processing of SB3 Simulant (U). WSRC-TR-2004-00548, Savannah River Site, Aiken, SC 29808 (2005a).

Koopman, D. C., and R. E. Eibling, Preparation and Heat-Treatment of DWPF Simulants with and without Co-Precipitated Noble Metals, WSRC-TR-2005-00285, Savannah River Site, Aiken, SC 29808 (2005b).

Koopman, D. C., DWPF Hydrogen Generation Study-Form of Noble Metal SRAT Testing, WSRC-TR2005-00286, Savannah River Site, Aiken, SC 29808 (2005c).

Lambert, D. P., and M. E. Stone, Feed Preparation for Source of Alkali Melt Rate Testing. WSRC-TR2005-00080, Savannah River Site, Aiken, SC 29808 (2005).

Pareizs, J. M., D. C. Koopman, D. R. Click, A. D. Cozzi, and N. E. Bibler, Sludge Batch 3 Qualification in the SRTC Shielded Cells. WSRC-TR-2004-00050, Savannah River Site, Aiken, SC 29808 (2004). 


\subsection{ACKNOWLEDGEMENTS}

The author is indebted to Terri Fellinger for her help in coordinating the hydrogen generation study activities, monitoring resources and spend out, and providing feedback as needed. The lead author wishes to acknowledge the contributions of C. C. Herman, T. H. Lorier, M. A. Baich, M. E. Stone, and D. P. Lambert in obtaining the data that was analyzed and reviewed in this document. 
WSRC-TR-2005-00206

Revision 0

\section{APPENDIX A. 22-L SRAT HYDROGEN DATA SUMMARY}


This report presented a review of hydrogen generation data from 2002-2005, section 4.0. Most hydrogen generation data came from simulations in 4-L SRAT vessels at about $1 / 10,000^{\text {th }}$ scale relative to 6,000 gallons of fresh sludge in DWPF. These sets of tests are typically grouped and documented in technical reports, e.g. the list in section 4.3.1. Larger quantities of SRAT and/or SME products are needed to support melt rate program testing than are produced in a single run at this scale. SRNL also operates a 22-L SRAT vessel to make larger quantities of material. These are at about $1 / 1500^{\text {th }}$ scale. Some hydrogen data from 22-L testing was included in section 4.3.1. The runs that produced the data have not all been documented to the same extent as the 4-L SRAT data. This appendix provides some additional detail concerning these tests.

An FAVC was added to the 22-L configuration to remove additional moisture and acidity from the offgas. Following this addition, opportunities arose to take GC data on the off-gas. This required a GC to be available and calibrated at the time of the start of a simulation. Often the GC's were tied up by smaller scale tests, or were in need of bake-out and recalibration when a 22-L run occurred. Nevertheless, some GC data became available from selected 22-L tests starting in January 2003. This was the end of the period of high oxalate feed testing. Table 11 summarizes the 22-L SRAT rig GC data for the 2002-2005 period. Most SRAT cycles were run either two or four times to make enough material for later melt rate testing. When two runs were needed, it was common to pump the product out of the SRAT following Run 1, add fresh sludge, and perform the second SRAT, Run 2, before cleaning the equipment. If four runs were needed, then two 22-L SRAT rigs were set up, and they were run in parallel with two runs per rig. In this case sometimes one rig had a GC and the other rig did not.

Table 11. Summary of 22-L SRAT Runs With Some GC Data

\begin{tabular}{|l|c|c|c|c|c|}
\hline Date & Stoichiometry & Redox & Run \# & Frit & Comment \\
\hline January 21, 2003 & n.a. & 0.2 & Run 1 & Frit 202 & No GC on 2 \\
\hline January 23, 2003 & n.a. & 0.2 & Run 3 & Frit 202 & No GC on 4 \\
\hline July 21, 2003 & $135 \%$ & 0.2 & Run 5 & Frit 202 & \\
\hline March 29, 2004 & $155 \%$ & 0.2 & Run 1 & Frit 418 & No GC \\
\hline March 29, 2004 & $185 \%$ & 0.2 & Run 1 & Frit 418 & \\
\hline April 1, 2004 & $155 \%$ & 0.2 & Run 2 & Frit 418 & \\
\hline April 1, 2004 & $185 \%$ & 0.2 & Run 2 & Frit 418 & \\
\hline April 12, 2004 & $155 \%$ & 0.1 & Run 1 & Frit 418 & \\
\hline April 14, 2004 & $155 \%$ & 0.1 & Run 2 & Frit 418 & \\
\hline April 12, 2004 & $155 \%$ & 0.0 & Run 1 & Frit 418 & \\
\hline April 14, 2004 & $155 \%$ & 0.0 & Run 2 & Frit 418 & \\
\hline June 28, 2004 & $155 \%$ & 0.2 & Run 1 & Frit 202+NaOH & \\
\hline June 29, 2004 & $155 \%$ & 0.2 & Run 2 & Frit 202+NaOH & No GC \\
\hline August 2, 2004 & $155 \%$ & 0.2 & Run 1 & Frit 320 & \\
\hline August 3, 2004 & $155 \%$ & 0.2 & Run 2 & Frit 320 & No GC \\
\hline
\end{tabular}

The first two runs from January 2003 were from a set of four runs to support slurry fed melt rate furnace testing of high oxalate (Decant 5) SB3 SME product. These runs had both SRAT and SME cycle data. The next run was from a set that made melter feed to study the SB3 Case $6 \mathrm{~b}$ wash endpoint. This was one of the first two low oxalate cases. The next eight runs, March 29 to April 14 of 2004, were the basis for a SB3 melt rate investigation into the effects of the stoichiometric acid addition equation factor (155\% versus 185\%) and the redox target (0.0, 0.1, and 0.2). The two runs in June 2004 were from a set of four runs looking at the melt rate impact of using frit 202 plus added caustic instead of frit 418 . The added 
caustic was to make up for the lower sodium content of frit 202 relative to frit 418 . The last two runs were to compare melt rates with frit 320 to frit 418. None of the sludges were trimmed with mercury.

Figure 24 and Figure 25 summarize the hydrogen concentration data for the Run 1 and Run 2 data respectively at $155 \%$ of stoichiometry in the frit 418 test program.

Figure 24. Stoichiometry and Redox Study - Run 1 Hydrogen Data

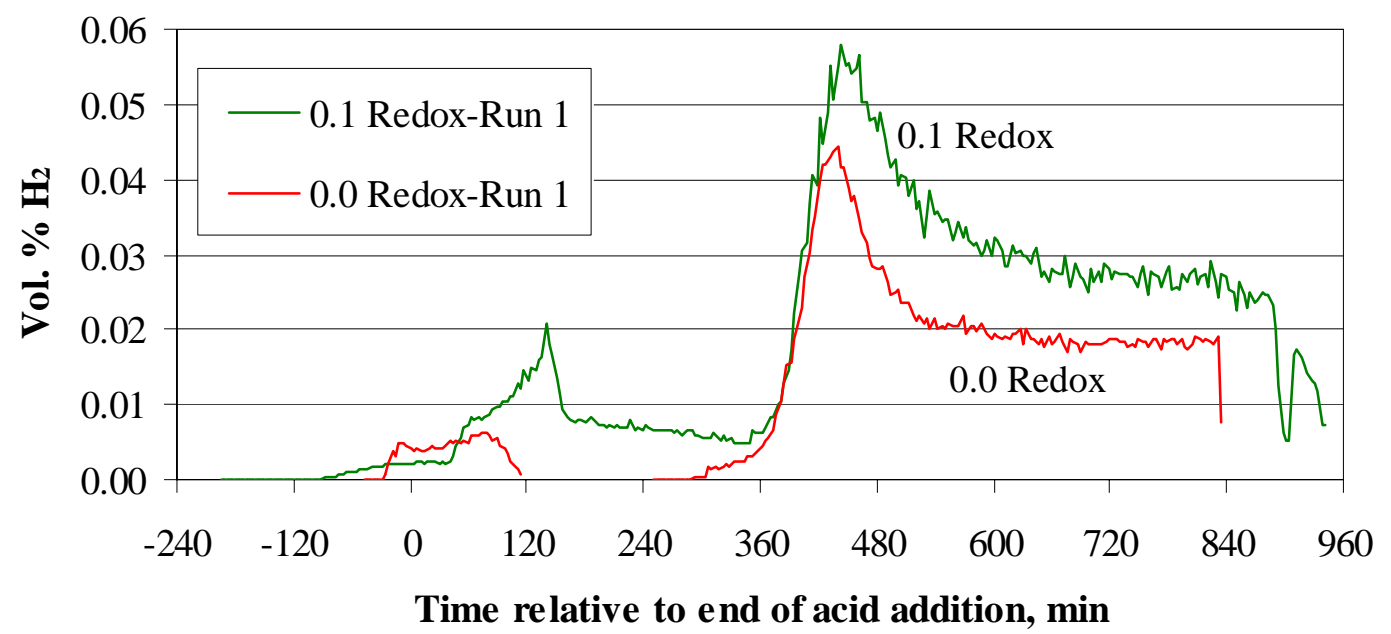

Figure 25. Stoichiometry and Redox Study - Run 2 Hydrogen Data

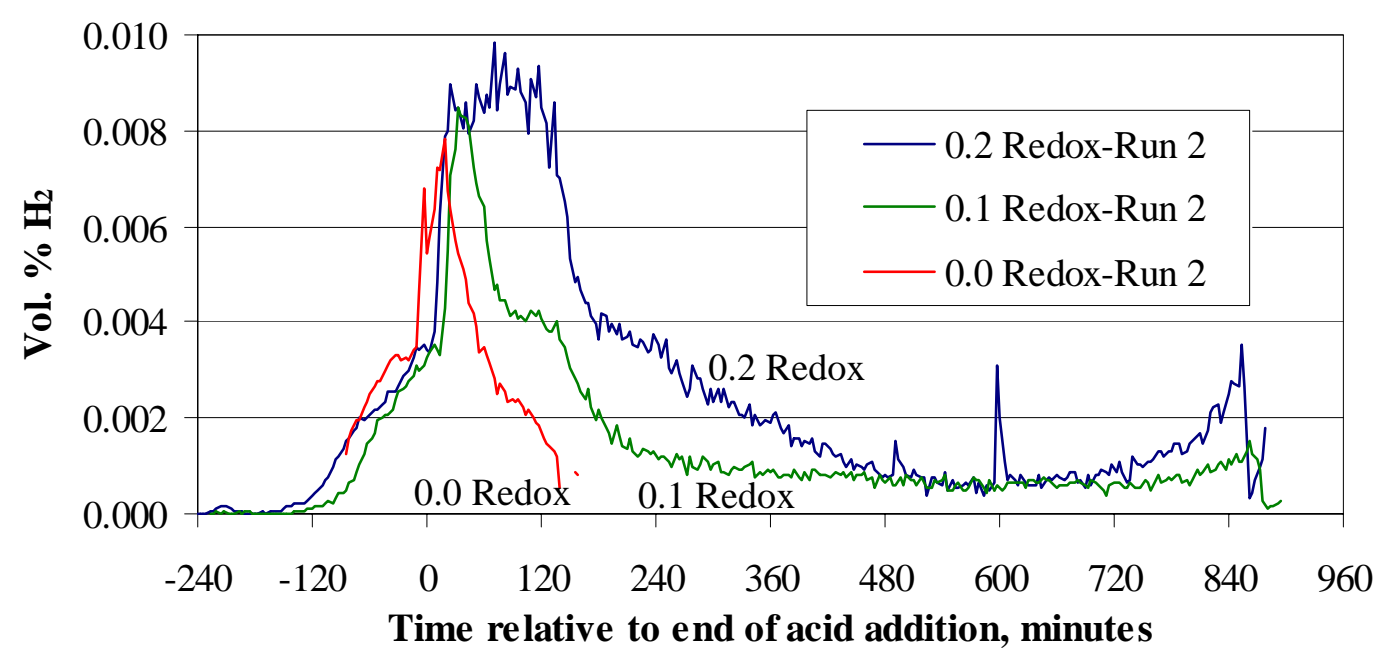

There was noticeably less hydrogen generation in the Run 2 set than in the Run 1 set. The reason(s) for this are not known. The peak hydrogen concentration fell with decreasing redox target in both Run 1 data and in Run 2 data. The stoichiometry and redox study also included two runs at 185\% of stoichiometry, Figure 26. Hydrogen fell with redox target, which would be expected due to the reduced formate concentrations. 
WSRC-TR-2005-00206

Revision 0

Figure 26. Stoichiometry and Redox Study - 185\% Stoichiometry Hydrogen Data

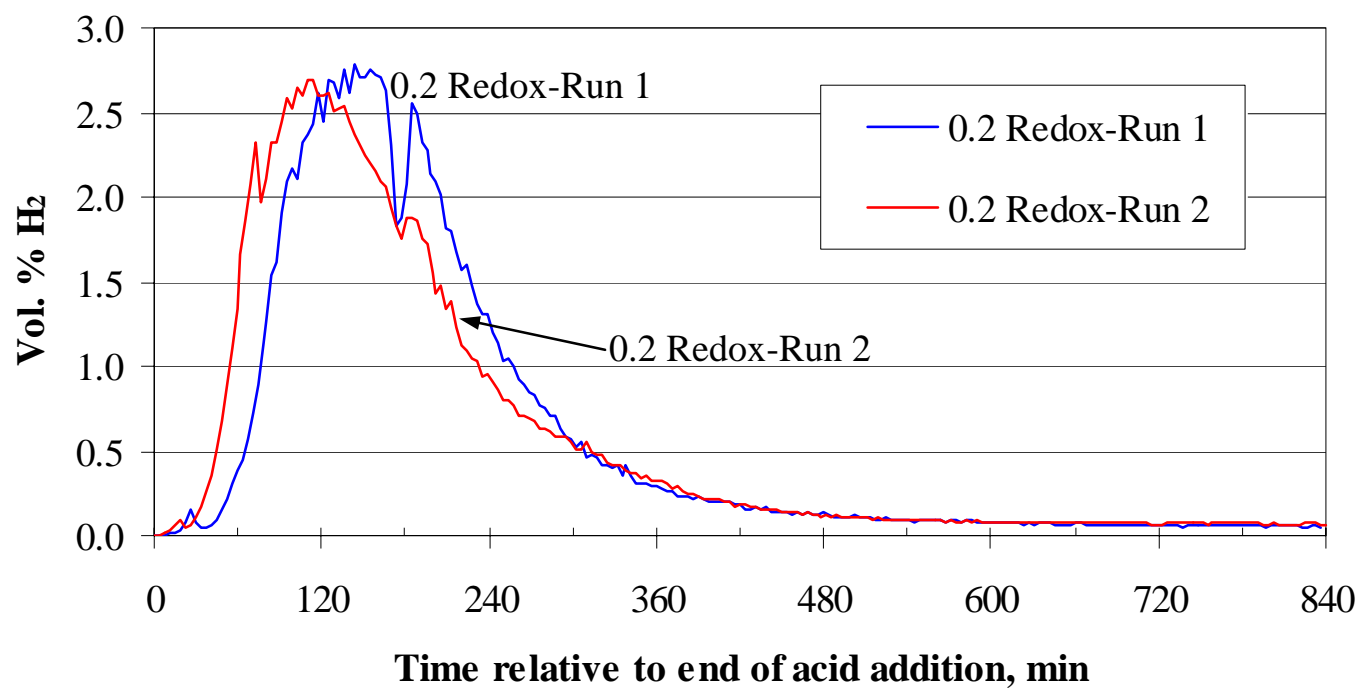

The reduction in hydrogen generation from Run 1 to Run 2 was much less at $185 \%$ than at $155 \%$.

The carbon dioxide data were also investigated, since they can help to evaluate the hydrogen generation data, see Figure 27.

Figure 27. Stoichiometry and Redox Study - Run 1 Carbon Dioxide Data

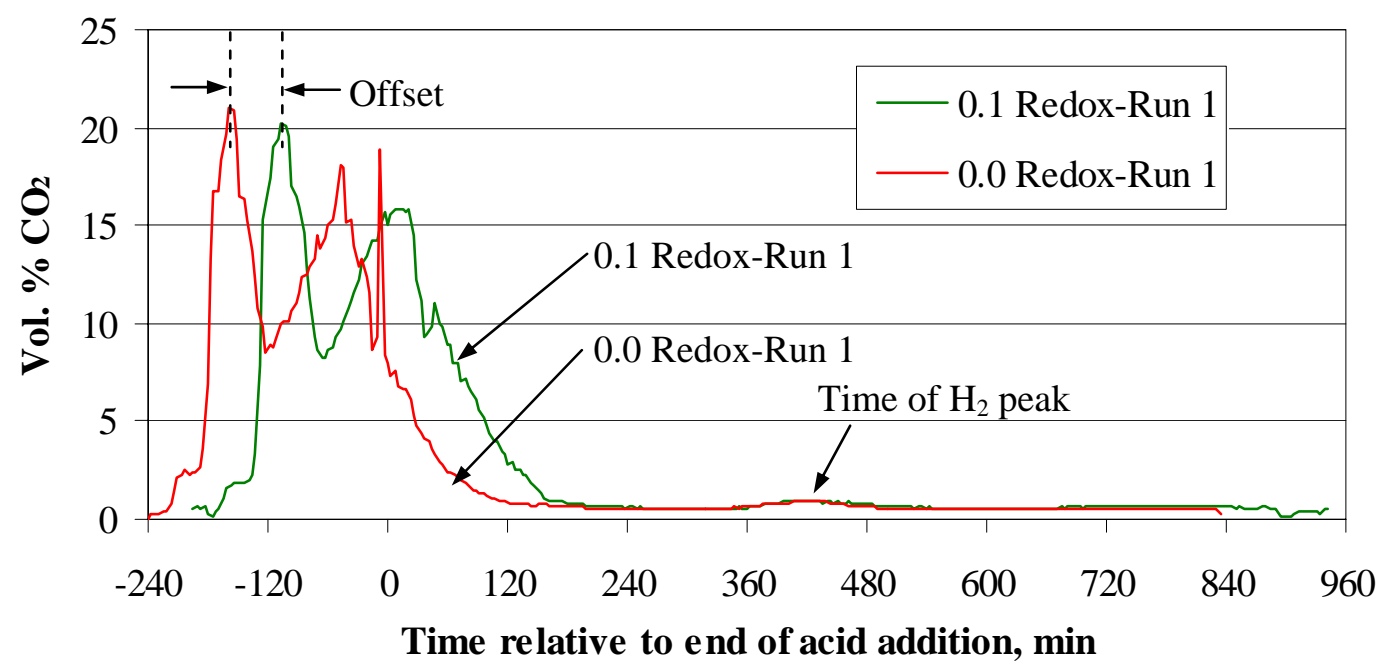

The 45 minute off-set in the main $\mathrm{CO}_{2}$ peaks during acid addition was unexpected between the redox 0.1 and 0.0 data for Run 1 . It could be interpreted to mean that the 0.0 redox run received relatively more acid than the redox 0.1 run. Supporting data have not been investigated in detail. Two small peaks in $\mathrm{CO}_{2}$ generation between 360 and 480 minutes correspond to the peak hydrogen generation periods.

Peak shifts in the three sets of data for Run 2 at 155\% were less noticeable, Figure 28. 
WSRC-TR-2005-00206

Revision 0

Figure 28. Stoichiometry and Redox Study - Run 2 Carbon Dioxide Data

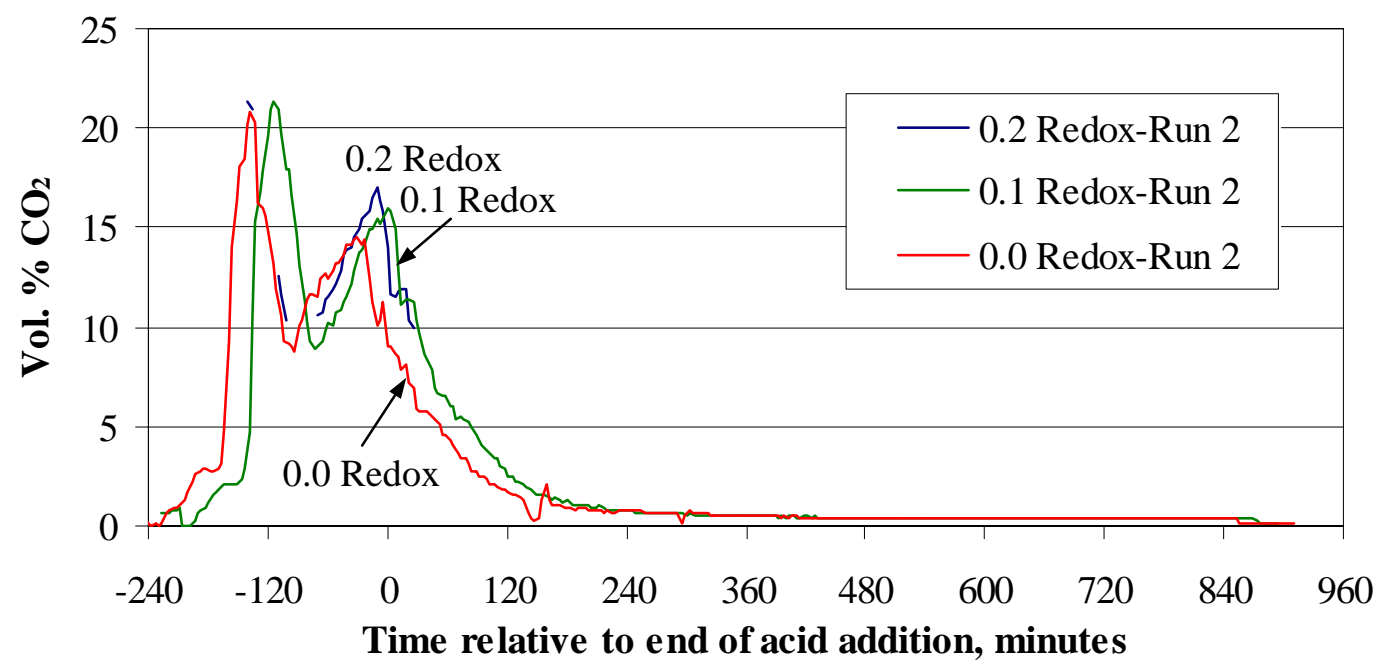

Most of the $\mathrm{CO}_{2}$ data for the 0.2 redox Run 2 was lost, but what was obtained placed the nitrite destruction peak at -40 minutes along with the other two redox Run 2's. The small hydrogen generation peaks at about +120 minutes were not big enough to noticeably impact the $\mathrm{CO}_{2}$ concentration profile.

Figure 29 shows the $\mathrm{CO}_{2}$ data for the $185 \%$ stoichiometry runs.

Figure 29. Stoichiometry and Redox Study - 185\% Stoichiometry Hydrogen Data

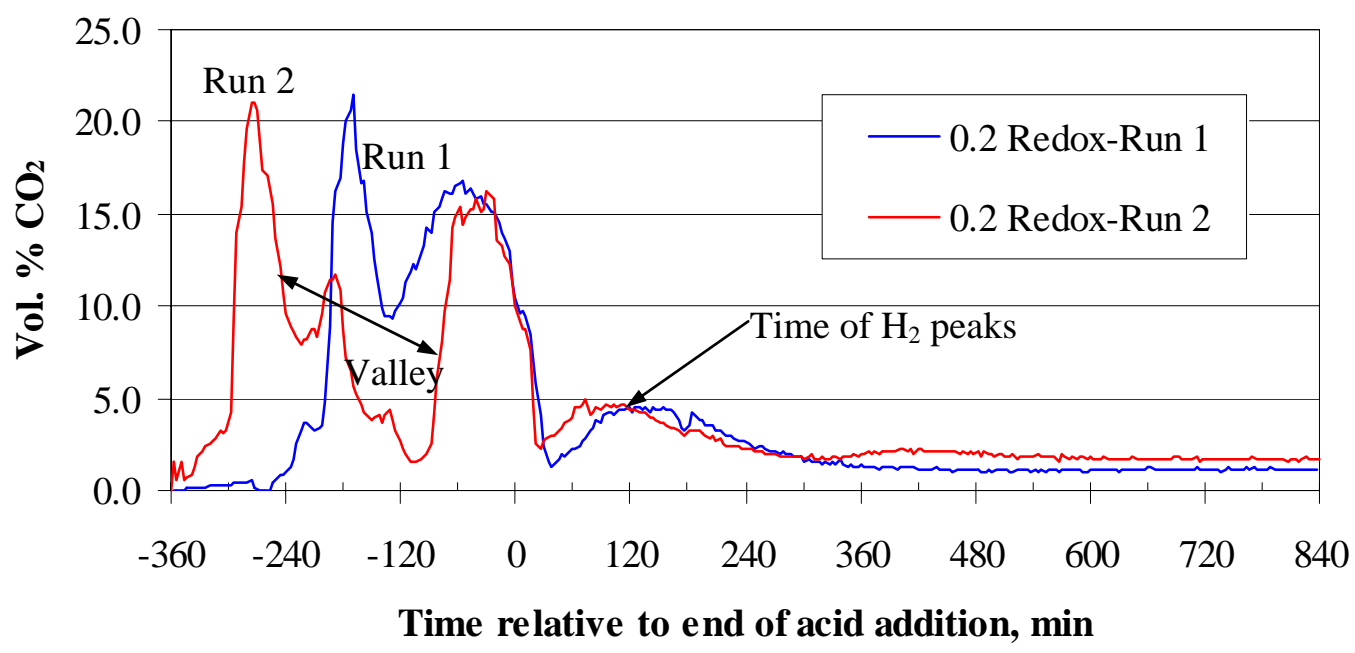

The $\mathrm{CO}_{2}$ data for the 185\% runs suggest that acid addition may have been interrupted in Run 2 which created a much broader valley between the two main $\mathrm{CO}_{2}$ peaks during acid addition. This interpretation was made based on the significant difference in timing of the initial peaks near the run labels along with the length of time that the concentration of $\mathrm{CO}_{2}$ was relatively low between the initial peak and the peak at -45 minutes. Such an upset to acid addition may have indirectly impacted the timing or magnitude of the later hydrogen generation peaks. The $\mathrm{H}_{2}$ peaks were matched with $\mathrm{CO}_{2}$ peaks at about +120 minutes. 
Testing was repeated at 155\% acid to prepare more SRAT product to be used with frit 320 instead of frit 418. The hydrogen data was somewhat unusual, Figure 30. This may have been due to problems with GC integration software. There were definitely problems shortly before the start of the trace.

Figure 30. Frit 318 Study - Hydrogen Data

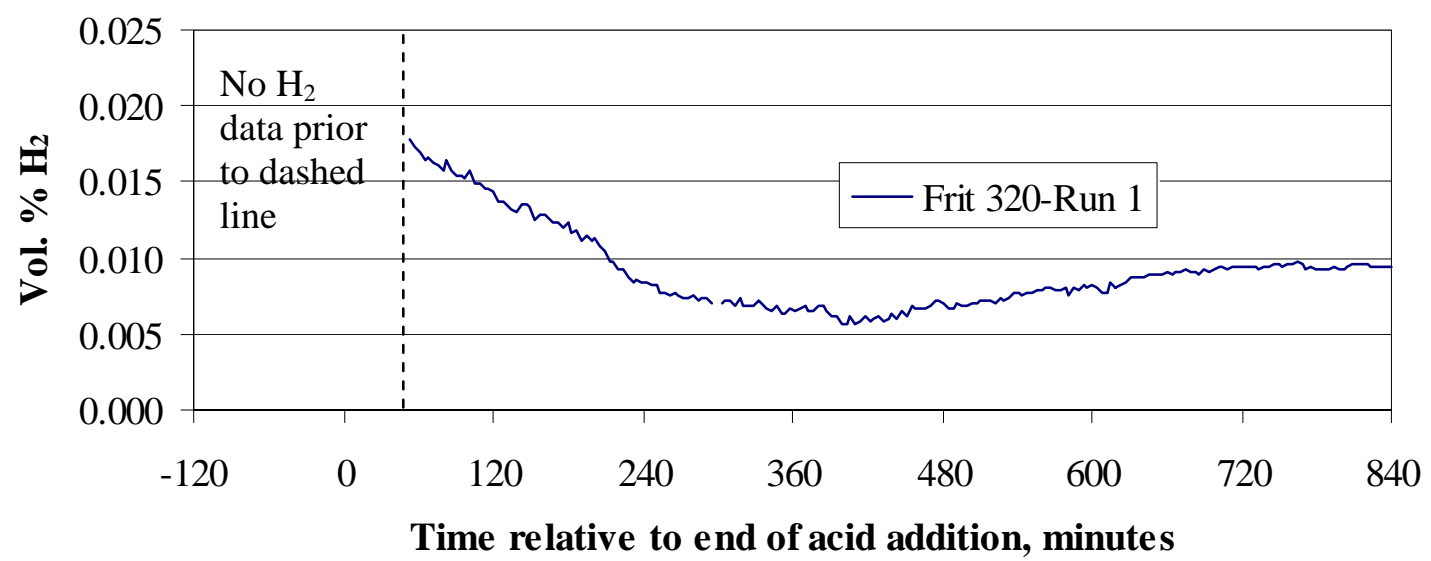

The hydrogen production was too small to show up distinctly on the $\mathrm{CO}_{2}$ data.

The last set of data, Figure 31, is for Run 1 with added caustic. This caustic was added to offset the lower sodium content of frit 202 relative to frit 418. This led to additional acid addition. The nominal addition was at $155 \%$ of stoichiometry; however this was not actually calculated using measured inputs to the acid calculation. The base equivalents were calculated from the measured value for normal SB3 simulant plus the increase expected from adding the caustic. The base equivalents measurement was not made on the sludge plus caustic feed to the SRAT.

Figure 31. Frit 202+Caustic Study - Hydrogen Data

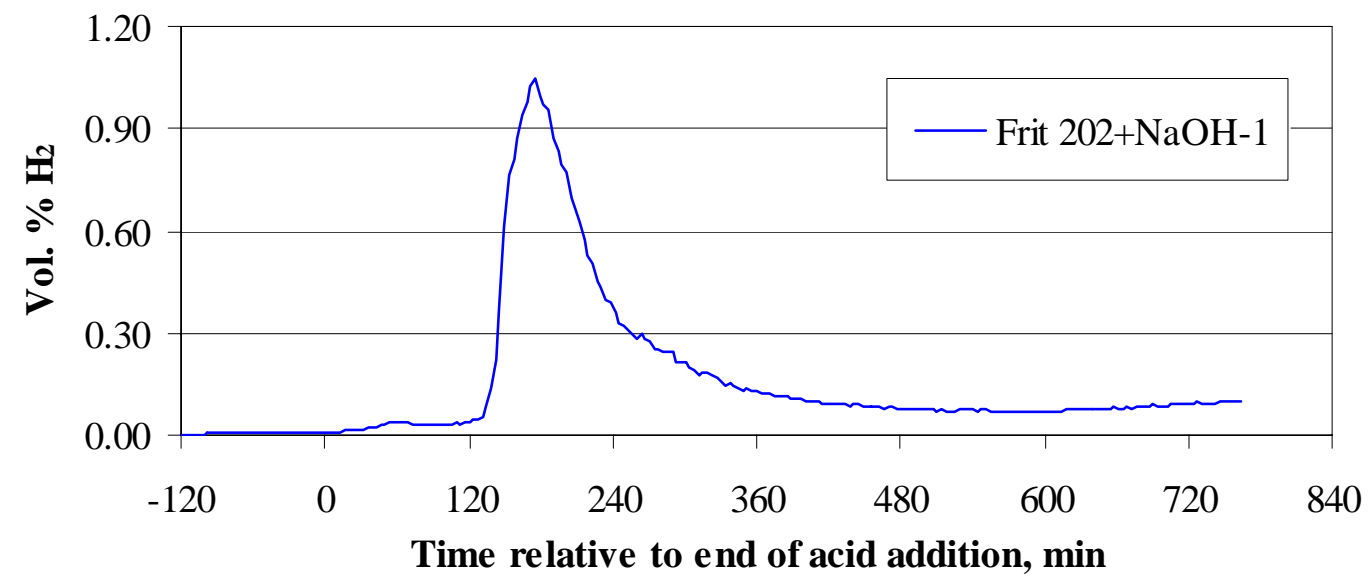

The corresponding $\mathrm{CO}_{2}$ data are given in Figure 32. 
WSRC-TR-2005-00206

Revision 0

Figure 32. Frit 202+Caustic Study - Carbon Dioxide Data

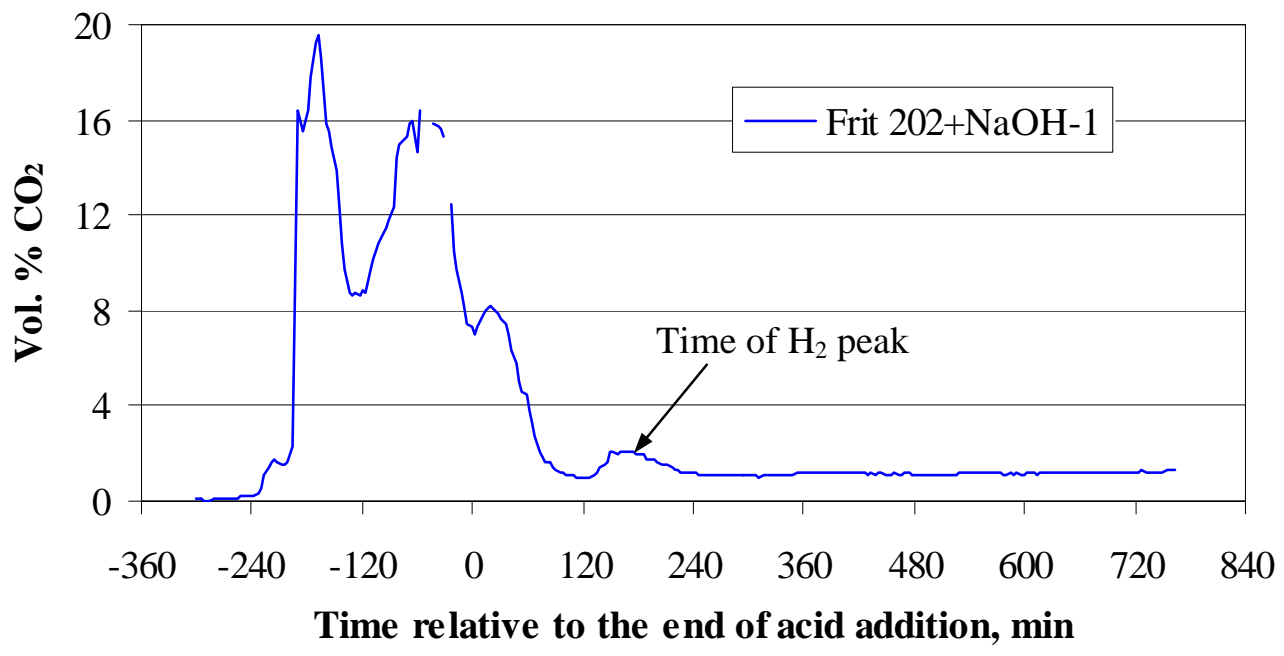

The large hydrogen peak has an associated peak in the $\mathrm{CO}_{2}$ data at about 150 minutes after acid addition. This addition strategy produced a significant increase in the excess acid available for hydrogen generation as seen in the above data. 


\section{Distribution:}

E. W. Holtzscheiter, SRNL

D. A. Crowley, 999-W

S. L. Marra, 999-W

T. B. Calloway, 999-W

N. E. Bibler, SRNL

C. M. Jantzen, SRNL

G. C. Wicks, SRNL

J. R. Harbour, 773-42A

C. A. Langton, 773-43A

T. L. Fellinger, SRNL

M. A. Baich, 999-W

C. C. Herman, 773-42A

M. E. Stone, 999-W

J. M. Pareizs, SRNL

C. J. Bannochie, 773-42A

M. J. Barnes, SRNL

M. S. Miller, 704-S

J. E. Occhipinti, 704-S

R. M. Hoeppel, 704-27S

H. H. Elder, 766-H

J. F. Iaukea, 704-30S

J. W. Ray, 704-S

F. A. Washburn, 704-28S

P. M. Patel, 704-27S

R. N. Mahannah, 704-28S

A. B. Sanders, 704-27S

W. B. Van-Pelt, 704-S 